\title{
I. Justizminister unter Hitler: das Schicksal des nationalkonservativen Beamten Franz Gürtner (1881-1941)
}

\begin{abstract}
Als am Mittag des 30. Januar 1933 nach der Vereidigung der Regierung Hitler durch Reichspräsident v. Hindenburg die Mitglieder des neuen Kabinetts bekanntgegeben wurden, hieß es in der amtlichen Verlautbarung, daß die Besetzung des Reichsjustizministeriums noch „,vorbehalten“ bleibe. ${ }^{1}$ In den ersten Kabinettssitzungen am Nachmittag und am folgenden Tag blieb daher der Stuhl des Justizministers leer. Da die Besetzung dieses Postens zwischen den nationalsozialistischen und deutschnationalen Koalitionspartnern nicht umstritten war - v. Papen hatte am 29. Januar über die Ministerliste und die darin aufzunehmenden Nationalsozialisten unter den Beteiligten völlige Einigung erzielt ${ }^{2}$-, mußten dafür andere Gründe vorliegen: dieser Ministersessel sollte - wenigstens nach außen hin - für das Zentrum freigehalten werden, um Hitlers nachträgliche „Verhandlungen“ mit dieser Partei vor der Öffentlichkeit glaubhaft erscheinen zu lassen, deren Scheitern den Vorwand zur Auflösung des Reichstags abgeben sollte. Daß die vorläufige Nichtbesetzung dieses Postens eine rein taktische Maßnahme war, geht auch daraus hervor, daß der Parteiführer der Deutschnationalen, der neue Reichswirtschaftsminister und Reichsminister für Ernährung und Landwirtschaft Alfred Hugenberg, schon in der ersten Kabinettssitzung eindeutig erklärte, daß er nicht an eine Aufnahme von Vertretern des Zentrums in die Regierung denke, „weil dadurch die Einheitlichkeit der Willensbildung gefährdet werde" " 3 Für die Einschätzung der Justiz durch Hitler ist immerhin bezeichnend, daß er gerade dieses Ressort für ein solches Manöver auswählte. Als Prälat Kaas in einer Unterredung mit Hitler am Vormittag des 31. Januar eine Beteiligung des bei den Vorverhandlungen übergangenen Zentrums an der Regierung ablehnte, da seiner Partei nicht zugemutet werden könne, „sich mit dem Kaffeesatz zu begnügen, den andere übriggelassen haben“ ${ }^{\text {, }}$ und
\end{abstract}

1 Amtl. Meldung v. 30.1.33, zit. nach Frankfurter Zeitung v. 31.1.33, S.1.

2 Durch vertraul. Besprechungen mit Hitler und Göring einerseits sowie Hugenberg und Seldte andererseits, vgl. O. Meissner, Staatssekretär unter Ebert, Hindenburg, Hitler, Hamburg 1950, S.268; E. R. Huber, Deutsche Verfassungsgeschichte seit 1789, Bd. VII: Ausbau, Schutz und Untergang der Weimarer Republik, Stuttgart-Berlin-Köln-Mainz 1984, S.1256f.

3 Vgl. Ministerbesprechung v. 30.Januar 1933, 17 Uhr. Akten der Reichskanzlei. Regierung Hitler 1933-1938, herausg. für die Historische Kommission bei der Bayerischen Akademie der Wissenschaften von K. Repgen, für das Bundesarchiv von H. Booms, Die Regierung Hitler, Teil I: 1933/34, Band 1., 30. Januar bis 31. August 1933, bearb. von K.-H. Minuth, Boppard am Rhein 1983, Dok. Nr. 1, S.3.

4 Vgl. Protokoll des Fraktionsvorsitzenden Perlitius über die Unterredung Hitlers und Fricks mit den Zentrumsführern Kaas und Perlitius (als Vertreter des erkrankten Brüning) am 31.1.33, 11 Uhr, vgl. die Dokumentation von R. Morsey, Hitlers Verhandlungen mit der Zentrumsführung am 31.Januar 1933 (VfZ 1961, S. 182 ff.), S. 188. Zur Haltung des Zentrums gegenüber der Regierung Hitler 1933 grundlegend: R. Morsey, Die Deutsche Zentrumspartei, in: Das Ende der Parteien 1933, herausg. von E. Matthias und R. Morsey, Düsseldorf 1960, S.339ff. 
sich das Zentrum nach einer Fraktionssitzung am Nachmittag auch nicht bereit fand, die Regierung Hitler ohne vorherige konkrete Zusicherungen zu tolerieren, war für Hitler jeder Grund weggefallen, den Posten des Justizministers weiter unbesetzt zu halten. Noch am selben Tag informierte er den Leiter des Rechtsamtes der NSDAP und Führer des „Bundes Nationalsozialistischer Deutscher Juristen“ (BNSDJ), Hans Frank, der sich seit dem Vorabend erwartungsvoll im „Hotel Kaiserhof“ bereit hielt, daß er ihn leider nicht als Justizminister vorschlagen könne, da ihm Hindenburg „das Zugeständnis abverlangt" habe, den bisherigen Fachminister in den Kabinetten Papen und Schleicher, Franz Gürtner, wieder mit diesem Ressort zu betrauen. ${ }^{5}$ Bei seinem ersten Vortrag bei Hindenburg am 1. Februar, bei dem Hitler vom Reichspräsidenten nach dem Fehlschlagen seiner „Verhandlungen“ mit dem Zentrum die Auflösung des Reichstages forderte - die er von vornherein zur Vorbedingung für die Annahme des Kanzleramts gemacht hatte -, leitete er auch die Bestätigung Gürtners für das Amt des Reichsjustizministers ein. Von einem oft behaupteten "Zögern“ Hitlers bei der Berufung Gürtners, das angeblichen Vorbehalten gegenüber der Person des Ministers entsprungen sei, oder auch einer Unentschlossenheit Gürtners, die die Verzögerung verursacht habe ${ }^{6}$, kann bei diesem rein taktischen Manöver keine Rede sein. Gürtners Bestätigung im Amt durch Hindenburg erfolgte noch am selben Tag. ${ }^{7}$

\section{Werdegang und berufliche Laufbahn bis zur Rückkehr aus dem Ersten Weltkrieg im März 1919}

Wer war dieser Mann, der am Vormittag des 1. Februar 1933 seinen Sitz als Justizminister in der Regierung Hitler einnahm und die Geschicke der deutschen Justiz im nationalsozialistischen Staat bis zu seinem Tod am 29. Januar 1941 leiten sollte? Im Gegensatz zu den meisten Juristen in führenden Stellungen, die aus dem mittleren und gehobenen Bürgertum kamen, entstammte Gürtner einer Familie des einfachen Bürgertums. ${ }^{8}$ Er wurde am 26. August 1881 in Regensburg als Sohn eines Lokomotivfüh-

s Vgl. J. Müller, Bis zur letzten Konsequenz. Ein Leben für Frieden und Freiheit, München 1975, S. 38; Müller war Studienkollege von Frank. Dazu auch H. Frank, Im Angesicht des Galgens. Deutung Hitlers und seiner Zeit auf Grund eigener Erlebnisse und Erkenntnisse, München-Gräfelfing 1953, S.110f., der die Unterredung auf den 30. Januar abends datiert.

6 So E. Reitter, Franz Gürtner. Politische Biographie eines deutschen Juristen 1881-1941, Berlin 1976, S. 120. Von einer anderweitig nicht belegbaren Demissionsabsicht Gürtners unmittelbar nach dem 30.1.33 berichtet aufgrund eines Gesprächs mit Gürtner im Mai 1933 F. Berber, Zwischen Macht und Gewissen, München 1986, S. $58 \mathrm{f}$.

7 Es handelt sich formal nicht um eine Ernennung, sondern um eine Bestätigung, da Hindenburg am 28.1.33 die Demission der Regierung Schleicher entgegengenommen, das Kabinett aber mit der einstweiligen Weiterführung der Geschäfte beauftragt hatte. Vgl. handschriftl. Verm. auf der Urkunde v. 1.2.33 (Personalakten Gürtner des RJM, BA).

${ }^{8}$ Soweit nichts anderes zitiert vgl. zum folgenden Reitter, a.a.O., Personalakten Gürtner des RJM (BA), die biographischen Artikel von H. Fritzsche in: Unsere Reichsregierung, herausg. v. H. H. Sadila-Mantau, Berlin 1936, S. 153 ff., und 2.Aufl. 1939, S. 173 ff., Reichshandbuch der Deutschen Gesellschaft, Berlin 1930, S.617f., Das Deutsche Führerlexikon 1934/35, Berlin 1934, S.20. In Reitters Biographie geht die Darstellung der persönlichen Entwicklung Gürtners in der Schilderung der politischen Vorgänge unter, so daß „der Leser wichtige Hinweise zum Verständnis von dessen Persönlichkeit (so über Familie und persönliche Beziehungen zu Ministerpräsident Held, so über Gürtners weltanschauliche Haltung) aus verstreuten Anmerkungen zusammentragen muß, während ... persönliche Zeugnisse und Äußerungen aus der Ministerzeit so gut wie vollständig fehlen“ (vgl. die Rezension von R. Morsey in Juristische Arbeitsblätter 1977, ÖR S. 84f.). Im 
rers - also eines unteren Eisenbahnbeamten - geboren; seine Mutter war die Tochter eines Regensburger Metzgermeisters. Die achtbare und arbeitsame Familie besaß in der Stadt trotz ihres bescheidenen Einkommens ein eigenes Wohnhaus. Die Erziehung im Elternhaus war konventionell und traditionell-katholisch: sie vermittelte Achtung vor religiösen Werten, Treue zum Vaterland, dankbare Liebe gegenüber den Eltern und Gehorsam gegen Vorgesetzte. ${ }^{9}$ Schon während seiner Schulzeit auf dem Königlich-Neuen Gymnasium in Regensburg, das er von 1891 bis zur Reifeprüfung im Juli 1900 besuchte, zeigte Gürtner jene Zielstrebigkeit, die er auch später in Studium und Beruf aufweisen sollte. Wie es in der abschließenden Beurteilung durch die Schulleitung hieß, „verband er mit musterhaftem Verhalten hervorragende Begabung und unermüdlichen, stets gleichmäßigen Fleiß“, die ihm in allen Unterrichtsfächern erstklassige Noten einbrachten. ${ }^{10}$ Die persönliche Beurteilung des Prüfungskommissars bescheinigte ihm „die guten Umgangsformen und seine feine angenehme Art des Auftretens ..., die sich gleichweit von Überhebung und falscher Unterwürfigkeit fernhalten, Fehler, die bei einem jungen Mann, der sich aus kleinen Verhältnissen emporgearbeitet hat, gar leicht vorkommen"."1 Es ist durchaus möglich, daß sich Gürtner - der sich in der Schule stark für Kunst interessierte, gut zeichnete, im Wahlfach Musik Cello spielen lernte und sein Leben lang ein passionierter Cellist blieb - mit dem Gedanken trug, ein musisches Fach zu studieren. Aber die Tatsache, daß er aufgrund seiner hervorragenden Abschlußprüfung einen Platz in der Stiftung des Königlichen Maximilianeums in München bekam, das durch Stipendium, freie Kost und Unterkunft die Ausbildung begabter Studenten nur in jenen Fächern förderte, die später im Staatsdienst gebraucht wurden, dürfte zu seinem Entschluß beigetragen haben, Jura zu studieren.

Vor Studienbeginn besuchte der Neunzehnjährige im Jahre 1900 Rom und erfüllte damit eine lang gehegte Sehnsucht, die Stätten zu sehen, „wo die großen Männer der Antike gelebt und gewirkt haben, deren Leben und Werke wir in der Schule mit Eifer und Begeisterung kennengelernt hatten“; die Baudenkmäler des antiken Rom machten auf ihn „tiefsten Eindruck“, während ihn das moderne Rom „viel weniger interessierte“. ${ }^{2}$ Das im Wintersemester 1900 an der Münchner Universität begonnene Jurastudium betrieb er sehr zielstrebig, nicht ohne auch Vorlesungen in Musik- und Literaturgeschichte sowie - beim berühmten Lujo Brentano - in Volkswirtschaftslehre zu besuchen und in "sehr guten Nachschriften“ festzuhalten. ${ }^{13}$ In seiner Freizeit musi-

folgenden hat sich der Verf. daher bemüht, die zum Verständnis wichtigen Hintergrundereignisse möglichst knapp darzulegen, die politischen Vorstellungen Gürtners herauszuarbeiten und die erwähnten Lücken durch die Heranziehung bislang unbeachtet gebliebener Quellen zu schließen.

9 Aufschlußreich dazu Gürtners Abschiedsrede, die er am 14.7.1900 als Jahrgangsbester auf der Abiturfeier im Regensburger Rathaus hielt. Handschriftl. Aufz. v. 12.7.1900 (Nachlaß Gürtner. Der im Besitz der Familie befindliche Nachlaß wurde dem Verf. freundlicherweise von Herm Dr. Fritz Gürtner für die Einsichtnahme zur Verfügung gestellt), auszugsweises Zitat bei Reitter, a.a.O., S. 23. Immerhin machte sich im Gymnasium eine nationale Strömung gegen Ultramontanismus und Partikularismus bemerkbar, die sich in entsprechenden Schülerstreichen gegen die Geistlichkeit und z. B. bei Feiern im demonstrativen Tragen schwarz-weißroter Schärpen statt der angeordneten bayerischen Farben äußerte. Vgl. Schr. des früheren Gymnasiasten Prof. Bohla an Gürtner vom Januar 1939 über gemeinsame Erlebnisse (Korrespondenz Ministerbüro Gürtner, BA, Sign. R 22/4096).

10 Vgl. Niederschr. des Maximilianeums (Nachlaß Gürtner), zit. bei Reitter, a.a.O., S. 22.

11 A.a.O.

12 So Gürtner in einem Vortrag, den er am 30.5.39 in Rom vor italienischen Juristen hielt (DJ 1939, S.977).

13 Vgl. K. A. von Müller, Aus Gärten der Vergangenheit. Erinnerungen 1882-1914, Stuttgart 1954, S. 264, der als Maximilianeer die damalige Atmosphäre in der Stiftung eindrucksvoll schildert. 
zierte er in einem Quartett und wanderte leidenschaftlich gern in den Alpen: in den Tourenberichten des deutsch-österreichischen Alpenvereins wurde er verschiedentlich „als Teilnehmer an kühnen Besteigungen“ genannt. ${ }^{14}$ Die Liebe zur Natur und der heimatlichen Landschaft behielt er auch späterhin. Da den Angehörigen des Maximilianeums der Eintritt in eine schlagende oder farbentragende studentische Verbindung untersagt war und ihm die Verpflichtung zu Kommers und Fechtboden ohnehin nicht lag, schloß er sich für den gesellschaftlichen Umgang mit Kommilitonen der Maximilianeums-Gesellschaft an, die aus aktiven und ehemaligen Maximilianeern mit meist nationalkonservativer Gesinnung bestand. Zu Gürtners näheren Bekannten jener Tage gehörte der fast gleichaltrige, spätere Münchener Historiker Karl Alexander von Müller und der damals dreißigjährige, schon als Amtsrichter im bayerischen Justizministerium tätige Theodor von der Pfordten, der am 9. November 1923 als Mitglied des Bayerischen Obersten Landesgerichts beim Hitlerputsch an der Feldherrnhalle erschossen wurde. Als Maximilianeer fand Gürtner auch unschwer Zugang zu führenden Kreisen der Münchner Gesellschaft.

Nach acht Semestern legte Gürtner im Sommer 1904 sein Universitätsexamen ab und trat als Rechtspraktikant (Referendar) in den dreijährigen Vorbereitungsdienst für die zweite Staatsprüfung - in Bayern „Staatskonkurs“ genannt - beim Amtsgericht Regensburg ein. Seine dortige Tätigkeit wurde schon nach kurzer Zeit durch den Heeresdienst unterbrochen, den er ab Oktober 1904 als Einjährig-Freiwilliger beim 11. bayerischen Infanterieregiment „von der Tann“ ableistete. Im Juni 1906 kam er ans Landgericht Regensburg, im März 1907 ans Bezirksamt des nahe gelegenen Kelheim, anschließend zum Stadtmagistrat von Nürnberg und im März 1908 schließlich für ein halbes Jahr in die Münchner Rechtsanwaltspraxis Kißkalt. Diese Jahre als Praktikant waren für Gürtner finanziell keine leichte Zeit, er lebte zurückgezogen und verwandte alle Energie für die Vorbereitung auf die zweite Staatsprüfung. ${ }^{15} \mathrm{Im}$ Dezember 1908 legte er diese Prüfung für den höheren Justiz- und Verwaltungsdienst mit sehr guten Leistungen $a b .{ }^{16}$

Der geprüfte Rechtspraktikant (Assessor) Gürtner ging am Jahresanfang 1909 als Geschäftsführer und Syndikus des Vereins und Ortsverbandes der Münchener Brauereien und des Bayerischen Brauerbundes zunächst in die Privatwirtschaft. Bei dieser Tätigkeit - die sich während seiner Arbeit im Anwaltsbüro Kißkalt angebahnt hatte, bei der er für diese Vereine in Vertretung des Rechtsanwalts erfolgreich tätig geworden war - erledigte er die rechtlichen und wirtschaftlichen Angelegenheiten dieser gewerblichen Interessenverbände auf den Gebieten des Namens- und Warenschutzes, der Preisregulierung, des Kartellwesens, in Zoll-, Steuer- und Gebührensachen sowie im Arbeitsvertrags- und Tarifrecht. Auf letzterem Gebiet machte er beim Aushandeln der Lohntarife für das Jahr 1909 Erfahrungen, die seine spätere ablehnende Haltung gegenüber der Sozialdemokratie und den Gewerkschaften beeinflußt haben dürften: Als die sozialdemokratischen Führer den ausgehandelten Kompromiß, der seiner Ansicht nach den Interessen der Arbeiter durchaus gerecht wurde, als „Schlag ins Ge-

14 Vgl. Lebenslauf Gürtners (Personalakten des RJM, BA); es handelt sich um einen von ihm selbst korrigierten Text (Korrespondenz Ministerbüro Gürtner, BA, Sign. R. 22/4099).

15 Ủber Gürtners Leben in der Praktikantenzeit geben seine Briefe an die Eltern ein anschauliches Bild (Nachlaß Gürtner). Auszüge finden sich bei Reitter, a.a.O., S. $26 \mathrm{ff}$.

16 Mit den Noten: Justiz I 19/20, Verwaltung I 18/20, Hauptergebnis I 37/40 (Personalakten, a.a.O.). 
sicht“ bezeichneten, machte Gürtner im April 1909 seinem Ärger in einem Brief an seine Eltern Luft: Den Parteiführern passe nur nicht in den Kram, daß die betroffenen Arbeiter mit dem Erreichten zufrieden seien.

„Welche Kurzsichtigkeit, welcher Fanatismus! ... Parola: Nur keine Zufriedenheit aufkommen lassen, immer hetzen und schüren. Wieviel Arbeitskraft, Aufregung und Geld könnte erspart bleiben, wenn die Leitung der Gewerkschaften in den Händen ruhiger, besonnener Männer, starker Persönlichkeiten läge! Ja, die sog. soziale Frage schaut im praktischen Leben doch ganz anders aus, als sie Brentano von seinem Katheder aus betrachtet." ${ }^{\text {"17 }}$

Aber auch seinen Arbeitgebern stand Gürtner distanziert gegenüber; die „Geldsäcke“ stiegen auch nicht in seiner Achtung, als sie ihn durch höhere Gehaltsangebote glaubten „kaufen“ zu können: Gürtner war entschlossen, der Wirtschaft den Rücken zu kehren und seine Stellung zum frühesten vertraglich möglichen Termin - 30. September 1909 - zu kündigen. Eine Zeitlang schwankte er zwischen dem Beruf eines freien Anwalts und dem Staatsdienst. Aber schon am 26. Mai bat er das bayerische Justizministerium, ihm seine gegenwärtige Tätigkeit als „außerordentliche Praxis“ für seine Bewerbung um Anstellung im höheren Dienst anzuerkennen, da er „noch in diesem Jahre in den Justizdienst zu treten beabsichtige". ${ }^{18}$ Ende Juni schrieb er an seine Schwester, er sei nun mit sich „völlig im reinen: sich selbst treu bleiben, das ist das Erstrebenswerteste und alles andere ist Plunder, das Geld, die Carriere und die ,ehrgeizige' Frau, wovor mich Gott bewahren wird“. ${ }^{19}$ In dieser Entscheidung vom Jahre 1909, mit der Gürtner eine wichtige Weiche für seinen weiteren Lebensweg stellte, wird ein Wesenszug erkennbar, der später bei ihm noch deutlicher hervortreten sollte: seine Abneigung gegen den Pluralismus widerstreitender Interessengruppen und seine Vorliebe für autoritär strukturierte Ordnungen, wie sie Staatsverwaltung, Justiz und Militär darstellten. Charakteristisch dafür ist seine Bemerkung, er habe selbst auf seinem beschrä̀nkten Arbeitsgebiet

„deutlich gesehen, daß im ganzen Leben nie etwas erreicht wird, wenn eine Mehrheit dirigiert, sondern daß es nur darauf ankommt, daß ein Wille herrscht. Offen und brutal oder auf Umwegen u. versteckt - das ist gleich, aber immer muß einer die Pfeife haben, wonach alle anderen tanzen. Überall ist's so, in der Politik wie im Wirtschaftsleben, und wenn es nicht so ist, dann geht auch nichts vom Flecke.“20

Am 1. Oktober 1909 trat Gürtner als III. Staatsanwalt am Landgericht München I in den bayerischen Justizdienst ein. Seine Befürchtung, daß er im Gegensatz zum freien Anwaltsberuf im Staatsdienst „auf die gewöhnliche u. übliche Laufbahn rechnen müßte“21 , war unbegründet: aufgrund seiner hervorragenden Qualifikation wurde er zur Verwendung ins bayerische Justizministerium berufen. Dort blieb er auch, als er im Januar 1912 die Planstelle eines Amtsrichters beim Amtsgericht München erhielt.

Man kann mit Fug und Recht behaupten, daß sich Gürtner in den folgenden fünf Jahren bis zum Ausbruch des Ersten Weltkrieges durch seine Arbeit im bayerischen Justizministerium die Wissens- und Erfahrungsgrundlage für seine spätere Stellung als

\footnotetext{
17 Vgl. Schr. Gürtners an seine Eltern v. 25.4.09 (Nachlaß Gürtner), auch Reitter, a.a.O., S. 28 f.

18 Vgl. Schr. Gürtners an das Königliche Staatsministerium der Justiz v. 26.5.09 (Personalakten, a.a.O.). Das bayer. JM entsprach seinem Gesuch in Schr. an den OLGPräs. München v. 10.6. und 5.7.09, a.a.O.

19 Vgl. Gürtners Brief an seine Schwester Anna v. 25.6.09 (Nachlaß Gürtner), auch Reitter, a.a.O., S. 29. Zum Charakter seiner späteren Ehefrau s. im folgenden S. $73 \mathrm{f}$.

${ }^{20} \mathrm{Vgl}$. Brief an seine Eltern v. 12.9.09 (Nachlaß Gürtner).

21 Vgl. Brief an seine Schwester Anna v. 17.5.09 (a.a.O.), auch Reitter, a.a.O., S.29.
} 
„Fachminister“ schuf. Da er im Ministerium von der Pike auf diente und in den wichtigsten Referaten selbst intensiv arbeitete, konnte ihm später kein Untergebener so leicht etwas vormachen. Er begann als Hilfskraft für zwei Ministerialräte, deren Referate (III und VII) ${ }^{22}$ die Personalangelegenheiten, Teile des Justizetats sowie des Unterstützungs- und Pensionswesens, die Beziehungen des Ministeriums zum Landtag und die Redaktion des Justizministerialblattes umfaßten. Durch seine guten Fachkenntnisse und seine rasche Auffassungsgabe für das Wesentliche arbeitete er sich rasch ein, so daß ihm die beiden Ministerialräte bei seiner Arbeit bald größere Selbständigkeit einräumten. Durch sein ruhiges und sachliches Wesen - von dem noch häufiger zu sprechen sein wird - ließ er sich von der in Ministerien leicht auftretenden Nervosität nicht anstecken. „Ich glaube, ich werde nie nervös, bloß deshalb weil mich der Gegensatz reizt", schrieb er in einem Brief vom November 1909 und berichtete, er habe seinen unmittelbaren Vorgesetzten das dauernde Drängen abgewöhnt, indem er selbst einen Termin für die Erledigung seiner Arbeit festsetze, diesen dann aber auch einhalte. „Klarheit. Oberstes Prinzip im Leben. Für alle Beteiligten eine Wohltat.“23

Seit Frühjahr 1910 konzentrierte sich seine Mitarbeit auf das Referat IV ${ }^{24}$, das zuständig war für die Personalangelegenheiten der gesamten Justizverwaltung - sowohl des Ministeriums selbst wie der Gerichte, Staatsanwaltschaften, der in Bayern beamteten Notare und der Bewerber für den höheren Justizdienst -, ferner für die Beteiligung des Ministeriums an den juristischen Prüfungen der Universität München, die Mitwirkung Bayerns an der Besetzung des Reichsgerichts sowie für die Angelegenheiten des Landtages, soweit sie Justizsachen betrafen. Bei seiner Arbeit im Ministerium entwikkelte Gürtner denselben Ehrgeiz, den er in der Schule, an der Universität und bei der Ablegung des Staatskonkurses gezeigt hatte, so daß ihm sein Vorgesetzter Teile seines Geschäftsbereiches delegierte und Gürtner bei dessen Abwesenheit z. B. die gesamten Personalsachen selbständig erledigte. Im April 1912 vermerkte er befriedigt, er habe in letzter Zeit „manchen Faden des großen Webstuhls ganz still und leise in die Hand genommen“, den er "nicht wieder hergebe“. ${ }^{25}$ Seine unerschöpfliche Energie erlaubte es ihm, sich zusätzlich noch die Vertretung anderer Referate aufbürden zu lassen. Wenn ihn das Schicksal auch vor Geldgier, Protzerei und der „ehrgeizigen Frau“ bewahren sollte: das Streben nach Karriere hatte Gürtner offensichtlich gepackt. Dennoch wurde er deshalb keineswegs zum kalten Justizfunktionär; als er den Referenten für Begnadigungen vertrat, nahm er am Los der Betroffenen inneren Anteil: „Die Tiefblicke in diese verschiedenen Menschenleben und Menschenschicksale gehen wohl nur an den ganz verknöcherten Bürokraten ohne Eindruck vorüber. - Ich sehne den Tag herbei, der mich von dieser Tätigkeit wieder befreit."26

Gürtners Arbeit im bayerischen Justizministerium wurde durch den Krieg unterbrochen. Am 7. August 1914 ging er - nach mehreren Friedensübungen im Februar 1908 zum Leutnant der Reserve befördert - mit dem 11. Infanterieregiment an die

${ }^{22}$ Vgl. Aktenverm. v. 29.9.09 und Geschäftsverteilungsplan des bayer. JM v. 1.5.09 (Akten des bayer. JM, BayerHStArch., Sign. MJu 16844).

${ }^{23}$ Brief Gürtners v. 14.11.1909 (Nachlaß Gürtner), auszugsweises Zitat bei Reitter, a.a.O., S. 30.

24 Das erwähnte frühere Referat VII, vgl. Geschăftsverteilungsplan des bayer. JM v. 1.4. 10 (a.a.O., Sign. MJu 16845). Die Numerierung der Referate wechselte im Laufe der Jahre.

${ }^{25}$ Vgl. seinen Brief vom 30.4.12 (Nachlaß Gürtner), auch Reitter, a.a.O., S. 31.

${ }^{26}$ Vgl. Brief v. 4.3.10 (a.a.O.), auszugsweise zit. bei Reitter, a.a.O., S. 31 f. 
Westfront. ${ }^{27}$ Er nahm an den Kämpfen in Lothringen teil, entging in der Schlacht von Luneville knapp dem Tode ${ }^{28}$ und lag nach den Gefechten auf den Maashöhen und nach Beginn des Stellungskrieges von Ende September 1914 bis Juli 1916 in St. Mihiel. Im Oktober 1914 mit dem Eisernen Kreuz II. Klasse ausgezeichnet - im nächsten Jahr sollte der Bayerische Militär-Verdienst-Orden 4. Klasse mit Schwertern folgen -, wurde Gürtner im Januar 1915 Oberleutnant und für ein halbes Jahr Gerichtsoffizier seines Regiments. Im Sommer 1916 war er in der Verdunschlacht bei den Kämpfen um Fleury und Fort Thiaumont, im Herbst im Argonnenwald sowie in der Schlacht an der Somme eingesetzt und dabei auch als stellvertretender Kriegsgerichtsrat der 6. Infanteriedivision tätig. Nach viermonatigen Stellungskämpfen in Flandern wurde Gürtner - seit Oktober 1916 auch Inhaber des Eisernen Kreuzes I. Klasse - im März 1917 zum Hauptmann befördert und nahm im nächsten Monat als Kompanieführer an der Abwehrschlacht bei Arras teil. Nach weiterem Einsatz in Flandern zum Teil als stellvertretender Bataillonsführer - wurde er im September 1917 zum neu aufgestellten deutschen Expeditionskorps „Pascha II“ versetzt, das im Februar 1918 an der Palästinafront aufmarschierte, um die Türken im Kampf gegen die von Ägypten her angreifenden Engländer zu unterstützen. Für seine Verdienste beim 702. Infanteriebataillon wurde Gürtner im März mit dem Türkischen Eisernen Halbmond und im Juni mit dem Ritterkreuz des Hausordens von Hohenzollern ausgezeichnet. Als die Palästinafront unter der englischen Offensive vom September 1918 zusammenbrach und sich die türkischen Verbände auflösten, bewahrte Gürtner die seiner Führung anvertrauten Reste des 702. und des 703. Infanteriebataillons durch umsichtige Taktik davor, abgeschnitten zu werden. Nach Teilnahme an den Durchbruchkämpfen bei El Funduq und Nablus, mit denen sich das deutsche Korps - das den allgemeinen Rückzug deckte - zusammen mit türkischen Einheiten den Weg nach Norden bahnte, zeichnete sich Gürtner abermals persönlich aus, als er mit seiner Truppe den Übergang des Korps über den Jordan südlich von Beisan (Beth Shaan) durch erfolgreiche Abwehr eines Angriffs der nachrückenden Engländer sicherte. ${ }^{29}$ Während der Rückführung der Truppe unter ständiger Bedrohung und Nachhutgefechten bewährten sich Gürtners „unerschütterliche philosophische Ruhe“, seine Zähigkeit und sein "durch alle Widerwärtigkeiten hindurchreichender Humor". ${ }^{30}$ Nach dem Rückzug durch Syrien wurde Gürtner am 31. Oktober 1918 - dem Tage des türkischen Waffenstillstandes mit den Alliierten - mit dem Kommando des Infanteriebataillons 702 betraut und führte die Truppe quer durch Kleinasien bis ans Schwarze Meer, von wo sie per Schiff nach Haidar Pascha bei Konstantinopel gebracht wurde. Im Januar 1919 erfolgte der Transport in die Heimat auf dem Seewege durch das Mittelmeer mit Aufenthalten vor Malta und Gibraltar. Erst am 17. März 1919 traf Gürt-

${ }^{27}$ Zum folgenden vgl. beglaubigte Abschrift der Militär-Dienstzeitbescheinigung des Bayer. Kriegsarchivs v. 10.10.34 und Auszug aus der Kriegs-Rangliste v. 5.4.19 (Personalakten Gürtner des RJM, BA).

${ }^{28}$ Gürtner schilderte diese Begebenheit anschaulich in einem Brief aus dem Felde v. 16.9.14 (Nachlaß Gürtner), ausführl. zit. bei Reitter, a.a.O., S.33, Anm. 43.

29 Vgl. handschriftl. Ber. Gürtners v. 23.9.18, Beilage zu seiner Eingabe v. 23.12.20 zwecks Aufnahme in den Bayerischen Militär-Max-Josef-Orden. Das Gesuch um die Verleihung dieses höchsten bayer. Kriegsordens wurde jedoch im Januar 1921 abschlägig beschieden (Nachlaß Gürtner); dazu Reitter, a.a.O., S.35.

$30 \mathrm{Vgl}$. Lutz Graf Schwerin von Krosigk, Es geschah in Deutschland. Menschenbilder unseres Jahrhunderts, Tübingen und Stuttgart 1951, S.318. Krosigk fügt hinzu: „Er sollte dieser Eigenschaften im späteren Leben noch häufig bedürfen." 
ner, der seit Oktober des Vorjahres ohne jegliche Nachricht von zu Hause geblieben war, in Wilhelmshaven ein, wo die Truppe demobilisiert und entlassen wurde.

Bei der Rückführung seiner Truppe von Palästina bis in die Heimat bewies Gürtner als Offizier gegenüber den ihm anvertrauten Mannschaften jene Fürsorge, die er später als Reichsjustizminister seinen Untergebenen in der Justizverwaltung angedeihen lassen sollte, wenn sie in die Schußlinie von Partei oder SS gerieten - unter der Voraussetzung, daß sie im „nationalen“ Sinn in Ordnung waren. ${ }^{31}$ Von Angehörigen seiner Truppe - vom einfachen Schützen bis zum Leutnant - erhielt Gürtner später zahlreiche Briefe, die seinen Gerechtigkeitssinn, seine menschliche Güte und seinen persönlichen Einsatz als Vorgesetzter bezeugten, mit dem er „immer wieder das leuchtende Beispiel militärischer Pflichterfüllung " gab. ${ }^{32}$

Für Gürtners Pflichtauffassung ist es bezeichnend, daß er sich bereits am Tage nach seiner Heimkehr nach Regensburg schriftlich bei seiner Dienststelle meldete und trotz zweijähriger Abwesenheit von zu Hause lediglich vierzehn Tage Urlaub zur Regelung seiner persönlichen Angelegenheiten erbat. ${ }^{33}$

\section{Im bayerischen Justizdienst von der Räterepublik bis zum Ende des Kabinetts Graf Lerchenfeld (I) im Juli 1922}

Als Gürtner am 11. April 1919 seinen Dienst als II.Staatsanwalt - er war während des Kriegsdienstes im September 1917 befördert worden - am Landgericht München I aufnahm $^{34}$, war vier Tage vorher in München die Räterepublik ausgerufen worden und die rechtmäßige Regierung Hoffmann mit dem sozialdemokratischen Justizminister Endres nach Bamberg ausgewichen. Fünf Tage nach seinem Dienstantritt erlebte Gürtner das in seiner bisherigen Justizlaufbahn einmalige Schauspiel, daß sein Vorgesetzter, der I.Staatsanwalt Sturm, im Münchner Justizpalast als „Generalstabschef der Bourgeoisie“ durch Rotarmisten verhaftet werden sollte und der Gefangennahme nur durch Flucht aus der Stadt entging. ${ }^{35}$ Wie hatten sich die politischen Verhältnisse verändert, seit er Deutschland 1917 verließ: alle Werte, die ihm aufgrund seines Werdeganges als Maximilianeer, Justizbeamter und Offizier Inhalt seines nationalbewußten Denkens waren, waren durch Niederlage und Revolution entweder zerstört oder diskriminiert. Das bayerische Königtum und das deutsche Kaisertum waren beseitigt, das Reich nach außen seiner Großmachtstellung, seiner militärischen Mittel beraubt und dem Diktat der Sieger unterworfen, im Innern durch gegensätzliche politische Kräfte zerrissen und seine Regierung durch das parlamentarische System mit ständig wech-

31 Vgl. z. B. die Fälle Fabig (Kapitel III.1.c., S. 192 ff.), Richter, Dohnanyi (Kapitel III.3.a., S. 242 f., 248, 253 ff.) und Brandmüller (Kapitel VIII.3., S. 1111).

32 Vgl. Schreiben in der Korrespondenz des Ministerbüros ab 1933 (Akten des RJM, BA, Sign. R 22/4090-4154), darunter solche, in denen sich ehemalige Angehörige seiner Truppe mit den verschiedensten Anliegen - Arbeitssuche, politische Schwierigkeiten, sogar Schutzhaftfälle - vertrauensvoll an ihn wandten. Das Zitat stammt aus dem Schr. o.D. des ehemaligen Schützen Gotthold A. (R. 22/4091).

33. Vgl. Schr. Gürtners an die StAschaft beim LG München I v. 24.3.19 (Personalakten Gürtner des RJM, BA).

34 Vgl. Aktenverm. v. 11.4.19 (a.a.O.).

35 Vgl. Chronik der Bayerischen Justizverwaltung 1918-1919. Niedergeschrieben von den Referenten des Staatsministeriums der Justiz, Eintr. v. 16.4.19 (Arch. des IfZ, Sign. Fa 285/1). 
selnden Koalitionen an einer kontinuierlichen und verantwortungsvollen Ausübung einer starken Staatsautorität - bei einer parlamentarischen Regierungsform nach Auffassung Gürtners auf die Dauer - gehindert. ${ }^{36}$ Die Überwindung dieses Zustandes sah Gürtner - je mehr die Schwäche der parlamentarischen Demokratie von Weimar hervortrat, um so eindeutiger - in der Aufrichtung eines autoritären Staates mit einer von wechselnden Parlamentsmehrheiten unabhängigen Regierung, die Deutschland im Inneren stärken, aus der Not herausführen und das Diktat von Versailles beseitigen könnte. Diesem Ziel glaubte er durch aktive Unterstützung der national-konservativen Kräfte am besten zu dienen, ferner durch eine - allerdings mit einem Schuß Mißtrauen gemischte - Sympathie gegenüber den nationalistischen und völkischen ,vaterländischen Verbänden" in Bayern, die einerseits den Wehrwillen hochhielten und als milizartige Organisationen in Krisenzeiten zur Verteidigung der staatlichen Ordnung gegen die radikale Linke benutzt werden konnten, andererseits aber selbst zu einer politischen Gefahr für die Staatsautorität wurden. Neben dem Justizapparat, dessen Beamtenkörper in Bayern trotz der Revolution 1918/19 keine Veränderung erfahren hatte, war für Gürtner nun einmal das Militär eine der tragenden Säulen des Deutschen Reiches gewesen: „Die Zerschlagung des Heeres und der Justiz war das eingestandene Ziel der Revolution. Der erste Teil des Planes wurde erreicht. Die Erreichung des zweiten scheiterte an der Integrität und Festigkeit der Beamtenschaft", stellte Gürtner später fest. ${ }^{37}$ Für die Integrität der bayerischen Justizbeamtenschaft im „nationalen Sinn“ sollte Gürtner ab 1922 als Justizminister selbst sorgen können ${ }^{38}$; der Wiederaufbau der Wehrmacht aber war ein Ziel, bei dem Gürtner später mit dem nationalsozialistischen Regime trotz sonstiger Vorbehalte konform gehen sollte. ${ }^{39}$

In der Sozialdemokratie sah Gürtner einen Gegner, der schon im Kaiserreich jene politischen Werte zu unterminieren begonnen hatte, die ihm teuer waren. Als klassischer Vertreter des damaligen Bürgertums lehnte er den Sozialismus ab. Zwar dürfte Gürtner, der eine nüchterne Einschätzung der Dinge und einen Blick für Realitäten besaß, die Dolchstoßlegende durchschaut und die wahre Ursache für die Niederlage Deutschlands im Kriege nicht in der "Zersetzung“ der Heimat gesehen haben. Aber die Sozialdemokraten trugen in seinen Augen die Hauptverantwortung für die Abschaffung der Monarchie, die Errichtung der von ihm als untauglich angesehenen parlamentarisch-demokratischen Republik und - durch ihre Nachgiebigkeit gegenüber der radikalen Linken - auch für die innenpolitischen Wirrnisse, die er nach seiner Rückkehr in der Heimat vorgefunden hatte. Daß sich auch die Mehrheitssozialisten,

36 Über Gürtners Einstellung zur parlamentarischen Demokratie vgl. seine Ausführungen gegenüber Moser v. Filseck im Dezember 1928, „daß im parlamentarischen System jede Kontinuität fehle und damit auch das Verantwortungsgefühl notleide ... Wenn nur einmal eine Regierung, gleichviel welcher Zusammensetzung, eine längere Reihe von Jahren bleiben würde, dann könnte man Politik auf weite Sicht machen, das gelte für die auswärtige Politik ebenso wie für die innere“, s. Politik in Bayern 1919-1933. Berichte des württembergischen Gesandten Moser v. Filseck, herausg. von W. Benz, Stuttgart 1971, S. 212 (Ber. v. 17.12. 28).

$37 \mathrm{Vgl}$. Schr. Gürtners an den bayer. MinPräs. Held v. 28.11.27 (Nachlaß Held, BayerHStArch., Sign. 357).

38 Vgl. dazu Kapitel III.2., S.231.

39 Sein langjähriger persönlicher Referent Hans v. Dohnanyi bezeichnete Gürtner als einen „Mann, der mit glühender Liebe an dem Wiederaufbau der deutschen Wehrmacht hing“, vgl. Eingabe Dohnanyis an Oberreichskriegsanwalt Kraell v. 29.8.43 (aus dem Nachlaß Dohnanyi, Ordner 13 I, Schriftstück 9 mit freundlicher Genehmigung von Frau Barbara Bayer-v. Dohnanyi zitiert). Daß Gürtner als Weltkriegsoffizier die Wiederherstellung der "Wehrhaftigkeit“ Deutschlands ein ernsthaftes Anliegen war, geht auch aus seinem Gespräch mit Moser v. Filseck hervor (Politik in Bayern 1919-1933 [s. Anm. 36], S. 174, Eintr. v. 14.3. 25). 
die das Erbe des militärischen und politischen Zusammenbruchs des Kaiserreichs angetreten hatten, um das Vaterland verdient gemacht hatten, indem sie die Radikalisierung der Massen abgefangen und - mit Hilfe der Beamtenschaft, der Reichswehr und der Freikorps - das Weitertreiben der Revolution im Reich zur Rätediktatur verhindert hatten, zählte dabei nicht: das Bollwerk gegen eine drohende Bolschewisierung Deutschlands sah Gürtner nur bei der Rechten. Gerade nach der Niederwerfung der Münchener Räterepublik durch Reichswehr und Freikorps bot sich ihm auf dem Justizgebiet abermals ein Beispiel, daß die Sozialdemokraten gegen die radikale Linke nicht entschieden genug vorgingen: als der Vorsitzende des Vollzugsrats der Räterepublik, Eugen Leviné, am 3. Juni 1919 vom Standgericht ${ }^{40}$ in München wegen Hochverrats zum Tode verurteilt wurde, stimmten die sozialdemokratischen Vertreter im Ministerrat der Regierung Hoffmann - die Ende Mai durch Hereinnahme von Vertretern der Bayerischen Volkspartei und der Demokratischen Partei umgebildet worden war - gegen die Vollstreckung und traten für die Umwandlung in eine Freiheitsstrafe ein; sie wurden allerdings durch die bürgerlichen Minister überstimmt. ${ }^{41}$

Nach der Beseitigung der Räteherrschaft wurde Staatsanwalt Gürtner vom Justizministerium zusammen mit anderen Justizbeamten an das politische Referat der Stadtkommandantur München abgeordnet, um die zahlreichen von den Regierungstruppen Verhafteten zu vernehmen ${ }^{42}$ und diejenigen festzustellen, die der Strafverfolgung durch die Justiz zugeführt werden sollten. Gegenüber dem in der Staatsanwaltschaft als Hilfsarbeiter beschäftigten Hoegner verglich Gürtner „die Niederwerfung der Räterepublik mit einem Sturmgewitter, das über Gerechte und Ungerechte niedergehe“, und meinte, daß man diese Bürgerkriegszeiten "nicht mit dem Strafgesetzbuch messen" könne. ${ }^{43}$ In der Tat gestaltete sich die juristische Aufarbeitung der Revolutionsgeschehnisse problematisch, soweit nicht eindeutig kriminelle Handlungen vorlagen $^{44}$, wie es z. B. beim Geiselmord im Luitpoldgymnasium am 30. April durch Rotarmisten und bei der Ermordung von Mitgliedern des Gesellenvereins St.Josef im Prinz-Georg-Palais am 6. Mai durch Angehörige der Regierungstruppen der Fall war. Auf der Seite der Regierungstruppen wurden Gewalttaten und Gesetzesverletzungen mit Hinblick auf die Ausnahmesituation des Bürgerkrieges meist nicht verfolgt, da diesen Reichswehr- und Freikorpsverbänden der Status einer Art kriegführenden Macht zuerkannt wurde. Selbst die Teilnehmer an Verhandlungen und Vollstreckungen von Todesurteilen der „Feldgerichte“, die bei der Württembergischen Freiwilli-

40 Das Standgericht wurde beim LG München I für die Bezirke der LGe München I und II aufgrund der Verhängung des Standrechts über das rechtsrheinische Bayern durch die Regierung Hoffmann v. 25.4. 19 errichtet. Es wurde erst am 19.7.19 mit Wirkung v. 1.8.19 wieder aufgelöst. Vgl. Chronik der Bayerischen Justizverwaltung, a.a.O., Eintr. v. 25.4. und 19.7.19.

41 Der sozialdemokratische Ministerpräsident Hoffmann, der sich zum Besuch seiner kranken Frau in der Schweiz befand, nahm an der Sitzung nicht teil, vgl. a.a.O., Eintr. v. 4.6.19.

$42 \mathrm{Vgl}$. Schr. Gürtners an seinen Vorgesetzten v. 9.7.19 (Personalakten Gürtner des RJM, BA), dazu die Selbstbiographie des damaligen Hauptmanns, späteren Bezirksamtmanns von Dachau und bayer. JM Christian Roth, der in dieser Zeit die Polizei- und Presseabteilung der Stadtkommandantur München übernahm (BayerHStArch., Sign. MJu 16934).

43 Vgl. W. Hoegner, Der schwierige Außenseiter. Erinnerungen eines Abgeordneten, Emigranten und Ministerpräsidenten, München 1959, S. 15.

44 Eine Úbersicht über die Übergriffe auf beiden Seiten gibt H. Hillmayr, Roter und Weißer Terror in Bayern nach 1918, München 1974. Zur juristischen Aufarbeitung vgl. Schr. des bayer. JM v. 28.9.21, 29.5. und 12.10.22 sowie Denkschrift v. 23.10.23 an das RJM, abgedruckt in: E. J. Gumbel, Vier Jahre politischer Mord, Heidelberg 1980, S.69ff., dazu Gumbels Kommentar S. $118 \mathrm{ff}$. 
gen-Abteilung eingerichtet waren und nach der späteren Feststellung des bayerischen Justizministeriums keinerlei gesetzliche Grundlage hatten ${ }^{45}$, wurden nicht belangt, da ihnen das Bewußtsein der Rechtswidrigkeit ihrer Handlungen gefehlt habe. Hinzu kam, daß für die Verfolgung von Ausschreitungen der Regierungstruppen bis Sommer 1920 zunächst die Militärgerichtsbarkeit zuständig war ${ }^{46}$, die die Ermittlungen entsprechend einseitig führte. Auf der Seite der Aufständischen wurden die Führer der Räterepublik wegen des Verbrechens des Hochverrats - außer dem zum Tode verurteilten Leviné - zu Festungs- und Zuchthausstrafen verurteilt. Dagegen mußten Gürtners Kollegen bei der Münchener Staatsanwaltschaft - Gürtner selbst plädierte vor dem Standgericht nicht - erleben, daß eine bloße Beteiligung am Umsturz durch Eintritt in die Rote Armee vom Standgericht entgegen ihrem Antrag nicht als Beihilfe zum Hochverrat bestraft, sondern die Angeklagten den ordentlichen Gerichten überwiesen wurden, die sie als verführte Mitläufer wegen Vergehens gegen die öffentliche Ordnung, insbesondere gegen das Verbot der Bandenbildung nach $\S 127 \mathrm{StGB}$, zu Gefängnisstrafen verurteilten. Dieser Auffassung des Standgerichts mußte sich in der Folge schließlich auch die Staatsanwaltschaft mit ihren Anträgen beugen. ${ }^{47}$ Ein Jahr später war mit Ausnahme der Rädelsführer weit über die Hälfte der im Zusammenhang mit dem Räteaufstand Verurteilten vorzeitig mit Bewährungsfrist wieder entlassen $^{48}$; im Dezember 1924 sollten ihnen die letzten zu Festungshaft verurteilten Räterepublikaner folgen. ${ }^{49}$

Diese erste strafprozessuale Bewältigung einer politischen Umsturz- und Ausnahmesituation, die Gürtner in seiner beruflichen Laufbahn erlebte, bestärkte ihn in der Auffassung, daß Täter, "die es sich zum klaren Ziel gesteckt haben, den konkreten Staat und die Staatsordnung zu erschüttern“, niemals amnestiert, sondern durch die Justiz verfolgt werden sollten: der Staat habe „das Recht der Selbstbehauptung genau so, wie jeder Organismus ... Würde der Staat auf dieses Recht verzichten, dann wäre er nicht lebensfähig“. Andererseits sollten aber bei allen politischen Verbrechen - nicht nur des Hochverrats - stets die Beweggründe geprüft werden: „Was im Verfahren differenziert werden kann, das sind die Motive, die zur Tat geführt haben. ${ }^{\text {(50 }}$ Bei der strafrechtlichen Würdigung nach dem Gesetz objektiv erfüllter politischer Tatbestände sollte nach Meinung Gürtners die subjektive Seite des Tatbestandes besonders berücksichtigt werden. Wenn die Straftat z.B. zur Unterstützung der rechtmäßigen Regierung und zur Verteidigung des Staatswesens begangen worden war, sollte sich - soweit dadurch unter Umständen ein strafbarer Tatbestand nicht überhaupt verneint werden konnte - dieses "nationale“ Motiv in der Strafzumessung niederschlagen. Konnten in einem solchen Fall durch Anwendung des Gesetzes im Einzelfall Härten nicht vermieden werden, sollten sie gegebenenfalls durch einen Gnadenakt gemildert werden.

\footnotetext{
$45 \mathrm{Vgl}$. Denkschrift des bayer. JM v. 23.10.23 (Gumbel, a.a.O.): Nach der VO II v. 28.12.1899 und $§ 3$ EG. zur MStPO durfte dieses feldgerichtliche Verfahren nur gegen Ausländer angewendet werden.

46 Vgl. G. betr. Aufhebung der Militärgerichtsbarkeit v. 17.8.20 (RGBl. I, S. 1579).

47 Vgl. Chronik der Bayerischen Justizverwaltung, a.a.O., Eintr. v. 17.5.19.

$48 \mathrm{Vgl}$. Ausführungen des bayer. JM Müller-Meiningen vor dem bayer. Landtag am 20.5.20 (Verhandlungen des Bayer. Landtags, Tagung 1919/1920, Stenogr. Ber., III. Bd., S. 252).

49 Es handelte sich um Mühsam, Sauber, Karpf und Olschewski, die sich seit 1919 in Festungshaft befanden und mit Bewährungsfrist entlassen wurden (vgl. Chronik, a.a.O., Eintr. v. 20.12.24).

so Vgl. Gürtners Ausführungen im Verfassungsausschuß des bayer. Landtages v. 3.7. 24, mit denen er Antrãgen des Völkischen Blocks, der SPD und der KPD auf Amnestierung und Entlassung politischer Häftlinge entgegentrat (Chronik, a.a.O., Eintr. v. 3.7.24).
} 
Diese Folgerungen, die Gürtner aus der Bürgerkriegssituation in Bayern von 1919 zog, sollte er als Justizminister 1923/24 gegenüber den reichstreuen politischen Straftätern in der französisch besetzten Pfalz anwenden, die gewaltsam gegen die dortigen Separatisten vorgingen; sie sollten auch seine Einstellung gegenüber den Teilnehmern am Hitlerputsch beeinflussen. Solche Maximen - denen wohl die Mehrzahl der Kollegen Gürtners in der Weimarer Zeit anhingen - ordneten das Prinzip unparteiischer Gerechtigkeit der Politik unter und öffneten den Weg zu einer unterschiedlichen Strafpraxis gegen die politischen Kräfte von rechts und links, die gegen das Prinzip der Gleichheit aller Staatsbürger vor dem Gesetz verstieß. „Daß die Angeklagten bei ihrem Tun von rein vaterländischem Geiste“ geleitet waren und „zur Rettung des Vaterlandes " $^{\text {" }}$ u handeln glaubten ${ }^{51}$, wurde beim Strafmaß gegen Hitler und die Teilnehmer an seinem Putsch im Hochverratsprozeß von 1924 ausdrücklich berücksichtigt. Der in diesem Zusammenhang von Hachenburg geäußerte Gedanke: „Auch der Arbeiter, der an das Heil der Räterepublik glaubt, handelt aus der Überzeugung, das Heil des Vaterlandes, wie er es versteht, zu fördern "s2 , mußte dem Denken des konservativen Juristen naturgemäß fremd und geradezu absurd erscheinen. Die spätere Forderung der nationalsozialistischen Führung einerseits nach Verschärfung der Strafbestimmungen für den Schutz des Staates - d. h. aber des nationalsozialistischen Regimes - und andererseits nach Berücksichtigung ,nationaler" Motive bei politischen Straftaten sollte daher auch beim Reichsjustizminister Gürtner auf Verständnis stoßen - allerdings nur soweit, wie diese Motive nicht zur Bemäntelung eigensüchtiger und rein krimineller Verbrechen lediglich vorgeschoben wurden. ${ }^{53}$

Das Zustandekommen der ersten rein bürgerlichen Regierung in Bayern Mitte März 1920 unter v. Kahr, die von einer Koalition aus Bayerischer Volkspartei, Deutscher Demokratischer Partei und Bayerischem Bauernbund gebildet wurde und in der der Deutschdemokrat Müller-Meiningen das Justizministerium behielt, hatte auf Gürtners Laufbahn noch keinen sichtbaren Einfluß. Am 1. April 1920 ließ er sich von der Staatsanwaltschaft beim Landgericht München I für drei Monate „zur informatorischen Beschäftigung" bei der Direktion der Bayerischen Vereinsbank in München ohne Gehalt beurlauben. ${ }^{54}$ In dieser Zeit legte Gürtner, der schon vorher auf die bayerische Verfassung vereidigt worden war, nunmehr auch den Eid auf die Reichsverfassung $a^{55}$ und war damit trotz seiner zu diesem Zeitpunkt wohl schon bestehenden Reservatio mentalis zugunsten einer nichtparlamentarischen autoritären Staatsform verpflichtet, die verfassungsmäßig existierende Staatsform in Bayern und im Reich zu achten. Denn zu diesem Zeitpunkt gab es jenen Gesinnungsvorbehalt nicht mehr, den im Herbst 1918 der königliche Staatsrat (Staatssekretär) im bayerischen Justizministe-

${ }^{51}$ Vgl. Urt. v. 1.4.24 im Hitlerprozeß, dazu im folgenden S. $33 \mathrm{ff}$.

\$2 Hachenburg in: Juristische Rundschau (DJZ 1924, S. 366 f.). H. forderte eine strenge Bestrafung des Hochverrats, damit er nicht „zum Sport“ werde, sie müsse jedoch unparteiisch erfolgen, da sonst der Vorwurf der Klassenjustiz nicht zu entkräften sei. Der jüdische RA Max Hachenburg, durch seine wissenschaftl. Kommentare zum Handelsrecht bekannt, war stellv. Vorsitzender des Deutschen Anwaltsvereins und Mitherausgeber der DJZ.

53 Vgl. dazu die Kapitel VII.3.a., IV und V.1.d.

34 Vgl. Gürtners Urlaubsgesuch v. 17.3.20 (Personalakten Gürtner des RJM, BA).

${ }^{55}$ Vgl. schriftl. Eidesabnahme v. 2.6.20 (Personalakten, a.a.O.). Sie erfolgte aufgrund der VO des Reichspräs. v. 14.8.19 (RGBl., S. 1419) und der bayer. VO v. 3.5.20 (GVBI., S. 191) über die Vereidigung der öffentlichen Beamten. Gürtners Vereidigung auf die bayer. Verfassung war schon aufgrund des bayer. G. v. 6.11.19 (GVBl., S. 783) erfolgt. 
rium v.Unzner - der bis Ende März 1919 im Amt blieb - in die Verpflichtungserklärung für die bayerischen Justizbeamten eingefügt hatte, als er gegenüber dem sozialdemokratischen Minister Timm einen Treueid auf die Republik unter der Regierung Eisner als unzumutbar ablehnte: „Wir verpflichten uns, dem Volksstaate Bayern unter Wahrung unserer Gesinnung und Ủberzeugung [!] freiwillig und aufrichtig im Interesse der Gesamtheit unsere Arbeitskraft zur Verfügung zu stellen." ${ }^{\text {"56 }}$ Dennoch hätte Gürtner möglicherweise auch 1920 noch offen den Vorbehalt machen können, „an Bestrebungen teilzunehmen, die darauf abzielen, die gegenwärtige Staatsform auf gesetzmäßigem Wege zu ändern"; wie der Richterdisziplinarhof am Obersten Landesgericht in einem bemerkenswerten Gutachten vom 27. Januar 1921 feststellen sollte, war „die Erklärung, nur mit einem solchen Vorbehalte den Eid leisten zu wollen, ... einer Eidesverweigerung nicht gleichzuachten". ${ }^{57}$

Während seiner Beschäftigung bei der Vereinsbank bereitete sich eine Entscheidung im Privatleben Gürtners vor: am 7. Juli 1920, wenige Tage nach Beendigung seines Arbeitsurlaubs, heiratete er Luise Stoffel, die zwölf Jahre jüngere Tochter eines verstorbenen Oberstleutnants aus Neuburg an der Donau. Aus dieser Ehe sollten drei Söhne hervorgehen: Fritz (geb. 1923), Franz (geb. 1925) und Heinz (geb. 1928). Für Gürtners Verhältnis zur katholischen Kirche ist bezeichnend, daß er aus ihr zwar nicht austrat, sich aber evangelisch trauen ließ und seine Söhne im protestantischen Glauben erziehen ließ $\beta^{57 a}$; den politischen Katholizismus lehnte er ab.

Die Bildung der zweiten bürgerlichen Koalitionsregierung unter v. Kahr am 16. Juli 1920, in der Christian Roth als Vertreter der Bayerischen Mittelpartei - in der die Deutschnationalen Bayerns organisiert waren - das Justizministerium übernahm, ebnete Gürtner den Weg zur Rückkehr ins Ministerium. Schon im April hatten ihm seine Vorgesetzten in der Staatsanwaltschaft ein ausgezeichnetes fachliches Zeugnis ausgestellt, in dem ihm überdurchschnittliche Fähigkeiten und Leistungen, „ein ruhiges, klares Urteil, ein zielbewußtes Handeln, eine tiefgründige Auffassung und Behandlung seiner Geschäftsaufgaben“ bescheinigt wurden. Er wurde darin als „ein kenntnisreicher, gewandter, charakterfester Mann mit sicherem Urteil" und im Gesamturteil als „ein besonders tüchtiger Beamter" bezeichnet. ${ }^{58}$ Was lag für den neuen Justizminister näher, als diesen ausgezeichneten Juristen, der zwar der Mittelpartei noch nicht angehörte, dessen nationale und konservative Gesinnung ihm aber - wahrscheinlich schon von der gemeinsamen Tätigkeit in der Münchener Stadtkommandantur her - bekannt war ${ }^{59}$, ins Ministerium zu holen. Möglicherweise half hier auch die Tatsache mit, daß Gürtner durch seine Heirat Schwager des Oberregierungsrats Dürr geworden war, der seit November 1919 im Ministerium saß. Jedenfalls verfügte

s6 Wiedergegeben in der unveröffentlichten Biographie Dr. Karl v. Unzner, die 1931 von Staatsrat Schmitt für das bayer. JM geschrieben wurde (BayerHStArch., Sign. MJu 16934). Nach seinem Austritt aus dem JM wurde v. Unzner Präsident des Bayerischen Obersten Landesgerichts.

57 Vgl. Chronik der Bayerischen Justizverwaltung, a.a.O., Eintr. v. 27.1.21.

s7a Maßgeblich dafür war Gürtners Ansicht, daß die religiöse Erziehung der Kinder in erster Linie Aufgabe der Mutter sei und daher in deren Glauben erfolgen müsse (mündl. Auskunft von Dr. Fritz Gürtner. an den Verf.).

58 Vgl. Dienstliche Würdigung Gürtners durch den OStA beim OLG München und den EStA beim LG München I v. April 1920 (Personalakten, a.a.O.).

59 Vgl. voranstehende Anm. 42. Reitter, a.a.O., S.37, Anm. 52, betont vor allem die Rolle des rechtsstehenden OberstLGRats von der Pfordten als Förderer Gürtners, mit dem Gürtner seit seinen Tagen im Maximilianeum näher bekannt war. 
Roth bereits drei Tage nach seinem Amtsantritt, daß Gürtner mit Wirkung vom 1. August 1920 zum Landgerichtsrat ernannt und zur Dienstleistung ins Ministerium berufen wurde. ${ }^{60}$. Dort übernahm er das Referat XVI: die stellvertretende Leitung des Begnadigungswesens, ferner die Beschwerden in Strafsachen und die Entschädigung wegen unschuldig erlittener Haft im Benehmen mit seinem Schwager, der das Referat XIV für Straf- und Strafprozeßrecht, Kriegs- und Belagerungszustandsrecht, Niederschlagung von Strafverfahren u.a. innehatte, und zu dessen Referat Gürtner Beihilfe zu leisten hatte. ${ }^{61}$ Bereits im April 1921 übertrug ihm Roth die Leitung des gesamten Begnadigungswesens sowie den Vorsitz in der Begnadigungskonferenz und befreite ihn von der Verpflichtung, im Referat Dürrs als Hilfsreferent tätig zu sein. ${ }^{62}$ Diesem Posten kam insofern eine erhöhte Bedeutung zu, als die Begnadigung die einzige Möglichkeit darstellte, Urteile der bayerischen Volksgerichte zu mildern, da es gegen sie kein Rechtsmittel und keine Wiederaufnahme des Verfahrens gab. ${ }^{63}$

Es ist anzunehmen, daß Gürtner bei seinem engen Kontakt zum Strafrechtsreferat die Aktivitäten v. Kahrs, Roths - der Anfang 1923 die politische Geschäftsführung der „Arbeitsgemeinschaft der vaterländischen Verbände“ übernehmen sollte - und des Polizeipräsidenten Pöhner bekannt waren, um Angehörige der Einwohnerwehren und vaterländischer Verbände, die an angeblichen „Verrätern“ geheimer Waffenlager Fememorde begangen hatten, nach Möglichkeit zu schonen. ${ }^{64}$ Dennoch ließ sich Gürtner als Referent in dieser Hinsicht keine nachweisbare Dienstverfehlung zuschulden kommen. So mußte auch der sozialdemokratische Reichstagsabgeordnete Levi seine Beschuldigung, Gürtner habe im März 1921 im Falle des ermordeten Kellners Hartung zwei Augsburger Staatsanwälte veranlaßt, den Vollzug des Haftbefehls gegen beschuldigte Angehörige der Einwohnerwehr auszusetzen ${ }^{65}$, nach der Beweisaufnahme durch den Femeausschuß des Reichstages im Oktober 1926 wieder zurücknehmen: laut Untersuchungsergebnis hatte Gürtner am 14. März 1921 in Vertretung des erkrankten Strafrechtsreferenten die beiden Staatsanwälte empfangen und lediglich ihren für Roth bestimmten mündlichen Bericht entgegengenommen, sich jedoch jeder Weisung zur Behandlung der Sache enthalten.$^{66}$ Es entsprach nicht Gürtners Charakter, seine Karriere durch ungesetzliche Handlungen aufs Spiel zu setzen. Sonst wäre es auch wenig wahrscheinlich gewesen, daß Graf Lerchenfeld, der nach dem Rücktritt

$60 \mathrm{Vgl}$. Verf. Roths v. 19.7.20 (Personalakten, a.a.O.).

61 Vgl. Geschäftsverteilungsplan des bayer. JM v. 18.7.20 (Akten des bayer. JM, BayerHStArch., Sign. MJu 16845).

$62 \mathrm{Vgl}$. AnO des JM Roth v. 4.4.21 (a.a.O.).

${ }^{63} \mathrm{Vgl}$. $\S 20$ des G. über die Einsetzung von Volksgerichten bei inneren Unruhen v. 12.7.19 (GVBl., S. 365). Zu den Volksgerichten grundlegend: F. J. Bauer und Ed. Schmidt, Die bayerischen Volksgerichte 1918-1924. Das Problem ihrer Vereinbarkeit mit der Weimarer Reichsverfassung (Z. f. bayer. Landesgeschichte 1985, S. $494 \mathrm{ff}$.$) .$

64 Vgl. dazu H. und E. Hannover, Politische Justiz 1918-1933, Frankfurt a. M. 1966, S. 152 ff.

6s Vgl. die Anschuldigungen Levis im „Vorwärts“ Nr.348 v. 27.7.26, S.1, und Nr.354 v. 30.7.26, S.1. Zur Mordsache Hartung s. E. J. Gumbel, Verräter verfallen der Feme, Berlin 1929, S. $112 \mathrm{ff}$.

${ }^{66}$ Vgl. die Ausführungen Levis als Berichterstatter des Femeausschusses v. 13.10.26: „Nach dem Ergebnis der in München stattgehabten Beweisaufnahme stehe ich nicht an, zu erklären, daß ... Herr Dr. Gürtner vielmehr lediglich im Auftrag des Justizministers einen Vortrag der Staatsanwälte entgegengenommen und dem Justizminister weitergegeben hat.“ Der Ausschuß stellte in seiner Entschließung fest, der Vorwurf sei widerlegt, daß Gürtner „in die schwebende Untersuchung eingegriffen oder seinen Einfluß geltend gemacht hat, um den Fortgang des Verfahrens zu hemmen" (Chronik der Bayerischen Justizverwaltung, a.a.O., Eintr. v. 13.10.26). Dazu neuerdings U. Hofmann, Verräter (2000), S. 234. 
v. Kahrs im September 1921 Ministerpräsident wurde und wegen des Austritts der Deutschnationalen aus der Regierungskoalition das Justizministerium selbst übernahm, der Ernennung Gürtners zum Oberregierungsrat im Ministerium am 1. Oktober und seiner weiteren Betrauung mit dem Begnadigungsreferat zugestimmt hätte. ${ }^{67}$ Auch hätten ihn die bayerischen Deutschdemokraten dann nicht als - von der Mittelpartei vorgeschlagenen - Justizminister akzeptiert, als die Bayerische Volkspartei im Frühjahr 1922 wegen eines Wiedereintritts der Deutschnationalen in die Regierung verhandelte, um Graf Lerchenfeld auf einen schärferen Kurs gegenüber der Reichsregierung festzulegen und ein „Abrutschen mehr nach links“ zu verhindern. Die Ablehnung der Deutschen Demokratischen Partei, mit den Deutschnationalen erneut eine Koalition einzugehen, lag keineswegs in der Person Gürtners begründet - gegen den sie „durchaus keine Bedenken“ hatte -, sondern in der Auffassung, daß die bestehende Regierung gerade ,ihre Stärke in der Stellung zwischen der Rechten und der Linken“ habe. ${ }^{68}$ Erst als die Demokraten im Zusammenhang mit der Auseinandersetzung der bayerischen Regierung mit Berlin um das Republikschutzgesetz im Juli aus der Koalitionsregierung austraten und damit den Weg für die Hereinnahme der Deutschnationalen freimachten, kam Gürtners Stunde: obwohl Gürtner auch zu diesem Zeitpunkt noch nicht Mitglied der Mittelpartei, „vielmehr politisch noch gar nicht hervorgetreten" war, schlug sie ihn als ihren Vertreter und neuen Justizminister vor. Die Gründe dafür waren vermutlich ,seine Fähigkeiten in seinem Amte und sein ruhiges Urteil in politischen Dingen". ${ }^{69}$ Gerade für die bevorstehenden schwierigen Verhandlungen mit Berlin bot Gürtners Persönlichkeit „mehr Gewähr für eine gemäßigte Politik ... als diejenige des Staatsrats Meyer", den die Bayerische Volkspartei als Justizminister durchzusetzen suchte. ${ }^{70}$ Meyer, der seit April 1919 das Amt des Staatsrats (Staatssekretärs) im bayerischen Justizministerium wahrnahm und in der Volkspartei aktiv tätig war, hatte sich bei der Ablehnung der Republikschutzbestimmungen, die als Eingriffe in die bayerische Justizhoheit angesehen wurden, stark engagiert. Er hatte den Erlaß einer gesonderten bayerischen Notverordnung durchgesetzt, die zwar die Strafvorschriften des Republikschutzgesetzes im wesentlichen übernahm, ihre Anwendung aber nicht dem Staatsgerichtshof des Reiches, sondern den bayerischen Volksgerichten übertrug und als Beschwerdeinstanz für Anordnungen der Regierung das Bayerische Oberste Landesgericht vorsah. ${ }^{71}$ Noch am 4 . August vormittags verzögerte sich die Ernennung Gürtners, da die Mittelpartei befürchtete, „daß er in zu große Abhängigkeit vom Grafen Lerchenfeld gerate“. Vom Landtag aus rief Gürtner seinen Vorgesetzten Meyer an und teilte ihm mit, die Mittelpartei sei daher nun einverstanden, daß Meyer Justizminister werde, wenn er selbst die Stelle eines politischen Staatssekre-

${ }^{67}$ Vgl. Personalakten Gürtner des RJM (BA) und Geschäftsverteilungsplan des bayer. JM v. 20.4.22 (Akten des bayer. JM, BayerHStArch., Sign. MJu 16845).

68 Vgl. Ber. Mosers v. Filseck v. 4.3.22, a.a.O. (s. Anm. 36), S. 93.

69 Ber. Mosers v. 5.8.22, a.a.O., S. 106.

${ }^{70}$ Unveröffentlichter Ber. Mosers v. 8.8.22 (WürttHStArch., Sign. Bestand E 130 II, Büschel 348). Die BMP sollte dafür das Handelsministerium besetzen.

${ }^{71}$ Vgl. VO zum Schutze der Verfassung der Republik v. 24.7.22 (GVBl., S. 374), dazu K. Schwend, Bayern zwischen Monarchie und Diktatur. Beiträge zur Bayerischen Frage in der Zeit von 1918 bis 1933, München 1954, S. 187 ff. Auf dieses Werk sei für den politisch-historischen Hintergrund, der im Rahmen dieser Biographie nicht behandelt werden kann, generell verwiesen. 
tärs $^{72}$ erhalte. Als Meyer jedoch ablehnte ${ }^{73}$, war das letzte Hindernis für die Ernennung Gürtners zum Minister am 4. August 1922 beseitigt.

\section{Bayerischer Justizminister in den Kabinetten Graf Lerchen- feld (II) und v. Knilling bis Juni 1924}

Bei den Verhandlungen mit der Reichsregierung Wirth, zu denen Gürtner mit Ministerpräsident Graf Lerchenfeld und Innenminister Schweyer noch im August 1922 nach Berlin fuhr und die unter dem Vorsitz des Reichspräsidenten Ebert stattfanden, bewährte sich die ruhige und sachliche Art des neuen Justizministers. Nach dem Urteil Lerchenfelds war Gürtner „ein ganz hervorragender Mann, der sich in Berlin durch klare Sachlichkeit und konziliantes Wesen beim Verhandeln ausgezeichnet habe, so daß der Herr Reichspräsident sich darüber ganz besonders anerkennend ausgesprochen habe ${ }^{\text {“ }}{ }^{74}$ Gürtners realistischer Sinn für politisch Erreichbares dürfte zu dem Kompromiß wesentlich beigetragen haben, der nach nochmaligen, durch die unzufriedenen bayerischen Koalitionsparteien erzwungenen Verhandlungen Gürtners und Schweyers in Berlin schließlich zustande kam: Die bayerische Sonderverordnung, deren Rechtsgültigkeit die Reichsregierung bestritt, wurde aufgehoben, dafür beim Staatsgerichtshof ein süddeutscher Senat errichtet, das Begnadigungsrecht vom Reichspräsidenten im Benehmen mit der Bayerischen Landesregierung ausgeübt, dem Oberreichsanwalt ein spezieller bayerischer Referent zugeteilt und den bayerischen Staatsanwälten bei der Entscheidung über die Überweisung einer Sache an den Staatsgerichtshof oder die Landesgerichte zumindest eine empfehlende Mitwirkung zugestanden.

Bei diesen Verhandlungen hatte Gürtner auch gegenüber dem Vorsitzenden der Mittelpartei Hilpert Selbständigkeit bewiesen, der das Ergebnis offensichtlich aus rein politischen Gründen kritisierte. ${ }^{75}$ Als der radikale Flügel der Partei unter Oberst a.D. Xylander Ende August sogar den Rücktritt Gürtners wegen „Schädigung von Parteiinteressen " forderte ${ }^{76}$, führte der Streit um die Parteidisziplin schlieflich im Spätherbst dazu, daß die Radikalen unter Xylander und Buttmann aus der Partei austraten und sich der "Deutschvölkischen Arbeitsgemeinschaft" anschlossen. Seitdem verfolgte die Mittelpartei - der im wesentlichen Angehörige des Mittelstandes, Geschäftsleute, Akademiker, ehemalige Offiziere, Bauern, aber fast keine Arbeiter angehörten und deren Mitglied Gürtner offenbar im September 1922 wurde - einen Kurs, der der politischen Einstellung Gürtners weitgehend entsprach: In der Ablehnung der parlamenta-

72 Zur Einrichtung des „Staatsrats“ und „Staatssekretärs“ als Vertreter des Ministers nach der bayer. Verfassung v. 14.8.19 vgl. S. 231, Anm. 51 .

${ }^{73}$ Vgl. die unveröffentlichte, für das bayer. JM geschriebene Autobiographie: Dr. Karl Meyer. Staatsrat im Staatsministerium der Justiz vom 1. April 1919 bis 30.September 1923, S. 77 (BayerHStArch, Sign. MJu 16934). Meyer wurde OLGPräs. in München, sobald dieser Posten frei war: „Es widersprach meinem Empfinden als altgedienter Beamter, daß ich im Ministerium verblieb, nachdem ich mit einem jüngeren Referenten des Ministeriums in der Ministerauswahl gestanden war."

${ }^{4}$ Vgl. Ber. Mosers v. 12.8.22, a.a.O. (Anm. 36), S. 107.

75 Vgl. Schwend, a.a.O., S. 186; zu den Verhandlungen S. 193 ff.

${ }^{76}$ Zur Entwicklung und Haltung der Mittelpartei vgl. Reitter, a.a.O., S. 46 ff., und H. Fenske, Konservatismus und Rechtsradikalismus in Bayern nach 1919, Bad Homburg-Berlin-Zürich 1969, S.68 ff. 
rischen Demokratie von Weimar mit den vaterländischen Verbänden und völkischen Gruppen einig, wollte sie eine Änderung jedoch nicht auf außerparlamentarischem, revolutionärem Wege, sondern durch Beteiligung am staatlichen Machtapparat auf legalem, evolutionärem Wege erreichen. Das bedeutete aber, einerseits mit dem Weimarer „System“ immer wieder Kompromisse zu schließen, um für die Mitwirkung an Parlament und Regierung koalitionsfähig zu bleiben, sich aber andererseits gegenüber den Bestrebungen der radikalen Rechten aus Furcht vor dem Verlust potentieller Wähler nie klar abzugrenzen, sondern bestenfalls auf deren Aktivitäten mäßigend einzuwirken. Die gleiche Ambivalenz mußte bei seiner politischen Einstellung Gürtner an den Tag legen: als Minister mußte er mit den realen Gegebenheiten des bestehenden Staates arbeiten, war seiner Verfassung, seinen Institutionen und Gesetzen verpflichtet und mußte sie mit seinem Ressort notfalls gegen Umstürzler verteidigen, während er gleichzeitig diesen konkreten Staat, seine Verfassung und einige seiner politischen Institutionen ablehnte. Um sich in diesem Spannungsfeld zehn Jahre als Justizminister und Vertrauensmann der Deutschnationalen im bayerischen Kabinett zu halten, bedurfte es des außerordentlichen juristischen Könnens und Geschicks, der Kompromißbereitschaft und der ruhigen, unüberlegte Handlungen und Äußerungen vermeidenden Art eines Gürtner.

Im folgenden soll keine Geschichte der bayerischen Justiz unter der Ministerschaft Gürtners in den Kabinetten v. Knilling und Held geboten werden, vielmehr Gürtners Haltung als Jurist und Politiker anhand zweier politischer Verfahren vor dem Volksgericht München I verdeutlicht werden: beim Fechenbach-Prozeß von 1922 und beim Hitler-Prozeß von 1924 und seiner Vorgeschichte.

Im Oktober 1922 wurde der 28jährige ehemalige Privatsekretär Eisners, Felix Fechenbach, vom Münchner Volksgericht wegen eines vollendeten und eines versuchten Landesverrats zu 11 Jahren Zuchthaus verurteilt. ${ }^{77}$ Er hatte aus bayerischen Archiven stammende diplomatische Dokumente aus der Zeit vor 1918 sowie Nachrichten über die Aktivitäten und die illegale Bewaffnung militanter rechter Organisationen, die gegen den Versailler Vertrag verstießen, und deren stillschweigende Duldung durch die Regierung an die ausländische Presse gegeben. Das Gericht hatte darin einen Verstoß gegen den Landesverratsparagraphen 92 Ziffer 1 StGB gesehen, wonach die Weitergabe oder Veröffentlichung von Urkunden oder Nachrichten, deren Geheimhaltung für das Wohl des Reiches oder eines Landes erforderlich war, mit Zuchthaus zu bestrafen war. ${ }^{78}$ Aufgrund einer Interpellation der Sozialdemokraten, die in dem Urteil einen „schweren Justizirrtum“ sahen, mußte sich Gürtner im November 1922 vor dem bayerischen Landtag zu dem Urteil äußern. Von seinem national-konservativen Standpunkt aus verteidigte er das Urteil, da Fechenbach durch seine Handlungsweise „dem Deutschen Reiche, der deutschen Volksgesamtheit und damit auch der deutschen Ar-

77 Diese Gesamtstrafe setzte sich zusammen aus $10 \mathrm{~J}$. Zuchthaus für den versuchten und $5 \mathrm{~J}$. Festungshaft für den vollendeten Landesverrat. Gleichzeitig wurden der Schriftsteller Gargas und der Journalist Lembke zu 12 bzw. 10 Jahren Zuchthaus verurteilt, vgl. Urt. des Volksgerichts für den LGBez. München I v. 20.10.22 (StArch. München, Sign. Staatsanwaltschaften 1682).

${ }^{78} \S 92$ Nr. 1 StGB lautete in der damaligen Fassung: „Wer vorsätzlich 1.Staatsgeheimnisse oder Festungspläne, oder solche Urkunden, Aktenstücke oder Nachrichten, von denen er weiß, daß ihre Geheimhaltung einer anderen Regierung gegenüber für das Wohl des Deutschen Reichs oder eines Bundesstaats erforderlich ist, dieser Regierung mittheilt oder öffentlich bekannt macht; ... wird mit Zuchthaus nicht unter zwei Jahren bestraft." 
beiterschaft“ (!) einen „schweren Nachteil“ zugefügt habe. Die Höhe der Strafe rechtfertigte er nicht zuletzt mit den politischen Motiven Fechenbachs, der in der von ihm geförderten „Forcierung der Gewaltpolitik der Entente“ den „Wegbereiter für die Räterepublik“ gesehen habe. ${ }^{79}$ Es stimme daher nicht, „daß ein Unschuldiger von einem ungerechten Urteil betroffen worden ist. Nein! Einen gefährlichen Schädling des ganzen Volkes hat seine gerechte Strafe erreicht ${ }^{\prime 80}$ Bei der Spruchpraxis der bayerischen Gerichte und der Haltung der aus der Zeit vor 1918 stammenden Justizbeamtenschaft sah Gürtner daher keine Notwendigkeit, für die Sicherung der „Unabhängigkeit der Rechtspflege" - die den Kernpunkt der sozialdemokratischen Anfrage ausmachte unmittelbare Maßnahmen zu ergreifen. Zu diesem Problem erklärte er, „die beste Gewähr für die Unabhängigkeit und Unparteilichkeit der Rechtsprechung" sehe er darin, „daß nach wie vor als Berufsrichter Männer wirken, die nach Vorbild und Charakter eine Gewähr für eine objektive und leidenschaftslose Rechtsprechung geben“ und sich nicht von der „politischen Freundschaft oder Gegnerschaft“ zum Beschuldigten oder durch öffentliche Angriffe von Parteiseite beeinflussen ließen. ${ }^{81}$ Für solche Richter zu sorgen, bedeutete für Gürtner in der Praxis, die bisherige Personalpolitik der von ihm übernommenen bayerischen Justizverwaltung fortzusetzen.

An der Behauptung, daß die bayerischen Gerichte bei politischen Straftaten immer völlig "objektiv und leidenschaftslos“ urteilten, ließ aber z.B. gerade das weitere Schicksal des Fechenbach-Urteils berechtigte Zweifel aufkommen. Die Feststellungen des in der Verhandlung als Sachverständigen mitwirkenden, in nationalen Kreisen geschätzten Historikers Thimme und des vom Auswärtigen Ausschuß des Reichstages eingesetzten Untersuchungsausschusses vom März 1923 zeigten hinsichtlich der „Schädigung des Reichswohls“ durch Fechenbachs Handlungen eine völlig andere Beurteilung. ${ }^{82}$ Als Gürtner erkannte, daß sich das Plenum des Reichstages möglicherweise diese Auffassung zu eigen machen und von der bayerischen Regierung eine Begnadigung des Verurteilten verlangen könnte - wie schon erwähnt, gab es gegen Volksgerichtsurteile weder Rechtsmittel noch Wiederaufnahme des Verfahrens -, bat er den bayerischen Gesandten in Berlin, diese Entwicklung durch Einwirkung auf die maßgebenden Parteien zu verhindern, da der bayerischen Regierung die Begnadigung Fechenbachs gegenwärtig aus politischen Gründen unmöglich sei: dieses Verlangen

„würde zwischen Bayern und dem Reich einen Konfliktfall schaffen, der alle früheren weit in den Schatten stellen würde. Es handelt sich nicht nur um die grundsātzliche Wahrung der bayerischen Justizhoheit und des bayerischen Begnadigungsrechts, sondern der Fall gewinnt seine besondere Bedeutung durch die Persönlichkeit Fechenbachs und sein Wirken vor, bei und nach der Revolution in Bayern [?]. In der Verurteilung dieses Mannes sind mit Ausnahme der Links-

79 Diese Behauptung geht auf den Artikel Fechenbachs „Die dritte bayerische Revolution“ in der „Baseler Nationalzeitung“ v. 9.4.19 zurück, in dem er schrieb: „Der beste Förderer dieser Entwicklung [Verwirklichung der Räterepublik] sitzt in Paris. Die Gewaltpolitik der Entente wird den Sieg des Rätegedankens in Deutschland beschleunigen.“

80 Vgl. Verhandlungen des Bayer. Landtags, III. Tagung 1922/23, 149. Sitzung am 17.11.22, Stenogr. Ber., VII. Bd., S. $123 \mathrm{f}$.

81 A.a.O., S. 120.

82 Vgl. F. Thimme, Zum Münchener Prozeß („Vorwärts“ Nr. 514 v. 31.10.22), und den Beschluß des Unterausschusses v. 13.3.23 (Beilage zum Schr. des bayer. Gesandten an das bayer. StMin. des Äußeren v. 9.5.23, Akten des bayer. JM, BayerHStArch., Sign. MJu 13247), vom Abg. Dittmann am 2.7.23 im Reichstag inhaltlich vorgetragen (Sten. Prot. der Verhandlungen, 372.Sitzung, S. $11525 \mathrm{ff}$. 
parteien alle Parteien des bayerischen Landtags einschließlich der Demokraten einig. Angesichts der Stimmung, die in Bayern gegen den Landesverräter Fechenbach besteht, ist seine Begnadigung für die bayerische Regierung einfach ausgeschlossen. ${ }^{\text {“83 }}$

Zu diesem Zeitpunkt mußte der Regierung v. Knilling ein solcher Schritt in der Tat schlechterdings unmöglich sein, da sie durch die Ereignisse des Krisenjahres 1923 - Ruhrkampf, beschleunigte Inflation und Erschütterung der Wirtschaft - zunehmend unter den Druck der wachsenden rechtsradikalen Opposition geriet, der sie ohnehin nicht „national“ genug war. Stellte doch die neu gegründete „Arbeitsgemeinschaft der vaterländischen Verbände“ an die Regierung regelrechte Ultimaten und drohte bei Nichterfüllung mit unberechenbaren Aktionen ihrer Anhänger. ${ }^{84}$ Für die Ablehnung eines Gnadenaktes, die unter diesen Umständen vom Standpunkt der Regierung aus eine politische Notwendigkeit darstellte, fand Gürtner die nötige juristische Handhabe: Er argumentierte, der Reichstagsausschuß habe verkannt, daß es für die Strafbarkeit nach $\S 92$ Ziffer 1 StGB nicht darauf ankomme, ob dem Reich tatsächlich ein Schaden entstanden sei, sondern lediglich darauf, „daß Nachrichten einer fremden Regierung mitgeteilt oder öffentlich bekannt gemacht werden, deren Geheimhaltung für das Wohl des Deutschen Reiches oder eines deutschen Landes erforderlich ist“; folglich seien die vom Ausschuß über die Verwirklichung des Tatbestandes getroffenen Feststellungen für die Frage der Rechtmäßigkeit des Urteils ohne Belang. ${ }^{85}$

Unterdessen wurde aber gegen das Urteil von berufener Juristenseite der rechtliche Einwand vorgebracht, daß das Delikt Fechenbachs durch Veröffentlichung in der Presse verübt worden war und die Tat somit nach $\S 22$ des Preßgesetzes vom 5. Mai 1874 zum Zeitpunkt der Strafverfolgung bereits verjährt gewesen sei. Diesem Einwand schloß sich auch Reichsjustizminister Heinze „nach eingehender Prüfung“ durch sein Ministerium an. ${ }^{86}$ Nunmehr lenkte die bayerische Regierung - sicher auf Anraten ihres Justizministers - ein: am 2. Juli 1923 gab der bayerische Gesandte im Reichstag die Erklärung ab, wenn Fechenbach ein Gnadengesuch einreiche, werde die bayerische Regierung - für deren Stellung zum Urteil „nicht politische [!], sondern ausschließlich tatsächliche und rechtliche Gesichtspunkte maßgebend“ seien - „ein Rechtsgutachten des bayerischen Obersten Landesgerichts über die gesamten Fragen“ einholen und „,ihrer Entscheidung in der Rechtsfrage zugrunde legen“. ${ }^{87}$ Es ist anzunehmen, daß dieses geschickte und in der Sache zu nichts verpflichtende Zugeständnis auf Gürtner zurückging, der es mit Berlin in dieser Sache nicht zur offenen Konfrontation kommen lassen wollte. Vermutlich war sich Gürtner bei seinen persönlichen Beziehungen zum Obersten Landesgericht dabei schon vorher sicher, wie dieses Gutachten ausfallen würde - daß es sich also im Grunde nur um eine „Scheinkonzes-

${ }^{83}$ Schr. Gürtners an den Bayer. Gesandten und bevollmächtigten Minister von Preger v. 14.3.23 (Akten des bayer.JM, BayerHStArch., Sign. MJu 13247).

${ }^{4}$ Zur Lage der Regierung v. Knilling vgl. L. Gruchmann, Der Weg zum Hitler-Putsch (1997), S. LII ff.

${ }^{85}$ Schr. Gürtners an v. Preger v. 14.3.23 (Akten des bayer. JM, a.a.O.).

86 Vgl. den Münchner Strafrechtslehrer und Presserechtspezialisten F. Kitzinger, Der Fall Fechenbach (Zeitschrift f. d. gesamte Strafrechtswissenschaft 1923, S. $136 \mathrm{ff}$.), dazu Heinzes Ausführungen in der Reichstagsdebatte v. 2.7.23 (Sten. Prot., a.a.O., S.11537) und seinen Schriftwechsel mit Gürtner v. 5./8.6.23 (Akten des bayer. JM, a.a.O.).

${ }^{87}$ Vgl. v. Preger in der Reichstagsdebatte v. 2.7.23 (Sten. Prot., a.a.O., S. 11535 f.). 
sion" handelte. ${ }^{88}$ Das Gutachten des 2.Strafsenats des Obersten Landesgerichts vom 30. Oktober 1923 erkannte zwar einige Rechtsverstöße des Volksgerichts an, die der Verteidiger Hirschberg im Gnadengesuch angeführt hatte, erklärte jedoch alle Einwände gegen das Urteil für unbegründet, auch den der pressegesetzlichen Verjährung, da es sich im vorliegenden Fall um eine ausländische Druckschrift gehandelt habe. Der Verfasser des Gutachtens war kein anderer als Oberstlandesgerichtsrat von der Pfordten, der zehn Tage später als Teilnehmer am Hitlerputsch umkommen sollte. ${ }^{89}$

Obwohl auch dieses Gutachten zur Höhe der Strafe einige Vorbehalte gemacht hatte und der Verteidiger in der Folge eingehende Gutachten namhafter - auch rechtsstehender - Strafrechtswissenschaftler beibringen und veröffentlichen konnte ${ }^{90}$, die das Urteil gegen Fechenbach scharf kritisierten, sprach die Regierung Held eine Begnadigung erst zu einem Zeitpunkt aus ${ }^{91}$, an dem es ihr politisch opportun erschien: Am 20. Dezember 1924, als das Oberste Landesgericht die Beschwerde der Staatsanwaltschaft gegen die Bewilligung einer Bewährungsfrist für Hitler und Kriebel verwarf und beide aus der Festungshaft entlassen wurden, erschien es ihr aus Gründen der politischen Optik geboten, auch die Strafe für Fechenbach auf dreieinhalb Jahre herabzusetzen, die Strafvollstreckung gleichfalls sofort zu unterbrechen und den noch bestehenden Strafrest zur Bewährung auszusetzen"2 ${ }^{92}$ ferner auf Vorschlag Dürrs gleichzeitig die letzten vier Festungsgefangenen aus der Zeit der Räterepublik unter Minderung der Strafe mit Bewährung zu entlassen. ${ }^{93}$ Die Begründung des Justizministeriums für die Begnadigung Fechenbachs macht deutlich, daß die Richter des Münchener Volksgerichts 1922 zumindest mit starken Vorurteilen gegen den Angeklagten behaftet gewesen waren. Darin hieß es, es bestehe kein Zweifel, „daß das Gericht im Strafmaß zu Ungunsten der sämtlichen Verurteilten über das nach Sachlage Gerechtfertigte hinausgegriffen“ und „verschiedene zu Gunsten der Verurteilten sprechende Umstände entweder nicht oder nicht ausreichend berücksichtigt" habe. Für das Ausmaß der Strafminderung sei ausschlaggebend, „daß das Reichsgericht wegen ähnlicher Verfehlungen auf ganz niedrige Strafen erkannt" habe. ${ }^{94}$ Nachdem durch ein Gesetz vom Juli 1925 ein Wiederaufnahmeantrag Fechenbachs an das Reichsgericht möglich

${ }^{88}$ Gürtner hatte bereits am 18.6.23 (?) den Präs. des OLG v. Unzner gebeten, „ein Gutachten eines der Strafsenate des Obersten Landesgerichts" in der Frage der Verjährung nach dem PresseG v. 7.5.1874 herbeizuführen (Akten des bayer. JM, a.a.O.). Eine Antwort ist in den Akten nicht enthalten. Die offizielle Anforderung des eigentlichen Fechenbach-Gutachtens erfolgte erst am 19.9.23 (a.a.O., Sign. MJU 13248).

89 Vgl. M. Hirschberg, Das Fehlurteil im Strafprozeß. Zur Pathologie der Rechtsprechung, Stuttgart 1960, S. 161. Bereits in einem Schr. v. 5.7.23 an Gürtner hatte der Reichstagsabgeordnete Emminger darauf hingewiesen, das Votum des OLG würde „eindrucksvoller sein, wenn Pöhner [!] und Müller-Meiningen nicht mitwirkten“ (a.a.O., Sign. MJu 13247). Das Gutachten ist enthalten in den Akten des bayer. JM (a.a.O., Sign. MJu 13248) und veröffentlicht in: Der Fall Fechenbach. Juristische Gutachten, herausg. v. M. Hirschberg und F. Thimme, Tübingen 1924, S. $29 \mathrm{ff}$.

90 A.a.O., S. $56 \mathrm{ff} . ;$ dazu M. Hirschberg, Jude und Demokrat (1998). S. $177 \mathrm{ff}$.

91 Noch in seiner Sitzung am 24.7.24 beschloß der bayer. Ministerrat, daß er "das Gnadengesuch als zurzeit nicht zur Berücksichtigung geeignet erachte“ (Niederschr., BayerHStArch., Sign. MA 99519, u. Verm. Gürtners v. 24.7.24, Akten des bayer. JM, a.a.O.).

92 Vgl. Chronik der Bayer. Justizverwaltung, a.a.O., Eintr. v. 20.12.24. Die Strafe des im Fechenbachprozeß mitverurteilten Gargas wurde auf 3 Jahre 10 Monate, die für Lembke auf 3 Jahre 2 Monate Zuchthaus herabgesetzt. Obgleich Gürtner die Entschließung schon am Vortage unterzeichnete, ist der Zusammenhang unzweifelhaft (Akten des bayer. JM, a.a.O.).

${ }^{3}$ Vgl. Akten des bayer. JM, a.a.O., und voranstehende Anm. 49.

94 Vgl. Stellungnahme des bayer. JM zur Begnadigung vom Dezember 1924 (Akten des bayer. JM, a.a.O.). 
geworden war ${ }^{95}$, bestätigte auch dieses Gericht den Mißgriff der bayerischen Richter: es hob das Volksgerichtsurteil im Dezember zumindest hinsichtlich des vollendeten Landesverrats mit der Einsatzstrafe von zehn Jahren Zuchthaus und Ehrverlust auf. ${ }^{96}$ Gürtner war sicher ein zu guter Jurist, als daß er die Korrekturbedürftigkeit des Volksgerichtsurteils nicht schon früher erkannt hätte. Aber es ist für ihn bezeichnend, daß er die Begnadigung Fechenbachs solange hinauszuzögern verstand, wie es die bayerische „Staatsraison“ erforderte, und dafür das juristische Rüstzeug lieferte, ohne dabei die Bestimmungen des Strafverfahrensrechts zu verletzen. Daß er in diesem Sinne das Recht der Politik unterordnete, sollte sich noch ausgeprägter bei seinem Verhalten gegenüber den ungesetzlichen Aktivitäten der radikalen „nationalen“ Verbände und Hitlers im Jahre 1923 erweisen.

Hitler war am 12. Januar 1922 vom Münchner Volksgericht wegen Landfriedensbruchs - seine Anhänger hatten eine Versammlung des „Bayernbundes“ gesprengt zu drei Monaten Gefängnis verurteilt, aber nach einem Monat Strafverbüßung Ende Juli mit Bewährungsfrist entlassen worden. Diese Bewährungsfrist drohte durch ein Strafverfahren nach $\S 127$ StGB (Bildung bewaffneter Haufen) widerrufen zu werden, das gegen Hitler und die Führer des „Kampfbundes“ wegen ihres bewaffneten Aufmarsches auf dem Oberwiesenfeld am 1. Mai 1923 eingeleitet wurde. ${ }^{97}$ Mit diesem Aufmarsch beabsichtigten Nationalsozialisten, „Reichsflagge“, „Bund Oberland“ und andere radikale vaterländische Verbände gegen die friedlich verlaufende Mai-Kundgebung der Gewerkschaften und Sozialdemokraten auf der Theresienwiese - deren Verbot sie von der Regierung Knilling vergebens gefordert hatten - vorzugehen, wurden aber durch einen Cordon von Landespolizei nebst unterstützender Reichswehr davon abgehalten und zur gewaltlosen Aufgabe ihrer Absicht bewogen. Das Ermittlungsverfahren, das die Staatsanwaltschaft beim Landgericht München I aufgrund einer Anzeige des Innenministers Schweyer durchführte, traf im Kabinett auf geteilte Unterstützung: von Gürtner darin bestärkt, wollte v. Knilling „die Elemente, die er in der Hitlerbewegung als gut und staatstreu auffaßte, ... durch eine Art Versöhnungspolitik“ an seine Regierung heranziehen. ${ }^{98}$ Als die staatsanwaltschaftlichen Ermittlungen, die nach der späteren Feststellung des parlamentarischen Untersuchungsausschusses ohne Eingriff des Justizministeriums verliefen, am 1. August 1923 abgeschlossen waren,

95 Vgl. G. über die Wiederaufnahme des Verfahrens gegenüber Urteilen der bayerischen Volksgerichte v. 4.7.25 (RGBl. I, S.95).

96 Vgl. Beschluß des RG, 5.Strafsenat, Sitzung v. 15.12.26 (Akten des bayer. JM, a.a.O.). Das RG hielt jedoch das Urteil aufrecht, soweit es den versuchten Landesverrat Fechenbachs - d.h. seine Mitteilungen über die vaterländischen Verbände und ihre illegale Bewaffnung an das Ausland - betraf, um sich selbst den Weg zur Verfolgung pazifistischer und linksstehender Journalisten nicht zu verbauen, die die illegale Aufrüstung durch Aufdeckung zu verhindern suchten.

97 Auch ohne ein neues Verfahren hatte der StA die Möglichkeit, den Widerruf der Bewährungsfrist zu beantragen; in der Praxis geschah das aber vor Durchführung des neuen Verfahrens nie.

98 Gürtner sah in der Hitlerbewegung „heterogene Elemente vereinigt“: „Hier traf man neben dem Gewaltmenschen und Revolutionär eine ganze Masse von ehrlichen aufrechten Leuten mit politisch gänzlich indifferenter Gesinnung, von Unzufriedenen, Verängstigten, Verzweifelten, die glaubten, auf einem kurzen und besseren Wege, als es jemals die derzeitige Staatsregierung machen könnte, aus allen Nöten der Zeit herausfinden.“ Aussage Gürtners am 7.10.27 vor dem vom bayer. Landtag eingesetzten „Untersuchungsausschuß zur Untersuchung der Vorgänge am 1. Mai 1923 und der gegen Reichs- und Landesverfassung gerichteten Bestrebungen vom 26. September bis 9. November 1923“ (Niederschr. der Verhandlungen, BayerHStArch., Sign. MA 103476/1, Bl. 237 ff.). Nach W. Hoegner, Der schwierige Außenseiter, München 1959, S.21, bezeichnete Gürtner die Nationalsozialisten einmal als „Fleisch von unserm Fleisch“. 
hielt Gürtner im September in seinem Ministerium mit Staatsrat Meyer, Strafrechtsreferent Ministerialrat Dürr und dem I.Staatsanwalt Stenglein eine Besprechung darüber ab, ob der Prozeß zu diesem Zeitpunkt stattfinden sollte. Der Staatsanwalt wies auf ein Schreiben Hitlers vom 16. Mai hin, in dem dieser gedroht hatte, im Falle eines Prozesses zu seiner Verteidigung eine Denkschrift zu veröffentlichen, in der die abgesprochene Zusammenarbeit zwischen bayerischer Reichswehr und vaterländischen Wehrverbänden im Falle eines französischen Sanktionseinbruchs in rechtsrheinisches bayerisches Gebiet aufgedeckt werden würde. Diese „landesverräterischen“ Enthüllungen hätten das Verhältnis Bayerns zum Reich erneut belastet. Hitlers Erpressung wirkte: der Meinung des Staatsanwalts, den Prozeß auf eine „ruhigere Zeit“ zu verschieben, schloß sich Strafrechtsreferent Dürr mit dem ergänzenden Hinweis auf die Verursachung möglicher außenpolitischer Schwierigkeiten für das Reich an. Gürtner selbst sah neben neuerlichen Störungen der öffentlichen Ordnung durch die Wehrverbände voraus, daß bei einem Prozeß die beteiligten Minister vernommen werden müßten und die wachsenden Meinungsverschiedenheiten im Kabinett wegen der unterschiedlichen Haltung gegenüber den radikalen vaterländischen Verbänden und der Hitlerbewegung an die Öffentlichkeit getragen würden. Darin erblickte er „die Katastrophe für die bayerische Regierung “.99 Als Ergebnis der Besprechung im Justizministerium wurde daher der untersuchungsführende Staatsanwalt Dresse instruiert, die Eröffnung der Hauptverhandlung vorerst nicht zu beantragen, sondern eine - nie erfolgende entsprechende Weisung abzuwarten. Durch diesen Entschluß, den er allein verantwortete und den er offensichtlich nicht allen Kabinettsmitgliedern mitteilte ${ }^{100}$, hatte Gürtner wieder einmal die „Staatsraison“ über das Recht gestellt: nach der später geäußerten Meinung der Opposition verstieß dieser Schritt gegen $\ 69$ Abs. VI der Bayerischen Verfassung, wonach „strafrechtliche Untersuchungen ... weder durch den Landtag noch durch die Ministerien oder sonstige Verwaltungsbehörden gehemmt" werden durften. ${ }^{101}$ Gürtners Politik, vermeintlich wertvolle Elemente der nationalsozialistischen Bewegung für den Staatsgedanken wiederzugewinnen und die von ihm bejahten, gleich noch zu erörternden Pläne des im September 1923 in Bayern als Generalstaatskommissar eingesetzten v.Kahr, mit Unterstützung der rechtsradikalen Verbände und norddeutscher national-konservativer Kreise die Stresemann-Regierung durch eine vom Parlament unabhängige „nationale Diktatur“ zu ersetzen, verhinderten, daß die radikalen Wehrverbände ihrer Führer vorübergehend beraubt und vielleicht den gemäßigten Verbänden wieder eingegliedert werden konnten. Selbst wenn ein Prozeß eingeleitet und gegen Hitler u.a. mangels Nachweises des inneren Tatbestandes nicht auf die Höchststrafe von zwei Jahren Gefängnis erkannt worden wäre - das Verteidigungsargument der Angeklagten, daß sie sich am 1. Mai nach den vorangegangenen Absprachen mit Reichswehr und Regierung zum bewaffneten Auftreten

99 Aussage Gürtners v. 7.10.27. a.a.O.; dazu L. Gruchmann, Hitler Denkschrift (1991).

100 Vgl. Aussage Gürtners, a.a.O., und Aussage Schweyers v. 19.10.27, a.a.O., Bl. 385.

101 Der parlamentarische Untersuchungsausschuß hatte aber auch nach Auffassung seines Mitberichterstatters, des SPD-Abgeordneten Hoegner, nur Tatbestände festzustellen, sie hingegen nicht Rechtsvorschriften zu subsumieren (a.a.O., Bl.541). Ein gerichtliches Vorgehen der Opposition gegen Gürtner zur Geltendmachung der Ministerverantwortlichkeit wäre auch aussichtslos gewesen, da dafür nach $\S 56$ der bayer. Verfassung eine verfassungsändernde Mehrheit im Landtag erforderlich gewesen wäre. Auch wäre der subjektive Tatbestand nur schwer nachweisbar gewesen. 
für befugt gehalten hätten ${ }^{102}$, wäre wohl nur schwer auszuräumen gewesen -, wäre Hitler der Bewährung aus seiner Strafe wegen Landfriedensbruchs von 1922 verlustig gegangen und somit für längere Zeit als Agitator ausgeschaltet gewesen. Bayern wäre auf jeden Fall der Novemberputsch erspart geblieben. ${ }^{103}$ Obwohl für Hitler die Kraftprobe mit der bayerischen Regierung - um eine Staatsstreichabsicht gegen sie handelte es sich am 1. Mai 1923 auch nach späteren Feststellungen im Meineidsverfahren gegen Hitler nicht, so daß eine Untersuchung wegen Hochverrats von vornherein entfiel - zu seinen Ungunsten ausgegangen war, mußte ihn die Schwäche seiner Gegner nur ermutigen. Die gewonnene Erkenntnis, daß ein Putsch nicht gegen, sondern nur durch ein wie auch immer erreichtes Zusammengehen mit den Inhabern der staatlichen Machtmittel möglich sein würde, bestimmte Hitlers Entschluß zum Putsch vom 9. November.

Der nach dem Novemberputsch erwogene Gedanke, das Verfahren wegen der Ereignisse vom 1. Mai 1923 mit dem Hochverratsverfahren gegen Hitler zu verbinden, wurde verworfen, um den ohnehin verwickelten Prozeß damit nicht auch noch zu belasten. Nachdem dann Hitler am 1. April 1924 wegen Hochverrats verurteilt war, wurde das Verfahren nach einer Besprechung Gürtners mit den Staatsanwälten Stenglein und Dresse im Ministerium eingestellt, da die Beschuldigten „nach den Umständen des Falles nur eine Strafe zu erwarten haben, die neben der rechtskräftig erkannten Strafe nicht ins Gewicht fällt" ${ }^{104}$ Rechtliche Grundlage dafür war der durch die Emminger-Novelle vom Januar 1924 neugefaßte $§ 154 \mathrm{StPO}^{105}$; vor Inkrafttreten dieser Novelle wäre eine Einstellung des Verfahrens ungesetzlich gewesen.

Bei seiner Stellung als Minister war es unumgänglich, daß Gürtner in den Strudel der politischen Ereignisse vom Herbst 1923 hineingezogen wurde, die einen neuen Konflikt Bayerns mit dem Reich auslösten und zum Hitlerputsch führten. Eine kurze Betrachtung dieser Ereignisse ist nötig, um Gürtners Einstellung zum Hitler-Prozeß verständlich zu machen. ${ }^{106}$ Als nach dem Abbruch des passiven Widerstandes im Ruhrgebiet durch die Regierung Stresemann, die sich auf eine Große Koalition einschließlich der SPD gründete, in Bayern neue Unruhen von rechts auszubrechen drohten, unterstützte Gürtner im bayerischen Kabinett am 26. September den Beschluß, den ehemaligen Ministerpräsidenten und nunmehrigen Regierungspräsiden-

102 Bezeichnend hierfür sind die Ausführungen des militärischen Führers des „Kampfbundes“, Kriebel, bei seiner Vernehmung durch den StA am 24.7.23: „Verschiedene Vorkommnisse der letzten Zeit gaben mir das Recht zu glauben, daß die ablehnende Haltung der Regierung gegenüber dem Vorgehen der Verbände nur scheinbar sei, daß die Staatsregierung in Wirklichkeit den Wunsch habe, durch illegale Formationen das ausführen zu lassen, was sie selbst mit ihren amtlichen Organen nicht ausführen konnte oder wollte“ (zit. a.a.O., Bl. 127).

103 So auch nach Ansicht Schweyers, Aussage v. 19.10.27, a.a.O.

$104 \mathrm{Vgl}$. Einstellungsbeschluß der StAschaft beim LG München I v. 22.5.24, zit. a.a.O., Bl.73, und Aussage des StA Dresse, a.a.O., Bl. $315 \mathrm{ff}$.

105 Laut $\S 24$ der VO über Gerichtsverfassung und Strafrechtspflege v. 4.1.24 (RGBl. I, S. 15) konnte von der Erhebung der öffentlichen Klage abgesehen werden, „wenn die Strafe, zu der die Verfolgung führen kann, neben einer Strafe, zu der der Beschuldigte wegen einer anderen Tat rechtskräftig verurteilt worden ist, oder die er wegen einer anderen Tat zu erwarten hat, nicht ins Gewicht fällt“.

$106 \mathrm{Zu}$ den im folgenden geschilderten Vorgängen vgl. E. Deuerlein (Herausg.), Der Hitler-Putsch. Bayerische Dokumente zum 8./9. November 1923, Stuttgart 1962, S. 65 ff., Schwend, a.a.O., S. 215 ff., H. H. Hofmann, Der Hitlerputsch. Krisenjahre deutscher Geschichte 1920-1924, München 1961, S. 95 ff., H. J. Gordon jr., Hitlerputsch 1923. Machtkampf in Bayern 1923-1924, Frankfurt a.M. 1971, S. 169 ff., H. Fenske, a.a.O., S. 188 ff.; L. Gruchmann, Der Weg zum Hitler-Putsch (1997), S. LIXff. 
ten von Oberbayern v. Kahr als "Generalstaatskommissar" einzusetzen und mit der Ausübung der vollziehenden Gewalt zu betrauen ${ }^{107}$, da Kahr auch bei den vaterländischen Verbänden unvermindertes Ansehen genoß. Diesem bayerischen Ausnahmezustand setzte die Reichsregierung, die in diesem überraschenden Schritt eine gegen sie gerichtete Maßnahme sah, noch in derselben Nacht den Ausnahmezustand für das Reich entgegen und übertrug Reichswehrminister Geßler die vollziehende Gewalt. Da Bayern den Grundsatz „Reichsrecht bricht Landesrecht“ nicht anerkannte, blieben beide Ausnahmeverordnungen nebeneinander bestehen; jedoch hob v. Kahr am 29. September die seinerzeit von Gürtner ausgehandelte bayerische Vollzugsverordnung vom 24. August 1922 zum Republikschutzgesetz auf, so daß Haftbefehle des Reichswehrministers in Bayern nicht vollzogen werden konnten. Der offene Konflikt brach aus, als der Befehlshaber des Wehrkreises VII und Landeskommandant der Reichswehrtruppen in Bayern, Generalleutnant v.Lossow, die Durchführung eines Befehls des Reichswehrministers ablehnte, sich auf die Seite v. Kahrs stellte und im Oktober die unter seinem Kommando stehenden Reichswehrtruppen auf die bayerische Regierung verpflichten ließ. Gürtner unterstützte diesen Schritt des vom Reichspräsidenten entlassenen Generals im Kabinett und arbeitete mit ihm gemeinsam die Verpflichtungsformel für die bayerischen Truppen aus. ${ }^{108}$ Für die Auseinandersetzung mit Berlin hatte v. Kahr somit neben der Landespolizei unter Oberst v. Seißer auch die bayerischen Reichswehrtruppen hinter sich, zu deren Unterstützung gegen die „marxistisch beeinflußte" Regierung in Berlin sich auch die vaterländischen Verbände nebst dem radikaleren „Kampfbund“ unter Oberstleutnant a. D. Kriebel bereit erklärten. Bei dieser Machtkonzentration war es nicht verwunderlich, daß das Triumvirat Kahr-LossowSeißer mit der Verfolgung politischer Ziele liebäugelte, die über eine Abschottung Bayerns gegen das "rote“ Berlin und die nach links tendierenden sozialdemokratischen Regierungen in Sachsen und Thüringen hinausgingen: durch militärischen Druck und im Zusammenwirken mit nationalen Kreisen in Norddeutschland, die gleichfalls auf eine Verfassungsänderung im Reich hinwirkten, die Reichsregierung zu veranlassen, die Regierungsgewalt in die Hand eines "nationalen Direktoriums“ zu legen, das vom Parlament unabhängig sein sollte. Nach Verhandlungen Seißers mit interessierten Kreisen in Berlin herrschte jedoch Anfang November über die Zusammensetzung des Direktoriums „noch völlige Unklarheit“, da der Chef der Heeresleitung General v. Seeckt zögerte, Reichspräsident Ebert illegal unter Druck zu setzen: als Direktoriumsmitglieder im Gespräch waren für das Amt des Reichspräsidenten v. Kahr und neben anderen Personen für weitere Posten als Reichsjustizminister Gürtner. ${ }^{109}$

Ob Gürtner von der Nennung seines Namens wußte oder ihr sogar zugestimmt hatte, ist nicht mehr feststellbar; sie kann auch lediglich aufgrund seiner bekannten deutschnationalen Gesinnung und Ablehnung des parlamentarischen Systems erfolgt sein. Daß er über v. Kahrs politische Pläne Bescheid wußte, ist dagegen wahrschein-

107 Vgl. Niederschr. der Ministerratssitzung v. 26.9.23, im Auszug zit. bei E. Deuerlein, a.a.O., S. 180 ff.

108 Vgl. Niederschr. der Ministerratssitzungen v. 20.10.23 vormittags und nachmittags, a.a.O., S. $240 \mathrm{ff.}$

109 Vgl. Oberst Seißer: Niederschr. über Besprechungen in Berlin am 3.11.23, a.a.O., S.301 ff. 
lich $^{110}$, daß er sie bei Kenntnis billigte, dürfte als sicher anzunehmen sein, solange der Druck auf den Reichspräsidenten mit der Forderung, aufgrund Art. 48 der Reichsverfassung eine Direktorialregierung einzusetzen, von den Stützen der staatlichen Autorität - Reichswehr und Polizei - und deren Führern und nicht von den radikalen vaterländischen Kampfverbänden und den Nationalsozialisten ausging, die damit nur einen Bürgerkrieg mit der außerbayerischen Reichswehr und als mögliche Folge eine Intervention Frankreichs ausgelöst hätten. Gürtner verhielt sich wie das bayerische Kabinett "gegenüber diesen Vorstellungen und Illusionen distanziert, schwankend zwischen der Hoffnung, vielleicht doch einen entscheidenden Beitrag zur Wiedergeburt Deutschlands leisten zu können, und der Furcht, widerstrebend in eine Katastrophe noch nicht vorstellbaren Ausmaßes zu geraten". ${ }^{111}$ So sah Gürtner z.B. die auf Weisung v. Kahrs erfolgende Verstärkung des Grenzschutzes in Oberfranken gegen das rote Mitteldeutschland, zu der vaterländische Verbände unter dem in Leipzig aus der Untersuchungshaft geflohenen Kapitän Ehrhardt herangezogen wurden, als äußerst bedenklich an: sie lägen „im Plane der Leute, die von einem Marsch nach Berlin träumen“. Bayern aber dürfe "nicht zum Schauplatz für die Betätigung politischer Condottieri gemacht werden ". ${ }^{12}$ Als auch Kahr, Lossow und Seißer den Vertretern der vaterländischen Verbände in einer Besprechung am 6. November eindeutig klarmachten, daß jede Aktion für ein Reichsdirektorium allein unter ihrem Befehl stehen und nur dann ausgelöst werden solle, wenn die Unterstützung der außerbayerischen Reichswehr gesichert sei, unternahm Hitler am 8. November seinen bekannten Coup im Bürgerbräukeller, um das zögernde Triumvirat mitzureißen und sich selbst die politische Führung zu sichern. Gürtner wurde bei dieser Gelegenheit im Bürgerbräu zusammen mit v. Knilling und anderen Ministerkollegen von einem SA-Kommando unter Rudolf Heß verhaftet und in der Villa des Verlegers Lehmann außerhalb Münchens festgehalten, bis das Kommando nach dem Zusammenbruch des Putsches am nächsten Abend verschwand. ${ }^{113}$

Das Urteil, das das Volksgericht München I am 1. April 1924 im Hochverratsverfahren gegen Hitler und die anderen führenden Putschisten fälte, war ausgesprochen milde: Hitler, Weber, Kriebel und Pöhner wurden wegen Hochverrats zu je fünf Jahren Festungshaft und einer Geldstrafe von 200 Goldmark, Brückner, Röhm, Pernet, Wagner und Frick wegen Beihilfe zum Hochverrat zu je einem Jahr drei Monaten Festungshaft und einer Geldstrafe von 100 Goldmark verurteilt. Ludendorff wurde freigesprochen. Obwohl die erlittene mehrmonatige Untersuchungshaft ohnehin schon auf die Strafe angerechnet wurde, wurde den Beihelfern für den Strafrest sofortige Bewährungsfrist, Hitler und den anderen drei Haupttätern „nach Verbüßung eines weite-

${ }^{110}$ Kahr gab jedenfalls bei seiner Vernehmung durch den III. StA Müller am 27.3.24 zu Protokoll, daß er die Regierung v. Knilling über die Direktoriumsbestrebungen informiert habe (Niederschr. des Untersuchungsausschusses, a.a.O. [s. Anm.98], Sign. MA 103476/3, Bl.1527 u. 1574). Als Verbindungsmann des JM zum Generalstaatskommissar war überdies der persönl. Ref. Gürtners, ORegRat Stauffer, abgestellt, der auch besonders enge Beziehungen zum Kampfbund unterhielt. Er wurde vor Beginn des Hitlerprozesses am 21.2.24 in der Münchener Arcisstraße „auf dem Gehsteig von einem Automobil überfahren“ (Chronik der Bayerischen Justizverwaltung, a.a.O., Eintr. v. 26.9.23 und 22.4.24).

111 So treffend Deuerlein, a.a.O., S.88 f.

112 Vgl. Niederschr. über die Ministerratssitzung v. 3.11.23, a.a.O., S. $296 \mathrm{f}$.

113 Vgl. die Ber. der Betroffenen vor dem Untersuchungsausschuß (Niederschr., a.a.O. [s. Anm. 98], Bl. 1365ff.). 
ren Strafteils von je sechs Monaten Festungshaft Bewährungsfrist für den Strafrest in Aussicht gestellt" ${ }^{114}$ Die in zahlreichen Veröffentlichungen geäußerte Kritik an der Prozeßführung und am Urteil ${ }^{115}$ soll hier nicht wiederholt werden. Im folgenden soll untersucht werden, inwieweit Gürtner auf den Prozeß Einfluß genommen hat. Diese Frage ist für die Beurteilung von Gürtners Karriere von zentraler Bedeutung, da vielfach behauptet worden ist, er sei von Hitler 1933 mit dem Posten des Reichsjustizministers belohnt worden, weil er sich bemüht habe, Hitler 1924 möglichst vor Bestrafung zu schützen bzw. ihn sobald wie möglich aus der Strafhaft zu befreien. ${ }^{116}$ Dazu erklärte Hitler später selbst:

„Davon, daß er Gürtner zum Justizminister gemacht habe, weil er ihn früher als Richter besonders verständnisvoll behandelt hätte, könne keine Rede sein. Er habe sich in vollstem Maße zur Objektivität, ja, geradezu zu einer abgeklärten Objektivität durchringen müssen, um den Mann, der ihn seinerzeit eingesperrt habe, zum deutschen Justizminister zu machen. " ${ }^{117}$

Gürtners Einflußnahme bestand zunächst einmal in dem Bestreben, den bevorstehenden Prozeß auf keinen Fall vor dem Staatsgerichtshof des Reiches, sondern vor dem bayerischen Volksgericht stattfinden zu lassen. Als er am 13. November in der „München-Augsburger Abendzeitung“ las, daß die Reichsregierung den Oberreichsanwalt beauftragt hatte, „den Hochverrats-Prozeß nach Leipzig zu ziehen“, erbat er sofort das Einverständnis des bayerischen Kabinetts, den neuen Staatsrat seines Ministeriums, Hermann Schmitt, zu Verhandlungen nach Berlin zu schicken. ${ }^{118}$

Mit aus diesem Grunde hatte sich Gürtner am Vortage im Kabinett der Absicht widersetzt, v. Kahr wegen seiner undurchsichtigen Haltung in der Putschnacht zum Rücktritt als Generalstaatskommissar aufzufordern, und hatte seinen Willen mit der eigenen Rücktrittsdrohung durchgesetzt ${ }^{119}$ : solange nämlich v. Kahrs Verbot aufrechterhalten blieb, Handlungen im Verfolg des Republikschutzgesetzes zu vollstrekken, konnte allein schon der Transport der Beschuldigten nach Leipzig unterbunden werden. Die Verhandlungen, die am 15. November im Reichsjustizministerium begannen und an denen vom bayerischen Justizministerium neben Schmitt auch Ministerialrat Dürr teilnahm und in die sich Gürtner durch Gespräche mit dem Vertreter der Reichsregierung in München unmittelbar einschaltete ${ }^{120}$, endeten mit einem

114 Text des Urt. in: Der Hitler-Prozeß 1924. Wortlaut der Hauptverhandlung vor dem Volksgericht München I, hrsg. von L. Gruchmann u. R. Weber, Teil 1 (1997), Dok. Nr. 10, S. $341 \mathrm{ff.}$

115 Die wohl fundierteste zeitgenössische Kritik stammt vom Heidelberger Strafrechtslehrer Graf zu Dohna, Der Münchener Hochverratsprozeß (DJZ 1924, S. 330ff.); vgl. neuerdings mit weiteren Nachweisen: $O$. Gritschneder, Das mißbrauchte bayerische Volksgericht, in: Hitler-Prozeß (s. Anm. 114), T. 1, S. XVIIff.; ders.: Bewährungsfrist für den Terroristen Adolf $\mathrm{H}$. Der Hitlerputsch und die bayerische Justiz, München 1990.

116 Vgl. z. B. G. F. Kramer, The Influence of National-Socialism on the Courts of Justice and the Police, in: The Third Reich, London 1955, S. 595 ff., S.604f.; Robert M. Kempner, Blueprint of the Nazi Underground (Research Studies of the State College of Washington 1945, S. $51 \mathrm{ff}$. ), S. 54.

117 Vgl. H. Picker, Hitlers Tischgespräche im Führerhauptquartier 1941-42, Bonn 1951, S. 212, am 29.3.42 abends.

118 Vgl. Niederschr. der Ministerratssitzung v. 13.11.23, Deuerlein, a.a.O., S.367. Staatsrat Schmitt hatte am 1.10.23 Meyer ersetzt, der OLGPräs. in München wurde.

119 Niederschr. der Ministerratssitzung v. 12.11.23, a.a.O., S.346.

$120 \mathrm{Vgl}$. Ber. des Gesandten Haniel von Haimhausen an die Reichskanzlei v. 21.11.23, Akten der Reichskanzlei. Weimarer Republik. Die Kabinette Stresemann I u. II, Bd. 2, bearb. v. K. D. Erdmann und M. Vogt, Boppard a. Rhein 1978, S. $1159 \mathrm{f}$. 
bayerischen Erfolg. Die neue Reichsregierung unter Marx, in der die Sozialdemokraten nicht mehr vertreten waren und in der Emminger als Angehöriger der Bayerischen Volkspartei den Posten des Reichsjustizministers innehatte, sah zwar von einer ausdrücklichen Überweisung des Verfahrens an das Münchner Volksgericht durch den Oberreichsanwalt ab, war aber bereit, die Durchführung des Prozesses vor diesem Gericht zu tolerieren. ${ }^{121}$ Als das bayerische Justizministerium die seit 1921 bestehende informelle Vereinbarung mit dem Reichsjustizministerium verwirklichte, die Volksgerichte spätestens dann abzuschaffen, wenn die Neuordnung der Strafgerichte im Reichsmaßstab erfolgt sei, erreichte Gürtner für das Volksgericht München eine Sonderregelung: während die übrigen Volksgerichte mit dem Inkrafttreten der Verordnung des Reichs über Gerichtsverfassung und Strafrechtspflege vom 4. Januar 1924 - der „Emminger-Verordnung“ - am 1. April aufgehoben wurden, wurde mit Zustimmung der Reichsregierung für das Münchner Volksgericht als Termin der 15. Mai 1924 festgesetzt ${ }^{122}$, um den Hitler-Prozeß beenden und im Anschluß daran noch drei Nachfolgeprozesse in der gleichen Sache durchführen zu können.

Gürtners Schritte, das Verfahren unbedingt in der Zuständigkeit des Münchner Volksgerichts zu halten, dienten jedoch nicht primär dem Ziel, Hitler zu einer möglichst milden Strafe zu verhelfen, sondern erfolgten in erster Linie, um die Vorgeschichte und die tieferen Zusammenhänge des Putsches nicht an die Öffentlichkeit zu bringen und dadurch das bayerische Triumvirat Kahr-Lossow-Seißer nicht zu kompromittieren. ${ }^{123}$ Beim Leipziger Gerichtshof, der „zum Teil mit Sozialdemokraten besetzt" war ${ }^{124}$, wäre diese Gefahr kaum auszuschalten gewesen. Die Absicht Gürtners geht eindeutig aus der vertraulichen Weisung an die Staatsanwaltschaft vor Prozeßbeginn hervor, daß gegen die öffentliche Behandlung bestimmter, im einzelnen aufgeführter Fragen vor Gericht - die die drei genannten und andere bayerische Regierungsstellen bloßstellen konnten - „die erheblichsten innen- und außenpolitischen Bedenken " bestünden und bei ihrer Erörterung die Öffentlichkeit ausgeschlossen werden sollte. ${ }^{125}$ Gürtners weitergehender Vorschlag, den ganzen Prozeß unter Ausschluß der Öffentlichkeit zu führen, wurde vom Gericht abgelehnt. ${ }^{126}$

${ }^{121} \mathrm{Zu}$ den Verhandlungen im einzelnen vgl. B. Steger, Der Hitlerprozeß und Bayerns Verhältnis zum Reich (VfZ 1977, S. $441 \mathrm{ff}$.), S. $446 \mathrm{ff}$.

$122 \mathrm{Vg}$. Gürtners Vorschlag im Kabinett am 27.3.24 (Niederschr. der Ministerratssitzung, BayerHStArch., Sign. MA 99518) und VO des Gesamtministeriums über die Aufhebung der Volksgerichte v. 27.3.24 (GVBl., S. 128). E. Kern, Der gesetzliche Richter, Berlin 1927, S. 203, nennt diese Sonderregelung „eine sachlich gebotene, durch zwingende Gründe der Prozeßökonomie gerechtfertigte Maßregel“".

123 Die Abwendung einer voraussichtlich schärferen Bestrafung Hitlers durch den Leipziger Staatsgerichtshof war hier nur eine Nebenwirkung. Bezeichnend Gürtners Bemerkung im Kabinett am 27.3.24 anläßlich der bevorstehenden Aufhebung der Volksgerichte: bisher flüchtige Angeschuldigte hätten „es sich selbst zuzuschreiben" (!), wenn sie sich nunmehr vor dem Staatsgerichtshof verantworten müßten (Niederschr. der Ministerratssitzung, a.a.O.)

124 So v. Knilling am 14.11.23 zu Moser v. Filseck, Politik in Bayern 1919-1933 (s. Anm. 36), S. 144.

125 Es handelte sich um folgende Fragen: die Existenz „schwarzer“ Waffen und die Kenntnis der Regierung darüber; geheime Mobilmachungspläne, Zusammenarbeit und Absprachen der Reichswehr mit den vaterländischen Verbänden; Versuche zur Bildung eines „nationalen Reichsdirektoriums“, das Grenzschutzaufgebot an der nordbayerischen Grenze und die Verwendung Ehrhardts dabei; die Besprechung Kahr-Lossow-Seißer mit den Organisationsführern der vaterländischen Verbände v. 6.11.23 u. a. Vgl. vertraul. Schr. des OStA beim OLG München an den I.StA beim LG München I v. 7.2.24 (StArch. München, Sign. Staatsanwaltschaften 3099).

126 Vgl. seine Ausführungen in der Ministerratssitzung v. 4.3.24 (Niederschr., BayerHStArch., Sign. MA 99518). 
Daß Gürtner über die weisungsgebundene Staatsanwaltschaft auf den Prozeß Einfluß nahm, verstieß nicht gegen das Gesetz. Er bediente sich dabei des Oberstaatsanwalts beim Oberlandesgericht München, Aull, dem die Aufsicht über die Staatsanwälte dieses Bezirks oblag und der der Hauptverhandlung vom Anfang bis zum Ende als Zuhörer beiwohnte, um dem Minister jeweils über den Verlauf des Prozesses zu berichten und dessen „Wünsche und Anregungen“ entgegenzunehmen. Auf Aulls Initiative legte der verhandelnde Staatsanwalt Stenglein nach der Beweisaufnahme Gürtner auch die Anklagerede nebst Strafanträgen „zwecks Prüfung und Billigung“ vor. ${ }^{127} \mathrm{Da}$ er in seinem Plädoyer am 21. März für sämtliche Angeklagten zwar die Zubilligung mildernder Umstände und die Anrechnung der erlittenen Untersuchungshaft beantragte, aber für Hitler unter allen Angeklagten den höchsten Antrag auf acht Jahre Festung stellte ${ }^{128}$, kann von einer besonderen Milde gegenüber Hitler nicht gesprochen werden. Günstig für Hitler war allerdings, daß sich die Staatsanwaltschaft gehindert sah, nach $\S 9$ des Republikschutzgesetzes im Falle einer Verurteilung seine Ausweisung als Ausländer - Hitler besaß die Staatsbürgerschaft Bayerns und des Reichs nicht $-z u$ beantragen, da der Vollzug dieses Gesetzes in Bayern durch v. Kahrs Verordnung vom 28. September 1923 „bis auf weiteres eingestellt und den Strafverfolgungs- und Polizeibehörden jede Mitwirkung beim Vollzug" untersagt war. Staatsanwalt Stenglein erklärte aber ausdrücklich, daß das Gericht „von Amts wegen die Anwendbarkeit der $\mathrm{zwingend}$ vorgeschriebenen Bestimmungen des genannten $\S 9 \mathrm{zu}$ prüfen haben" werde. ${ }^{129}$ Somit war Hitlers Ausweisung von der Staatsanwaltschaft immerhin nicht ausdrücklich abgelehnt worden; im Gegenteil will Aull den Gerichtsvorsitzenden "wiederholt und noch unmittelbar vor der geheimen Beratung des Urteiles“ auf diese gesetzliche Pflicht hingewiesen haben. ${ }^{130} \mathrm{Da}$ die bayerischen Gerichte dem Generalstaatskommissar nicht unterstellt worden waren ${ }^{131}$, wandten sie das Republikschutzgesetz auch nach dem September 1923 verschiedentlich an. ${ }^{132}$ Das Volksgericht München selbst sollte Hitler aufgrund dieses Gesetzes zu der erwähnten Geldstrafe verurteilen und die Anwendung der Ausweisungsbestimmungen nur deshalb verneinen, weil sie „auf einen Mann, der so deutsch denkt und fühlt wie Hitler, der freiwillig $4 \frac{1}{2}$ Jahre lang im deutschen Heere Kriegsdienste geleistet" hatte, ausgezeichnet und verwundet worden war, ,ihrem Sinn und ihrer Zweckbestimmung nach" nicht angewendet werden könnten. ${ }^{133}$ Wenngleich Gürtner für diese Begründung mit vaterländi-

127 Vgl. schriftl. Erkl. des OLGPräs. a.D. Aull v. 20.8.46 (Spruchkammerakten Neithardt, StArch. München). Aull, der 1929 OLGPräs. in Augsburg und 1932 in Bamberg wurde, trat im Herbst 1933 auf eigenes Ansuchen in den Ruhestand (s. Kapitel III.2, S. 236).

$128 \mathrm{Vgl}$. Anträge des StA Stenglein im Hitler-Prozeß (Chronik der bayer. Justizverwaltung, a.a.O., Eintr. v. 21.3.24), dazu sein Plädoyer betr. Hitler und Ludendorff und das Plädoyer StA Ehards betr. die übrigen Angeklagten v. 21.3.24 (Hitler-Prozeß [s. S. 34, Anm. 114] T. 4 (1999), S. 1224 ff.). Zu Ehard s. die Angaben in Kapitel III.2, S. 232.

129 Verhandlungen, Hitler-Prozeß a.a.O., S. 1248.

${ }^{130}$ Vgl. schriftl. Erkl. Aulls v. 20.8.46 und Zeugenprotokoll Dresses v. 31.1.49 (a.a.O., s. Anm. 127).

131 In der VO v. 26.9. 23 waren die Gerichte von der Unterstellung der Behörden unter den Generalstaatskommissar ausdrücklich ausgenommen. Von der rechtlichen Möglichkeit, der Staatsanwaltschaft (!) Weisungen zu erteilen, machte v. Kahr nur einmal Gebrauch: bei der Entlassung Ludendorffs aus der vorläufigen Haft gegen ehrenwörtliche Versicherung (Chronik der Bayerischen Justizverwaltung, a.a.O., Eintr. v. 14.2. 24).

132 Vgl. die Ausführungen Graf v. Pestalozzas im bayer. Landtag: Dem StA passierte „das Malheur, daß fast zu gleicher Zeit in einem anderen Sitzungssaale sein Kollege auf dieses Gesetz Bezug nimmt und das Gericht unter Bezugnahme auf dieses Gesetz urteilt" (Verhandlungen des Bayerischen Landtages. Stenogr. Ber., 13. Sitzung v. 22.7.24, S. 280).

133 Vgl. Urt., a.a.O. (s. Anm. 114) S. 364. 
schen Motiven Verständnis gehabt haben dürfte, gibt es keine Anzeichen dafür, daß er in irgendeiner Form die Bemühungen der bayerischen Regierung behinderte, Hitler bei Bewilligung der Bewährungsfrist und Haftentlassung auf dem Verwaltungswege in sein Heimatland Österreich auszuweisen: die Ausweisung scheiterte an der Weigerung der österreichischen Bundesregierung, Hitler aufzunehmen, da er die österreichische Staatsangehörigkeit durch mehr als zwölfjährige Abwesenheit von Österreich und durch den Eintritt in das deutsche Heer verloren habe. ${ }^{134}$

Wesentlich ist ferner die Frage, ob Gürtner auf die personelle Zusammensetzung des sachlich und örtlich zuständigen Volksgerichts München $\mathrm{I}^{135}$, das mit zwei Berufsrichtern und drei Laienrichtern besetzt war, Einfluß genommen hat, um ein günstiges Urteil für die Angeklagten zu bewirken, d.h. ob er sie entgegen $\S 16$ des Gerichtsverfassungsgesetzes und Artikel 105 der Reichsverfassung ihrem bisherigen ,gesetzlichen Richter entzogen" und für sie ad hoc ein Gericht zusammengesetzt hat. Nach dem Volksgerichtsgesetz hatte der Oberlandesgerichtspräsident München die beiden $\mathrm{Be}$ rufsrichter zu ernennen, die ,in der Strafrechtspflege besonders erfahren sein“ sollten und von denen der rangältere den Vorsitz führte. ${ }^{136}$ Der Vorsitzende im Hitlerprozeß, Landgerichtsdirektor Neithardt, gehörte dem Münchner Volksgericht schon seit 1919 an und hatte bereits in anderen großen Prozessen - so auch im Hochverratsprozeß Fuchs-Machhaus im Juni/Juli 1923 - den Vorsitz geführt. Er war offensichtlich auch nach der Geschäftsverteilung des Volksgerichts für die Führung des bevorstehenden Prozesses zuständig. Oberstaatsanwalt Aull, der Neithardt wegen seiner politischen Einstellung als Vorsitzenden für diesen Prozeß nicht geeignet hielt, regte in einer Besprechung im Justizministerium 1923 einen Wechsel im Vorsitz an, der „ohne Verstoß gegen ein Gesetz leicht mit der neuen Geschäftseinteilung für das Jahr 1924 vollzogen werden“ könne. Er drang jedoch mit seinem Vorschlag nicht durch, „weil die Herren des Ministeriums der Ansicht waren, es könnte trotzdem der Vorwurf erhoben werden, man habe die Angeklagten ihrem ordentlichen Richter entzogen “. ${ }^{137}$ Gürtner, der im Kabinett erklärte, daß er Neithardt zwar „persönlich nicht genau kenne“, daß sich dieser Richter nach dem Urteil seiner Vorgesetzten aber „für die Leitung des Prozesses bestens eigne" ${ }^{138}$, dürfte gerade in der von Aull beanstandeten ,vaterländischen Gesinnung“ Neithardts keinen Grund gesehen haben, ihn als Vorsitzenden abzulösen, da er ein Interesse daran hatte, daß der Prozeß wegen seiner delikaten Materie so geführt wurde, daß der „nationale“ Gedanke keinen Schaden litt. Wie Neithardt später bekannte, besaß er für die Angeklagten „nicht mehr Sympathie, als sie jeder vaterländisch Gesinnte empfinden wird für überzeugungstreue Vorkämpfer“ der deutschen

${ }^{134}$ Vgl. zu diesem Problem D. C. Watt, Die bayerischen Bemühungen um Ausweisung Hitlers 1924 (VfZ 1958 , S. 270 ff.), zu Gürtner insbes. S. 279.

135 Die sachliche Zuständigkeit für Hochverrat ergab sich aus Art. 4 des G. über die Einsetzung von Volksgerichten bei inneren Unruhen v. 12.7.19 (GVBl., S. 365), die örtliche Zuständigkeit aus $§ 22$ der Bekanntmachung über die Einsetzung von Volksgerichten (Vollzugsvorschriften) v. 19.7.19 (JMBI., S. 254), da die Straftat in München begangen war.

$136 \mathrm{Vgl}$. Art. 6 des G. über die Einsetzung von Volksgerichten bei inneren Unruhen (a.a.O.).

137 Vgl. Prot. der Vernehmung des damaligen StA Dresse v. 31.1.49, der mit StA Stenglein bei dieser Besprechung anwesend war. Ferner Erkl. Aulls v. 20.8.46 (Spruchkammerakten Neithardt, StArch. München).

$138 \mathrm{Vgl}$. Niederschr. der Ministerratssitzung v. 4.3.24 (BayerHStArch., Sign. MA 99518). Zu Neithardt, der 1933 zum OLGPräs. von München ernannt wurde, s. Kapitel III.2., S. 236, und III.3.a., S. 274. 
Sache. ${ }^{139}$ Er sah in ihnen offensichtlich „Patrioten und Frontsoldaten, die sich in guter Absicht in der Wahl ihrer Mittel vergriffen hatten ". ${ }^{140}$ Schon während des Prozesses gingen Gerüchte um, er solle „sich auch dafür ausgesprochen haben, daß Ludendorff freigesprochen würde“. ${ }^{141}$

Die geschäftsverteilungsmäßige Zuständigkeit dürfte auch für den richterlichen Beisitzer, Landgerichtsrat Leyendecker ${ }^{142}$, bestanden haben, da sie sich normalerweise auf den Rechtsprechungskörper als solchen bezog. Der zum Ersatzrichter bestellte Oberlandesgerichtsrat Simmerding, der vorher in einer Zivilkammer des Landgerichts tätig war, wurde im Dezember 1923 verständigt, daß er ab 1. Januar 1924 zum Volksgericht kommen und im Hitlerprozeß für diese Funktion eingeteilt werde. ${ }^{143}$

Die Laienrichter des Volksgerichts waren nach dem Volksgerichtsgesetz vom Oberlandesgerichtspräsidenten in Gemeinschaft mit vier durch Wahl bestimmten Mitgliedern des Kreistages aus den in die Schöffenliste aufgenommenen Personen ausgewählt, die am Sitze des Volksgerichts oder in seiner Umgebung wohnten. Die Reihenfolge ihrer Verwendung war zwar vorher bestimmt, jedoch konnte der Vorsitzende des Volksgerichts ,in dringenden Fällen“ von ihr abweichen. ${ }^{144}$ Diese außerturnusmäßige Berufung von Schöffen durch den Vorsitzenden kam vor allem dann vor, wenn es sich um längere Prozesse mit vielen Sitzungstagen handelte, für die Laienrichter schwer zu finden waren: so hatten z. B. im Fechenbachprozeß 1922 ,nicht weniger als 30 turnusmäßig nacheinander zuständige Schöffen" ihre Mitwirkung wegen der voraussichtlichen Länge des Prozesses abgelehnt, so daß ein Laienrichter berufen werden mußte, der schon Monate vorher im Hochverratsprozeß gegen den des Separatismus beschuldigten Freiherrn von Leoprechting mitgewirkt hatte. ${ }^{145}$ Aber auch aus anderen Gründen gab es gelegentlich Abweichungen von der festgelegten Reihenfolge. So wurde in zwei Prozessen, die in den Tagen nach dem Hitlerprozeß stattfanden, je ein Laienrichter aus dem Hauptprozeß vom Vorsitzenden „außerhalb der Tour“ verwendet, „um wenigstens einen Richter noch im Gericht zu haben, der über den Verlauf des Hauptprozesses und den komplizierten Tatbestand, der Gegenstand der Verhandlung war, unterrichtet" war. ${ }^{166} \mathrm{Ob}$ im Hitlerprozeß bei der Bestellung der beiden Versicherungs-

139 Vgl. Bemerkungen Neithardts zu Presseangriffen, die er dem zum Ersatzrichter bestellten damaligen OLGRat Simmerding nach 1933 übergab. Anlage zum Schr. LGDir. a. D. Simmerding an OLGRat Otto B. v. 14.3.49 (Spruchkammerakten Neithardt, StArch. München).

140 Vgl. Schr. RA Hanns C. v. 11.4.50 an die Spruchkammer/Berufungskammer München (a.a.O.).

141 So Innenminister Schweyer in der Ministerratssitzung v. 4.3.24 (Niederschr. im BayerHStArch., Sign. MA 99518).

142 Die Namen der mitwirkenden Berufs- und Laienrichter sind veröffentlicht in: Hitler-Prozeß (s. S. 34, Anm. 114), S. 341.

143 Vernehmungsprotokoll Simmerding v. 11.3.49 (Spruchkammerakten Neithardt, AG München, Registratur S). S. war bei allen Sitzungen des Prozesses außer bei der Urteilsberatung anwesend, um bei Ausfall eines der Berufsrichter einspringen zu können.

144 Vgl. Art. 6 des G. über die Einsetzung von Volksgerichten bei inneren Unruhen v. 12.7.19 (GVBl., S.365) und $\S \S 12$ u. 13 der Vollzugsvorschriften v. 19.7.19 (JMB1., S. 254).

145 Vgl. Gürtners Erkl. im bayer. Landtag am 17.11.22, die durch eine Anfrage wegen der Mitwirkung von zwei gleichen Laienrichter im Leoprechting- und im Fechenbachprozeß ausgelöst worden war. Der zweite beanstandete Laienrichter war für den Fechenbachprozeß „turnusmäßig berufen und konnte nicht deswegen ausgeschlossen werden, weil er vor Monaten im Leoprechting-Prozeß tātig war" (Verhandlungen des Bayer. Landtags, III.Tagung 1922/23, 149. Sitzung, Stenogr. Ber., VII. Bd., S.159).

$146 \mathrm{Vgl}$. Gürtner auf eine entsprechende Anfrage im bayer. Landtag am 23.7.24 (a.a.O., I. Tagung 1924, 14. Sitzung, Stenogr. Ber., I. Bd., S.310). Sonst wurden in den Verhandlungen, die nach dem Hitlerprozeß stattfanden, an vier Verhandlungstagen zwölf verschiedene Laienrichter beteiligt. 
Privatbeamten Herrmann und Zimmermann und des Kaufmanns Beck als Laienrichter sowie des Zigarrenhändlers Brauneis als Ersatzlaienrichter ein "dringender Fall“ angenommen und von der vorbestimmten Reihenfolge abgewichen wurde, entzieht sich der Nachprüfung. ${ }^{147}$ Oberstaatsanwalt Aull soll zwar über die Auswahl dieser Laienrichter „äußerst ungehalten“ gewesen sein, da sie „zu den sogen. Berufsschöffen gehörten, d.h. zu jenen gehörten, die in großen, mehrere Tage oder auch Wochen dauernden Prozessen immer auftauchten und als stark rechts eingestellt bekannt waren“. ${ }^{148}$ Aber mit der Tatsache allein, daß sie aufgrund ihrer politischen Anschauungen die Sympathie Neithardts für die Angeklagten teilten - sie traten für den Freispruch des von ihnen verehrten Feldherrn Ludendorff ein ${ }^{149}$, wollten Hitler, Kriebel, Weber und Pöhner nur schuldig sprechen, wenn diesen Angeklagten Bewährungsfrist in Aussicht gestellt werde ${ }^{150}$, und lehnten die Ausweisung Hitlers ab, „weil er als Soldat den Krieg auf deutscher Seite mitgemacht" hatte ${ }^{151}$-, kann die Behauptung einer außerturnusmäßigen „Auslese“ der Laienrichter nicht gestützt werden. Falls diese - formal nicht ungesetzliche - Maßnahme tatsächlich ergriffen wurde, ging sie mit größter Wahrscheinlichkeit auf die Eigeninitiative Neithardts und nicht auf eine - in diesem Fall höchst überflüssige - Einwirkung Gürtners zurück. Weder hinsichtlich der Berufsrichter noch der Laienrichter ist jedenfalls eine Einflußnahme Gürtners auf die Zusammensetzung des Volksgerichts für den Hitlerprozeß konkret nachweisbar.

Es stellt sich ferner die Frage, inwieweit Gürtner auf die Prozeßführung und Urteilsfindung des Gerichts eingewirkt hat. Als Innenminister Schweyer eine Woche nach Prozeßbeginn im Ministerrat kritisierte, „daß sich Reichswehr und Landespolizei in dem Prozeß täglich Verunglimpfungen gefallen lassen müßten, ohne daß vom Vorsitzenden auch nur ein Finger gerührt werde“, daß die Angeklagten nicht vernommen würden, sondern Agitationsreden hielten und daher "gegen die Prozeßführung des Vorsitzenden ... schwere Bedenken“ bestünden, entgegnete Gürtner, „die Justizverwaltung müsse sich vor dem Vorwurf einer Beeinflussung des Gerichts hüten und könne eigentlich nur durch die Staatsanwaltschaft eingreifen“. Nichtsdestoweniger habe er mit dem Vorsitzenden "durch einen Kollegen" - es handelte sich um Oberstaatsanwalt Aull - „wiederholt" Verbindung aufgenommen und ihm übermitteln lassen, daß es einen „peinlichen Eindruck gemacht [habe], daß er Hitler 4 Stunden habe sprechen lassen“, und daß er ferner „das Fragerecht der Verteidiger ausschließen müßte“. Er habe mit dem Vorsitzenden auch „hinsichtlich der Reihenfolge bei der

147 Auch im Untersuchungsausschuß des bayer. Landtages von 1927 (s. voranstehende Anm. 98) wurde diese Frage gestellt, aber vom Ausschuß nicht beantwortet (Niederschr. der Verhandlungen, BayerHStArch., Sign. MA 103476/3, Bl. 1423).

148 Aussage des StA Dresse v. 31.1.49 (Spruchkammerakten Neithardt, StArch. München).

149 Vgl. Aussage Dresses v. 19.9.49 (a.a.O.). Auf Dresses Frage, wie er zu einem Freispruch Ludendorffs gekommen sei, antwortete ihm Neithardt „ganz gelassen: ich war ja auch überzeugt, daß Ludendorff Hochverrat begangen hat, nachdem aber die Schöffen für die Freisprechung Ludendorffs waren, habe ich mich ihnen angeschlossen“. Da nach Art. 19 des VolksgerichtsG v. 12.7.19 (GVBI., S.365) zur Verurteilung oder Freisprechung eine Mehrheit von vier Stimmen erforderlich war, mußte einer der Berufsrichter mit den drei Laienrichtern gestimmt haben.

$150 \mathrm{Vgl}$. dazu im folgenden S.42 und Anm. 165.

151 Vgl. Zeugenvernehmung des ehemaligen Ersatzlaienrichters Brauneis, Prot. v. 28.2.50 (Spruchkammerakten Neithardt, a.a.O.). Nach seiner Aussage im Zeugenprotokoll v. 9.5.49 (a.a.O.) standen die Laienrichter sogar auf dem Standpunkt, „daß den Bayerischen Staat ein Verschulden treffe, weil er Hitler für sein vaterländisches Verhalten [im Kriege] nicht eingebürgert habe“. 
Vernehmung der Zeugen Fühlung genommen“. Als weitere Kabinettskollegen ausführten, „daß das Gericht noch nie habe merken lassen, daß es anderer Ansicht sei als die Angeklagten“, und dadurch die Auffassung der Staatsautorität zur Tat nie zum Ausdruck gebracht habe, daß der Vorsitzende ferner für die Angeklagten günstige Suggestivfragen stelle, antwortete Gürtner, er teile die Auffassung nicht, „daß der Vorsitzende seine Rechtsauffassung über die unter Anklage stehenden Vorgänge zum Ausdruck bringen solle“. Er werde ihm aber Schweyers Beschwerde über die ungerügten Verunglimpfungen der Polizei mitteilen lassen, bitte jedoch das Kabinett, mit dem Urteil über das Gericht „noch zurückzuhalten, da der weitere Verlauf des Prozesses erst seine Unparteilichkeit erweisen müsse“. ${ }^{152}$

Ob Gürtners Einflußnahme auf die Prozeßführung durch Aull, „der in Pausen wiederholt in das Richterzimmer kam" und sich - außer bei der Beratung des Urteils auch „wiederholt bei Beratungen im Beratungszimmer" aufhielt ${ }^{153}$, über die erwähnten Mitteilungen an den Vorsitzenden und „Anregungen des Justizministers in bezug auf die Beschleunigung des Verfahrens und die Terminbestimmung “154 hinausging, muß offenbleiben. An sich unterlag die Zweckmäßigkeit richterlicher Maßnahmen nicht der Nachprüfung im Wege der Dienstaufsicht. ${ }^{155}$ Die von Gürtner erwähnte „Fühlungnahme“ mit Neithardt wegen der Reihenfolge bei der Vernehmung der Zeugen hätte sicherlich einen Eingriff in dessen richterliche Tätigkeit dargestellt, wenn sie in Gestalt einer massiven Forderung vorgebracht und nicht ohnehin mit der Prozeßtaktik Neithardts in Einklang gestanden wäre: beabsichtigte Neithardt doch, durch die „möglichst breit“ angelegte Einvernahme der Angeklagten eine Vernehmung v. Kahrs, v. Lossows und v. Seißers unnötig zu machen und zu vermeiden, da sie „eine unerquickliche und das Staatsansehen schädigende Sache zu werden" versprach; seine Absicht wurde aber durch die schweren Angriffe der Angeklagten und Verteidiger auf die drei Genannten durchkreuzt. ${ }^{156}$ Für die mit der Prozeßtaktik zusammenhängende Behauptung, daß Gürtner schon vor dem Prozeß mit den Verteidigern einen regelrechten Vergleich ausgehandelt habe, wonach die Angeklagten das Verfahren ohne Schädigung des Vaterlandes - d.h. unter Eingeständnis des objektiven Tatbestandes und damit unter Verzicht auf ausgedehnte Zeugenvernehmungen für ihre Verteidigung - führen und dafür milde Urteile bzw. baldige Begnadigung erhalten sollten, gibt es dagegen keinerlei Anhaltspunkte. ${ }^{157}$ Das Verhalten der Angeklagten und Verteidiger widersprach auch der Existenz einer solchen Abmachung. Gürtner selbst erklärte

152 Vgl. Niederschrift über die Ministerratssitzung v. 4.3.24 (BayerHStArch., Sign. MA 99518). Auch zwei Wochen später beschwichtigte Gürtner seine Kabinettskollegen, auch er billige „zwar die Sitzungspolizei des Vorsitzenden nicht“, empfehle „aber doch mit dem Urteil über die Prozeßführung noch zu warten, bis der Prozeß zu Ende sei“ (Niederschrift über die Ministerratssitzung v. 17.3.24, a.a.O.).

$153 \mathrm{Vgl}$. Zeugenvernehmung des Ersatzlaienrichters Brauneis, Prot. v. 9. 5.49 (Spruchkammerakten Neithardt, a.a.O.).

154 Vgl. schriftl. Erkl. Aulls v. 20.8. 46 (a.a.O.).

155 Vgl. zu diesem Problem Kapitel VIII.3., S. 1108.

156 Vgl. Bemerkungen Neithardts. Anlage zum Schr. Simmerdings v. 14.3.49 (a.a.O., voranstehende Anm. 139).

157 Der Versuch eines Anwalts, für das Aushandeln eines Vergleichs über den damaligen Abgeordneten der BVP, Fritz Schäffer, an Neithardt heranzukommen, scheiterte, da Schäffer ablehnte und Neithardt „als künftiger Leiter des Prozesses aus begreiflichen Gründen mit der Sache nichts zu tun haben wollte" (Bemerkungen Neithardts. Anlage zum Schr. Simmerdings v. 14.3.49, a.a.O., voranstehende Anm. 139, und Schr. Schäffers v. 23.11.49 an den Generalkläger beim Kassationshof im Bayer. StMin. für Sonderaufgaben, Spruchkammerakten Neithardt, StArch. München). 
im Juli 1924 im bayerischen Landtag, daß er „ein einziges Mal vor dem Prozeß mit den Beteiligten verhandelt" habe, als es um den Ort und den Raum der Hauptverhandlung ging. Ein weiteres Mal verhandelte er „während des Prozesses mit der Verteidigung und der Staatsanwaltschaft gleichzeitig“, nachdem Staatsanwalt Stenglein aufgrund von Entgleisungen eines Verteidigers sein Amt niedergelegt und dadurch die Hauptverhandlung unterbrochen hatte: er wollte den Staatsanwalt in dieser Unterredung zur Wiederaufnahme seines Amtes verpflichten und die Verteidigung zur Selbstdisziplin ermahnen. ${ }^{158}$ Soweit ersichtlich, zielte Gürtners Einwirkung auf die Prozeßführung auf eine rasche Durchführung, eine straffere Sitzungsdisziplin und die Wahrung der Interessen bayerischer „Staatsraison“ ab, aber nicht auf eine Begünstigung Hitlers.

Eine unmittelbare Einwirkung Gürtners auf die Urteilsfindung des Gerichts ist selbst von seinen entschiedensten politischen Gegnern nie behauptet worden und hätte auch seiner Grundanschauung von der sachlichen Unabhängigkeit des Richters widersprochen, die er später sogar unter dem NS-Regime in heiklen Situationen aufrechtzuerhalten trachtete. ${ }^{159}$ Deshalb muß auch die Behauptung Otto Strassers, Hitler habe von Gürtner schon vor Prozeßbeginn „die Zusage erhalten, daß er die Strafe nicht bekommt, die er am meisten fürchtet: die Ausweisung “160, ins Reich der Fabel verwiesen werden: Gürtner hatte keinerlei Veranlassung, sich Hitler durch ein solches kompromittierendes Versprechen - das ja eine Einwirkung auf die Urteilsfindung voraussetzte - in die Hand zu geben, dessen Bekanntwerden ihn als Justizminister ein für allemal erledigt hätte.

Gegen Gürtner wurde ferner vorgebracht, daß er der Staatsanwaltschaft zugunsten Hitlers in den Arm gefallen sei, als sie gegen den Beschluß des Volksgerichts vom 1. April 1924, Hitler nach sechsmonatiger Strafverbüßung eine Bewährungsfrist in Aussicht zu stellen, Beschwerde eingelegt habe. Als Ministerpräsident v. Knilling am 12. April die Frage der Einlegung einer Beschwerde anschnitt, erläuterte Gürtner, daß es sich bei diesem Gerichtsbeschluß nicht schon um die Bewilligung, sondern lediglich um die Inaussichtstellung einer bedingten Begnadigung handele. Sie „binde weder das Gericht noch erzeuge sie einen Anspruch der Verurteilten“. Würde gegen sie bereits jetzt Beschwerde eingelegt, so werde das für die Entscheidung zuständige Bayerische Oberste Landesgericht „die Notwendigkeit einer sachlichen Würdigung der Beschwerde zu umgehen suchen, um nicht jetzt schon eine Entscheidung von enormer politischer Tragweite treffen zu müssen. Erst nach Ablauf der 6 Monate werde das [nach Auflösung des Volksgerichts dann zuständige] ordentliche Gericht einen bindenden Beschluß über die bedingte Begnadigung zu fassen haben“. Innenminister Schweyer kritisierte, daß sich das Volksgericht mit seinem Beschluß „eine Formalgewalt angeeignet habe, die ihm gar nicht zukomme. Es habe suggestiv wirken wollen, insofern als es für das ordentliche Gericht nach 6 Monaten außerordentlich schwer sein werde, anders zu entscheiden“. Deshalb müsse die Beschwerde zum gegenwärtigen Zeitpunkt eingelegt werden, da die Regierung sonst „eine enorme politi-

158 Vgl. Verhandlungen des Bayerischen Landtags, I. Tagung 1924, 13. Sitzung v. 22.7.24, Stenogr. Ber., I. Bd., S. 272 f. Zu Stengleins Verhalten vgl. Chronik der Bayerischen Justizverwaltung, a.a.O., Eintr. v. 6.3.24.

159 Vgl. dazu Kapitel III.1.a., S. 192; IV.3., S. 371; VII.3.d., S. 897 f., VIII.3., S. 1110 (rückwirkende Gesetzesänderung statt „Lenkung“ des Richters).

160 Vgl. O. Strasser, Hitler und ich, Konstanz 1948, S. 73. 
sche Belastung" auf sich nehme. Das Kabinett schloß sich in seiner Mehrheit der Ansicht v. Knillings an, die Beschwerde im Hinblick auf die öffentliche Meinung schon jetzt und ohne Rücksicht darauf zu erheben, „wie sich das Oberste Landesgericht von politischer Belastung freizumachen vermöge". ${ }^{161}$ Die Staatsanwaltschaft leitete daraufhin drei Tage später die an die Adresse des Obersten Landesgerichts gerichtete Beschwerde zunächst vorschriftsgemäß dem Volksgericht München zur Stellungnahme zu, „ob der Beschwerde abgeholfen wird“. Sie verknüpfte damit gleichzeitig das Ersuchen „um grundsätzliche Äußerung zu dem Beschluß“ über die Bewährungsfrist, da sie die Fassung dieses Beschlusses für „unklar erachtete“. ${ }^{162}$ Das Volksgericht erklärte in einem Beschluß vom 22. April, daß der Beschwerde der Staatsanwaltschaft nicht abgeholfen werde: es habe „mit Absicht scharf zwischen Bewilligung [bei Brückner, Röhm, Pernet, Wagner und Frick] und Inaussichtstellung von Bewährungsfrist unterschieden". Bei Hitler und drei weiteren Haupttätern

„schien dem Gericht zwar einerseits eine alsbaldige Entscheidung der Bewährungsfrist nicht veranlaßt, andererseits hatte aber besonders das im Gericht vertretene Laienelement [?] die Empfindung, daß die erkannten fünf Jahre Festungshaft, obwohl gesetzlich Mindeststrafmaß, doch eine zu schwere Sühne für die Tat seien und glaubte deshalb, dafür sorgen zu müssen, daß die Bewährungsfristfrage im Auge behalten und in angemessener Frist gelöst werde“.

Deshalb habe in sechs Monaten „unter allen Umständen das dann zuständige Gericht sich über die Bewährungsfristfrage schlüssig zu machen ". ${ }^{163}$

Mit diesem Beschluß grenzten sich die Berufsrichter des Volksgerichts ${ }^{164}$ entschieden von seinen Laienbeisitzern ab, die bei der Urteilsberatung dem Schuldausspruch und der Verhängung der Mindeststrafe gegen Hitler und die drei anderen Haupttäter nur unter der Bedingung zugestimmt hatten, daß diesen eine Bewährungsfrist bestimmt in Aussicht gestellt werde, und die folglich die Ansicht vertraten, „daß die Nichtgewährung der Bewährungsfrist dem Urteil seine Grundlage“ entziehe. ${ }^{165}$

Demgegenüber sollte gemäß dem Beschluß der Berufsrichter nach Ablauf von sechs Monaten ohne bereits bestehende sachliche Bindung darüber entschieden werden können, „ob bei den Verurteilten die nach den Begnadigungsvorschriften notwendi-

161 Niederschr. über die Ministerratssitzung v. 12.4.24 (BayerHStArch., Sign. MA 99518).

162 Beschw. der StAschaft beim Volksgericht München I v. 15.4.24, zit. nach der Erklärung der amtl. Pressestelle, Entw. im Schr. des I. StA Stenglein an den OStA beim OLG München v. 28. 5.24 (StArch. München, Sign. Staatsanwaltschaften 3099). Auszüge aus der Beschw. zit. in: Hitler und Kahr. Die bayerischen Napoleonsgrößen von 1923. Ein im Untersuchungsausschuß des Bayerischen Landtags aufgedeckter Justizskandal, II. Teil Mai 1928 [Verfasser: W. Hoegner], herausg. vom Landesausschuß der S.P.D. in Bayern, S. 198 f.

$163 \mathrm{Vgl}$. Beschl. des Volksgerichts München I v. 22.4.24. Wortlaut zit. in der Niederschr. der Verhandlungen des Untersuchungsausschusses des bayer. Landtags von 1927 (a.a.O. [s. Anm.98], Bl.1496).

164 Bei einem Beschluß des Volksgerichts wirkten die Laienrichter nicht mit, an ihre Stelle trat der dritte Berufsrichter (Ersatzrichter), vgl. $\S 6$ des G. über die Einsetzung von Volksgerichten bei inneren Unruhen v. 12.7.19 (GVB1., S. 365).

165 Vgl. Schr. der beiden Laienrichter Herrmann und Beck an das bayer. JM v. 6.7.24, das an die StAschaft beim LG München I weitergeleitet wurde (StArch. München, Sign. Staatsanwaltschaften 3099). Darin baten die Laienrichter „mit großer Sorge und Gewissensnot“, dafür zu sorgen, daß die Bewährungsfrist tatsächlich gewährt werde. Sie seien „bei der Urteilsberatung nicht darüber aufgeklärt worden, daß die Bewährungsfrist einseitig ohne Änderung des Urteils aufgehoben werden“ könne, fühlten sich daher von den Staatsanwälten und Berufsrichtern hintergangen und müßten „schon jetzt für diesen Fall alle Verantwortung für die daraus entstehenden Folgen ablehnen“. Dazu auch Hitler am 3./4. 2.42 (Adolf Hitler. Monologe im Führerhauptquartier 1941-1944, herausg. von W. Jochmann, München 1982, S. 260). 
gen Voraussetzungen für die Bewilligung von Bewährungsfristen überhaupt vorliegen [!] und ob und von wann ab etwa Bewährungsfristen bewilligt werden sollten" ${ }^{166}$

$\mathrm{Da}$ also nach der eigenen Interpretation des Volksgerichts vorläufig noch gar keine bindende Bewilligung einer Bewährungsfrist vorlag, ließ Gürtner am 24. April den II. Staatsanwalt Dresse - der I. Staatsanwalt Stenglein befand sich in Urlaub - durch Ministerialrat Dürr telefonisch anweisen, die eingelegte Beschwerde zurückzunehmen ${ }^{167}$, weil die Verwaltungsbeschwerde an das Oberste Landesgericht nur gegen „die Bewilligung oder Versagung “ einer Bewährungsfrist möglich war und der Beschluß auf bloße Inaussichtstellung einer Bewährungsfrist daher durch sie nicht anfechtbar war. ${ }^{168}$ Damit befreite Gürtner zugleich das Oberste Landesgericht aus der peinlichen Lage, entweder eine Entscheidung unter Berufung auf formale Gründe zu vermeiden oder das politisch heiße Eisen tatsächlich aufzugreifen und zu entscheiden, ob die rechtlichen Voraussetzungen für die Inaussichtstellung einer Bewährungsfrist überhaupt gegeben waren - ein heikles Problem angesichts der Tatsache, daß sich die Verurteilten vor Gericht ihrer Taten offen gerühmt und ihre Bereitschaft zu erkennen gegeben hatten, bei passender Gelegenheit wieder gegen diesen Staat zu handeln, und damit kaum jenes „künftige Wohlverhalten“ erwarten ließen, das die Bestimmungen als Voraussetzung für eine Bewährungsfrist forderten. ${ }^{169}$

Über alle entgegenstehende Bedenken setzte sich kurz vor Ablauf der sechs Monate die nach Auflösung des Volksgerichts nunmehr zuständige III. Strafkammer des Landgerichts München I durch Beschluß vom 25. September 1924 hinweg und bewilligte Hitler ab 1. Oktober für den noch nicht verbüßten Strafrest eine Strafunterbrechung und Bewährungsfrist von vier Jahren. Sie erklärte ferner, daß auch kein Anlaß bestehe, die Hitler gewährte Bewährungsfrist für den Strafrest von zwei Monaten Gefängnis aus dem Urteil vom 12. Januar $1922 \mathrm{zu}$ widerrufen. In der Begründung wurde ausgeführt, daß die Kammer die im Beschluß vom 1. April 1924 zum Ausdruck gekommene Ansicht des Volksgerichts teile, daß bei der Persönlichkeit des Verurteilten und seinen Beweggründen „voraussichtlich die Verbüßung eines verhältnismäßig geringen Strafteiles eine genügende Sühne sein werde“, daß die Führung Hitlers „nach dem Gutachten der Direktion der Festungshaftanstalt eine vorzügliche gewesen sei - das Herausschmuggeln unzensierter Briefe wurde als „kleiner Verstoß gegen die Hausordnung" gewertet - und daß ihm keine strafbaren Absichten oder Beziehungen zu Röhms „Frontbann“ nachgewiesen werden könnten ${ }^{170}$, der als Ersatz für die verbotenen vaterländischen und SA-Verbände gegründet worden war.

166 So die Auslegung des Beschl., zit. nach der Erklärung der amtl. Pressestelle (a.a.O., Anm. 162).

167 Vgl. den Ber. an den OStA v. 26.4.24, den Dresse zu seiner Deckung fertigte, im Wortlaut zit. in der Niederschr. der Verhandlungen des Untersuchungsausschusses des bayer. Landtags von 1927 (a.a.O. [s. Anm. 98], Bl. 800); dazu Aussage Dresses (a.a.O., Bl.324).

168 Vgl. Nr.15 der „Bekanntmachung, die bedingte Begnadigung betreffend“ v. 11.7.19 (JMBl., S. 239). Die Verwaltungsbeschwerde war nicht den ordentlichen Rechtsmitteln des Strafverfahrens zuzurechnen.

169 Vgl. § 14 der Bekanntmachung über Begnadigung, Strafaufschub, Anderung des Straforts, beschränkte Auskunft aus dem Strafregister und Tilgung von Strafvermerken v. 5.3.22 (JMBl., S. 67): „Eine Bewährungsfrist darf nur Verurteilten bewilligt werden, die nach ihren persönlichen Verhältnissen und nach den Umständen der Tat besondere Berücksichtigung verdienen und die Erwartung rechtfertigen, daß sie sich auch ohne die ganze oder die teilweise Vollstreckung der Strafe künftig wohlverhalten werden. Bei der Entscheidung ist besonders zu berücksichtigen, ob der Verurteilte sich nach Kräften bemüht hat, den durch die Tat entstandenen Schaden wieder gutzumachen."

170 Vgl. Beschl. der III. Strafkammer des Landgerichts München I v. 25.9.24. Abschr. in den Spruchkammerakten Neithardt (StArch. München). Kriebel erfuhr die gleiche Behandlung wie Hitler, während die 
Nachdem Gürtner die Angelegenheit schon am folgenden Tag mit dem im Urlaub befindlichen Ministerpräsidenten Held vorbesprochen hatte, erklärte er am 27. September im Kabinett, „daß er unter allen Umständen die Staatsanwaltschaft anweisen werde, gegen den Gerichtsbeschluß Beschwerde einzulegen“ und zu beantragen, daß "die Bewährungsfrist versagt" werde, Hitlers Bewährungsfrist aus dem Urteil von 1922 widerrufen werde, oder zumindest auch bei Hitler und Kriebel - wie bei Weber durch das Landgericht München schon geschehen - die Entscheidung ausgesetzt werde, bis das gegen Oswald u.a. wegen Verfehlung gegen das Republikschutzgesetz eingeleitete Verfahren („Frontbann“-Verfahren) beendet sei. Die Beschwerde werde bei Hitler mit dem dringenden Verdacht zu begründen sein, daß er von der Festungshaft aus die am 9. November 1923 verbotenen Verbände weiter betreut habe und „an der Gründung der strafrechtlich verbotenen Kampforganisation des Frontbannes beteiligt gewesen“ sei. Auf die Frage seiner Ministerkollegen, ob sich die Begründung der Beschwerde auf das gesamte Tatsachenmaterial auch vor dem Urteil vom 1 . April beziehen werde oder sich auf die seit der Verurteilung neu aufgetretenen Gründe beschränken solle, antwortete Gürtner, er glaube, „daß die Geltendmachung der neuen Gründe ausreichen werde". 171

In der Tat bezog sich die am 29. September 1924 beim Obersten Landesgericht eingelegte Beschwerde der Staatsanwaltschaft in ihrer Begründung nur noch auf nach dem 1. April aufgetretene Tatsachen und schob damit die Angelegenheit auf ein Gleis, auf dem die Berechtigung der Inaussichtstellung einer Bewährungsfrist im Urteil vom 1. April gar nicht mehr geprüft wurde. Ob diese Beschränkung auf eine Weisung Gürtners zurückging oder auf der noch zu erörternden Rechtsauffassung des Obersten Landesgerichts über die Zulässigkeit der Beschwerde beruhte, bleibt ungeklärt. In der Beschwerde wurde argumentiert, daß bei Hitler und Kriebel durch ihren Briefschmuggel während des Strafvollzugs der dringende Verdacht bestehe, „daß sie sich wieder einer auf der gleichen Linie liegenden strafbaren Handlung schuldig gemacht" und damit gezeigt hätten, „daß eben die Erwartung künftigen Wohlverhaltens durchaus nicht gerechtfertigt“ sei. Der Bewilligung einer Bewährungsfrist stünden außerdem „die allgemeinen Interessen“ aufs schärfste entgegen. ${ }^{172}$ Aber die Beschwerde begnügte sich nicht mit dem Hinweis auf das Verhalten der Strafgefangenen nach der Verurteilung: sie hob hervor, daß die nach dem 1. April 1924 abgeschlossenen Nachfolgeprozesse des Hitlerputsches und die in ihrem Zusammenhang vorgenommenen Ermittlungen „das Bild der Tat vom 8./9.11.1923 zu ungunsten der Verurteilten noch verstärkt“ und erneut bestätigt hätten, daß sie „für die Folgen der Tat voll verantwortlich ge-

Entscheidung über Webers Bewährungsfrist bis zur Klärung des Verdachts auf Fortsetzung der verbotenen Organisation „Oberland“ ausgesetzt wurde; Pöhner war nicht betroffen, da er seine Strafverbüßung wegen Haftunfähigkeit überhaupt erst am 5.1.25 antrat (er wurde am 1.4.25 mit Bewährung entlassen). Der Strafkammer stand nicht Neithardt vor, wie Schwend, a.a.O., S. 293, meint, sondern der stellv. LGDir. L.; s. dazu auch die Meldung in den Münchner Neuesten Nachrichten v. 29.9.24, S. 1, daß kein Richter des ehemaligen Volksgerichts an der Beschlußfassung des LGs mitgewirkt habe.

171 Vgl. Niederschr. der Ministerratssitzung v. 27.9.24 (BayerHStArch., Sign. MA 99519).

172 Vgl. $§ 14$ der Bekanntmachung über Begnadigung, Strafaufschub, Änderung des Straforts, beschränkte Auskunft aus dem Strafregister und Tilgung von Strafvermerken v. 14.6.24 (JMBI., S. 89), die verschiedene Paragraphen der entsprechenden Bekanntmachung v. 5.3.22 (s. Anm. 169) änderte und ergänzte: „Eine Bewährungsfrist darf nicht bewilligt werden, wenn die allgemeinen Interessen ... entgegenstehen.“ 
macht werden müssen, und zwar in noch weiterem Umfange als das erkennende Gericht es angenommen hat“. ${ }^{173}$ Auch diese späteren Feststellungen könnten nach den vorliegenden Bestimmungen eine Verweigerung der Bewährungsfrist begründen. ${ }^{174}$ Die Staatsanwaltschaft beantragte daher, den Verurteilten eine Bewährungsfrist zu verweigern bzw. im Falle des Urteils gegen Hitler von 1922 zu widerrufen. Für den Fall aber, daß sich das Beschwerdegericht zu einer Ablehnung der Bewährungsfrist nicht entschließn konnte, stellte sie vorsorglich den weiteren Antrag, dann wenigstens „die Entscheidung auch gegenüber Hitler und Kriebel bis zur genügenden Klärung des Sachverhalts“ im Frontbann-Verfahren auszusetzen. ${ }^{175} \mathrm{Da}$ die Beschwerde aufschiebende Wirkung hatte, mußten die Verurteilten dann auf alle Fälle weiter in Haft bleiben.

Der 2. Strafsenat des Obersten Landesgerichts beschied die Beschwerde durch seinen Beschluß vom 6. Oktober 1924. Entgegen der Äußerung des Volksgerichts vom 22. April und der Strafkammer des Landgerichts vom 25. September 1924 vertrat der Senat nunmehr den Standpunkt, daß das erkennende Volksgericht mit seinem Beschluß vom 1. April 1924 Hitler und den anderen betroffenen Haupttätern schon definitiv „eine Bewährungsfrist für den Fall guter Führung während der Strafvollstreckung bewilligt" habe (!). Er begründete diese Feststellung damit, daß das Volksgericht in seinen Urteilsgründen „eingehend die zugunsten der Verurteilten sprechenden Umstände“ angeführt habe, „aus denen ,das Gericht die Bewilligung von Bewährungsfristen in dem Umfang für angezeigt erachtet' hat, ,wie er aus dem mit dem Urteil verkündeten Beschluß ersichtlich ist"“. Somit habe das Oberste Landesgericht nunmehr ausschließlich zu prüfen, „ob die Verurteilten durch ihr Verhalten nach der Verurteilung und während des Strafvollzugs die Erwartung rechtfertigen, daß sie sich auch ohne die volle Vollstreckung der Strafe künftig wohl verhalten werden“. Die Entscheidung darüber müsse aber auf unbestimmte Zeit verschoben werden, bis das Strafverfahren gegen Oswald u.a. (Frontbann) eine hinreichende Klärung des von der Staatsanwaltschaft angenommenen Verdachts strafbarer Handlungen der Verurteilten erbracht habe. Daher werde der Antrag der Staatsanwaltschaft verworfen, Hitler und den anderen Betroffenen die Bewährungsfrist ,im gegenwärtigen Zeitpunkt zu versagen und jetzt die Bewährungsfrist zu widerrufen", die Hitler bezüglich seiner Strafe von 1922 bewilligt worden war. Die Entscheidung hinsichtlich Hitlers und Kriebels bleibe vielmehr auf unbestimmte Zeit ausgesetzt, bis sie aufgrund sicherer Anhaltspunkte möglich sein werde; der Senat werde sich zu diesem Zwecke von der zuständigen Strafverfolgungsbehörde in zeitlichen Abständen Auskünfte einholen. ${ }^{176}$ Dieser Auf-

${ }^{173}$ Die Zitate entstammen dem vom II.StA Ehard paraphierten Entw. eines Schr. des I. StA beim LG München I an den OStA beim OLG München v. 5.12.24 (StArch. München, Sign. Staatsanwaltschaften 3099), das den Inhalt der Beschwerde v. 29.9.24 wiedergibt (a.a.O., Sign. Staatsanwaltschaften 14344). Die den Hitlerprozeß betreffenden Vorgänge wurden nach 1933 durch die Parteiführung angefordert und 1945 vernichtet. Sie sind deshalb bis auf Bruchstücke in den Aktenbeständen der bayerischen Justiz, die im BayerHStArch. und im StArch. München verwahrt werden, nicht mehr enthalten. Wie aus den Anm. zu vorliegender Arbeit hervorgeht, mußten sie anderen Provenienzen entnommen werden.

174 Laut $\S 18$ der Bekanntmachung v. 5.3.22 (s. Anm. 169) konnte die Bewilligung einer Bewährungsfrist wicder aufgehoben werden, ,wenn dem Gericht nachträglich Tatsachen bekannt werden, die ... es von der Bewilligung einer Bewährungsfrist abgehalten hätten“.

175 Aus der Beschw. zit. im Beschl. des BayerObLG. v. 6.10.24 (s. folgende Anm.).

176 Beschl. des BayerObLG v. 6.10.24 (StArch. München, Sign. Staatsanwaltschaften 14344) als Abschrift aus dem "Völkischen Kurier" v. 10.10.24 enthalten in den Spruchkammerakten Neithardt (StArch. München), dazu Chronik der Bayerischen Justizverwaltung, a.a.O., Eintr. v. 6.10.24. 
schub kam zugleich der wohl als notwendig angesehenen Einhaltung einer „Anstandsfrist“ für Hitlers Entlassung entgegen. Rund drei Monate später, am 19. Dezember 1924, wies das Oberste Landesgericht die Beschwerde der Staatsanwaltschaft gegen den Beschluß des Landgerichts München I endgültig zurück und setzte damit Hitler nebst Kriebel auf freien Fuß. ${ }^{177}$ In einer Unterredung mit dem Entlassenen, die durch die Vermittlung Helds zustande kam, lehnte Gürtner die Forderung Hitlers ab, auch $\mathrm{He} ß$ und andere seiner Mithäftlinge freizulassen. ${ }^{177 a}$

Die Kritik, die Gürtner eine Einwirkung zugunsten Hitlers in der Bewährungsfrage zuschreibt, richtet sich auf die von ihm verantwortete Zurücknahme der ersten staatsanwaltschaftlichen Beschwerde vom 15. April 1924. Denn das Bayerische Oberste Landesgericht hatte in seinem endgültigen Entscheid vom Dezember den Standpunkt vertreten, daß der Beschluß des Volksgerichts vom 1. April 1924 über die Inaussichtstellung einer Bewährungsfrist nach Ablauf von sechs Monaten eine zeitlich befristete Zubilligung der Bewährungsfrist darstelle, die durch die Zurückziehung der erwähnten Beschwerde rechtskräftig und unanfechtbar geworden sei. Deshalb habe das Oberste Landesgericht gar keine rechtliche Möglichkeit mehr gehabt, die Frage nachzuprüfen, ob die vom Volksgericht ausgesprochene Inaussichtnahme der Bewährungsfrist überhaupt rechtlich zulässig gewesen sei, sondern habe nur noch Hitlers Verhalten nach der Verurteilung prüfen können. Es wurde bereits dargelegt, daß Gürtner die $\mathrm{Zu}$ rücknahme rechtlich damit begründen konnte, daß ein Beschluß auf bloße Inaussichtnahme einer Bewährungsfrist - das Volksgericht selbst hatte ja auf Nachfrage bestätigt, daß durch seinen Beschluß noch keine Bewilligung einer Bewährungsfrist vorlag durch die Beschwerde nicht anfechtbar war. Die Überlegung, Gürtner habe diesen formalen Grund nur vorgeschoben, weil er die rechtlichen Folgen einer Zurückziehung - d.h. die später dadurch unvermeidbar werdende Bewilligung der Bewährungsfrist für Hitler - vorausgesehen habe, ist nach dem geschilderten komplizierten Verlauf der Angelegenheit abzulehnen. Gürtner hatte zwar auf die Staatsanwaltschaft, nicht aber auf die beteiligten Gerichte unmittelbaren Einfluß. Hätte Gürtner, wie es z. B. Hoegner nachträglich für richtig hielt, die Beschwerde aufrechterhalten, um „unter allen Umständen" eine Entscheidung des Obersten Landesgerichts in der Frage der rechtlichen Zulässigkeit einer Inaussichtstellung von Bewährungsfrist herbeizuführen ${ }^{178}$, so konnte er keineswegs voraussehen, ob sich das Beschwerdegericht nicht mit dem erwähnten formalen Grund seiner Unzuständigkeit für eine Entscheidung dieser Frage aus der Affäre ziehen ${ }^{179}$ oder aber sogar eine Entscheidung zugunsten der Verurteilten fällen würde, wie es das später getan hat. Geht man aber davon aus, daß Gürtner schon jetzt mit einer für Hitler günstigen Entscheidung des Obersten Landesgerichts rechnen konnte, dann hätte er im Gegenteil die Beschwerde getrost aufrechterhalten kön-

177 Zum Beschl. des BayerObLG v. 19.12.24 vgl. die halbamtl. Mitteilung in der Chronik, a.a.O., Eintr. v. 20.12.24. Der Wortlaut des Beschlusses ist laut Auskunft des BayerHStArch. nicht mehr nachweisbar, da die Akten des Bayer. Obersten Landesgerichts 1945 vernichtet wurden.

177a Vgl. die Wiedergabe des Gesprächs durch Hitler mit entsprechenden Bemerkungen über den "Juristen“ Gürtner im nächtlichen Monolog v. 3./4.2.42 (Adolf Hitler. Monologe, a.a.O. [voranstehende Anm. 165], S. 261). Die Unterredung ist in den Mitteilungen der Vereinigten Vaterländischen Verbände Bayerns v. 1.1.25 erwähnt (BayerHStArch., Sign. Bayern und Reich, Bd. 11/1).

178 Vgl. W. Hoegner, Die bayerische Justiz vor dem Untersuchungsausschuß (Die Justiz, Bd.III, 1927/28, S. 318 f.); ders. im Untersuchungsausschuß des bayer. Landtages von 1927 (Niederschr. der Verhandlungen, BayerHStArch., Sign. MA 103476/3, Bl.1567ff.).

179 Vgl. die in der Ministerratssitzung v. 12.4.24 geäußerten Befürchtungen Gürtners (voranstehend S.41). 
nen, falls er wirklich Hitler zu einer baldigen Bewährungsfrist hätte verhelfen wollen. Hoegners Feststellung: „Die Beschwerde des Staatsanwalts gegen diese unerhörte Begünstigung von Staatsverbrechern wurde auf Veranlassung des bayerischen Justizministers Gürtner zurückgezogen, so daß Hitler nach kaum einjähriger ... Festungshaft wieder in Freiheit kam “180, ist in dieser Verkürzung zumindest irreführend, da sie die zweite Beschwerde der Staatsanwaltschaft und die Entscheide der von Gürtner unabhängigen Gerichte unberücksichtigt läßt. Die geschilderten Vorgänge lassen vielmehr die Deutung zu, daß Gürtner durch die Handhabung der staatsanwaltschaftlichen Beschwerden eine Bewilligung der Bewährungsfrist für Hitler, die bei der mehrfach an den Tag gelegten Einstellung der bayerischen Gerichte geradezu unvermeidbar war, aus politischen Gründen hinauszögern wollte: Die Rücknahme der ersten Beschwerde im April sollte eine zu früh erzwungene Entscheidung des Obersten Landesgerichts in dieser Richtung vermeiden, die in der noch nicht abgeklungenen, erregten Atmosphäre nur zu erneuten Angriffen auf die bayerische Justiz geführt und die Bildung der neuen Koalitionsregierung nach den Landtagswahlen vom 6. April erschwert hätte, bei der die Deutschnationalen Gürtner gegen den Wunsch der Bayerischen Volkspartei wiederum als Justizminister durchzusetzen trachteten. ${ }^{181}$ Der in der zweiten Beschwerde vom September enthaltene Antrag, die Entscheidung bis zur Klärung des Verdachts einer erneuten Beteiligung Hitlers an strafbaren Handlungen auszusetzen, sollte dem Obersten Landesgericht für seine Entscheidung einen gewissen zeitlichen Spielraum gewähren. Gürtners Wunsch nach Aufschub war justizpolitisch und innenpolitisch begründet: Einmal handelte es sich bei Hitler schließlich um eine wegen Hochverrats verhängte Strafe, die trotz aller Berücksichtigung des „nationalen“ Tatmotivs aus Gründen der Autorität staatlicher Strafjustiz und der Prävention nicht durch einen extremen Verzicht auf ihren Vollzug entwertet werden sollte. Zum anderen: Wenngleich Gürtner in Hitler keine Gefahr für den Staat mehr sah - seine Einstellung zum Redeverbot gegen Hitler im Frühjahr 1925 zeigt das deutlich -, so war ihm doch daran gelegen, dessen vorzeitige Haftentlassung nicht in die Zeit der notwendigen Beruhigung der innenpolitischen Atmosphäre und der Normalisierung des Verhältnisses Bayerns zum Reich fallen zu lassen, die sich unter der Regierung Held anbahnten und vollzogen. ${ }^{182}$ Nachdem die Völkischen zwar in den Aprilwahlen zunächst Erfolge erzielt, aber seit Jahresmitte in der bayerischen Bevölkerung ständig an Resonanz verloren und in den Reichstagswahlen vom 7. Dezember 1924 in Bayern schließlich eine Niederlage erlitten hatten, war die Weihnachtszeit für die Haftentlassung Hitlers wesentlich günstiger, zumal sie durch die gleichzeitige Entlassung $\mathrm{Fe}$ chenbachs und verurteilter Räterepublikaner ausgeglichen werden konnte. Auch in der Frage der Bewährungsfrist für Hitler hatte Gürtner somit Ziele der „Staatsraison“ durchgesetzt, ohne das formale Recht zu verletzen.

Es bleibt festzuhalten: Daß Hitler in seinem Hochverratsprozeß von 1924 so günstig wegkam, ist - soweit heute nachweisbar - keinen speziellen Einwirkungen Gürt-

$180 \mathrm{Vgl}$. W. Hoegner, Die Verratene Republik. Deutsche Geschichte 1919-1933, München 1979, S. 190.

181 Zur Bildung der Reg. Held vgl. Schwend, a.a.O., S. $264 \mathrm{ff}$.

182 Vgl. Gürtners Äußerung zu Moser v. Filseck v. 6.11.24: „Wenn er etwas dazu tun könnte, so würde er dafür sorgen, daß der Prozeß gegen den Frontbann nicht vor dem 7. Dezember zur Verhandlung käme, daß Hitler wenigstens noch über die Wahlen in Haft bleiben müsse“ (Politik in Bayern 1919-1933 [s. Anm. 36], S. 167). 
ners zu seinen Gunsten, sondern der allgemeinen Haltung der damaligen bayerischen Justiz zuzuschreiben. Nicht Gürtner, sondern die Richter des Münchner Volksgerichts, des Landgerichts und des Obersten Landesgerichts haben Hitler milde beurteilt bzw. für seine vorzeitige Entlassung aus der Festungshaft gesorgt. Allerdings kann Gürtner für diese Einstellung der Justiz insoweit verantwortlich gemacht werden, als er sie nach seinem Amtsantritt 1922 nicht zu ändern versucht, sondern im Gegenteil mehrmals vor dem Landtag als „unpolitisch“ und „unparteiisch“ verteidigt hatte.

\section{Bayerischer Justizminister in den beiden Kabinetten Held bis Juni 1932}

Daß Gürtner im Juni 1924 trotz erheblicher Angriffe auf seine Justizpolitik seitens der Bayerischen Volkspartei (BVP) im Kabinett Held wieder Justizminister geworden war, verdankte er der Situation nach den Landtagswahlen vom 6. April, die den Koalitionsparteien zugunsten des "Völkischen Blocks" erhebliche Stimmeneinbußen gebracht hatten. Da die BVP bei der Regierungsbildung dringend auf die Bayerische Mittelpartei angewiesen war - die von Held vertretene national-konservative bayerische Politik verbot eine Koalition mit den Völkischen oder den Sozialdemokraten -, konnten die Deutschnationalen die abermalige Aufnahme Gürtners ins Kabinett durchsetzen. Gürtners Partei, die sich von nun an wie im Reich „Deutschnationale Volkspartei“ (DNVP) nannte, schlug jetzt einen radikaleren Kurs ein, um nicht noch mehr politisches Terrain an die Völkischen zu verlieren: so bestand sie z. B. darauf, daß Schweyer als Innenminister aus der Regierung ausschied, der sich durch sein entschiedenes Vorgehen gegen die radikalen vaterländischen Verbände bei den Völkischen verhaßt gemacht hatte. Auch das Regierungsprogramm wies deutliche Züge deutschnationaler Politik auf und kam damit auch Gürtners persönlichen Vorstellungen entgegen: Einerseits sollten illegale Einflußnahmen radikaler Verbände auf die Regierung künftig verhindert und gewaltsame Eingriffe in die Verfassung durch die Staatsgewalt unterdrückt werden, andererseits sollte die Regierung ,jede auf die Staatserhaltung und Staatskräftigung abzielende vaterländische Bewegung und Organisation hegen und fördern, gleichzeitig aber darüber wachen, daß die vaterländische Bewegung und ihre Organisation nicht parteipolitischen oder engherzigen persönlichen und materiellen Eigenzwecken verfallen". ${ }^{183}$

In den beiden Kabinetten Held sollte Gürtner als Beauftragter seiner Partei - von deren inneren Rivalitäts- und Richtungskämpfen er sich als „unpolitischer" Fachminister weitgehend fernhielt - bis zu seiner Berufung zum Reichsjustizminister im Juni 1932 wirken. Ein tragendes Element der Zusammenarbeit Gürtners mit der BVP - mit der er wegen der Haltung gegenüber der extremen Rechten häufiger Differenzen hatte - war das Ziel der Regierung Held, einer weiteren Aushöhlung der bayerischen Eigenstaatlichkeit durch die Reichsregierung vorzubeugen und zu diesem Zweck eine legale Revision der Reichsverfassung zur Wiederherstellung des Föderalismus zu erreichen. Mit seinem Eintreten für die föderalistische Gestaltung des

183 Schwend, a.a.O., S. 270. 
Reichs ${ }^{184}$ gegen die unitarischen Tendenzen der Sozialdemokraten, Demokraten und des linken Zentrumsflügels wollte Gürtner zugleich der Forderung nach „Verreichlichung“ der Justiz entgegenwirken, die vor allem seit 1928 in Juristenkreisen verstärkt erhoben wurde. ${ }^{185}$ Es erscheint widersprüchlich und als Ausdruck einer opportunistischen Haltung, daß Gürtner die Übernahme der Justizverwaltung durch das Reich ablehnte, die er nach 1933 mit organisatorischem Geschick und innerem Engagement durchführte, war aber von seiner politischen Einstellung her nur folgerichtig: solange in Berlin eine von dauernd wechselnden Parlamentsmehrheiten abhängige und damit sozialdemokratischen und linksliberalen Einwirkungen ausgesetzte Reichsregierung saß, sollte die seit 1920 unter deutschnationaler Leitung stehende bayerische Justiz gegen diese Einflüsse abgeschirmt werden. Auch seine Haltung als Reichsjustizminister zu v. Papens „Preußenschlag“ im Jahre 1932 deutet darauf hin, daß Gürtner eine einheitliche, starke Reichsgewalt mit einer autoritär organisierten, national-konservativen Regierung im Grunde als ideal ansah. Während der Föderalismus für seinen Koalitionspartner BVP zu den unverrückbaren Grundsätzen gehörte, vertrat Gürtner die föderalistische Position nur aus taktischen Gründen. In seinen Stellungnahmen als bayerischer Justizminister befürwortete er daher die „Verreichlichung“ der Justiz zwar nicht, lehnte aber eine reichseinheitliche Justizverwaltung nie aus grundsätzlichen Erwägungen ab. So führte er 1927 im Haushaltsausschuß des Landtages aus, daß „überzeugende Gründe für die Zentralisierung“ der Justizverwaltung gegenwärtig kaum vorgebracht werden könnten und das Thema daher „besser unerörtert“ bleibe, weil „das deutsche Volk augenblicklich eine innere Ruhe und Stärkung“ brauche. ${ }^{186} \mathrm{Nach}$ dem das Problem mehrfach öffentlich erörtert und von der sozialdemokratischen Opposition bei den Beratungen des bayerischen Justizhaushaltes im Februar 1929 abermals aufgeworfen worden war, nahm Gürtner bei dieser Gelegenheit im Landtag dazu ausführlicher Stellung: Für die Anwendung des Rechts, d.h. die Rechtsprechung sei es völlig gleichgültig, ob sie von Gerichten des Reichs oder der Länder ausgeübt werde allerdings unter der Voraussetzung, daß „die verfassungsmäßigen Garantien für die richterliche Unabhängigkeit bestehen“ blieben. Bei der Justizgesetzgebung, für die hinsichtlich des materiellen und des Verfahrensrechts ohnehin schon das Reich zuständig sei, sei an der Verzögerung grundlegender Gesetzgebungswerke nicht - wie die Zentralisten meinten - die Mitwirkung der Landesjustizverwaltungen schuld; gerade auf diesem Gebiet sei die Zusammenarbeit zwischen der Reichsregierung und den Landesregierungen „eine außerordentlich enge und vertrauensvolle“. Die Verzögerung ergebe sich vielmehr aus der „dauernden Unstetigkeit“ der Reichsregierung: es sei einfach unmöglich, „daß ein Reichsjustizministerium zu einer umfassenden, abschließenden und durchgreifenden Arbeit überhaupt kommen“ könne, wenn es „ungefähr jedes

${ }^{184}$ Vgl. dazu Gürtners Aufsatz: Einheitsstaat oder Bundesstaat? Zur Rechtsfrage (in: Dem bayerischen Volke, herausg. von G. J. Wolf, München 1930, S.400 ff.), in dem er die Möglichkeit verneinte, das Reich über den Änderungsartikel 76 der RV zum Einheitsstaat umzugestalten, ohne die Identität der Weimarer Verf. zu beseitigen, aber gleichzeitig betonte, daß „eine politische Beurteilung der Bestrebungen, die den Einheitsstaat zum Ziele haben, ... nicht im Rahmen dieser Betrachtung“ liege; sie dürften nur nicht unter "Vergewaltigung des Rechtes" verwirklicht werden.

185 Vgl. Kapitel II.1., S.85.

186 Vgl. mündl. Ber. des Ausschußberichterstatters Rutz in der Sitzung des Bayer. Landtags v. 2.7.27 (Verhandlungen des Bayerischen Landtags 1926/27, Sten. Berichte, Bd.VI, S.997) und Gürtners Wiederholung seiner Ausführungen in der Sitzung v. 21.2.29 (s. folgende Anm. 189). 
Jahr seinen Chef wechselt“, und dazu jedesmal „auch ein Wechsel der grundlegenden Anschauungen“" stattfinde. Unausgesprochen stand hinter dieser Feststellung die Ansicht, daß die Justizgesetzgebung sehr wohl in der Hand der Reichsregierung konzentriert werden könne, wenn es sich um eine vom Parlament unabhängige, d.h. autoritäre - selbstverständlich gleichbleibend „nationale“ - Regierung handelte, die zur Verwirklichung längst fälliger Reformen fähig war - ein „Idealzustand“, wie er 1933 nach dem Ermächtigungsgesetz gegeben zu sein schien.

Bei der Justizverwaltung im engeren Sinn führte Gürtner einige Argumente gegen die „Verreichlichung“ ins Feld ${ }^{187}$ : Sie würde die Entfernung zwischen Justizverwaltung und Parlament sowie der Bevölkerung vergrößern und „die liebevolle Kleinarbeit, die bei der Kontrolle der Justizverwaltung jährlich im Landtage“ geleistet werde, unmöglich machen; ob Gürtner diese detaillierte, meist mit Kritik verbundene Kontrolle tatsächlich so begehrenswert fand, sei dahingestellt. Abzulehnen sei auch das Argument, daß die Übernahme durch das Reich die Justizverwaltung verbillige. Wie der fast alljährlich im Haushaltsausschuß vorgenommene Vergleich zwischen Preußen und Bayern zeige, würden die relativen Kosten mit zunehmender Größe des Rechtsgebiets keineswegs geringer; die „Verreichlichung“ sei also kein wirtschaftliches Problem. Auch die anderen Argumente, die für die reichseinheitliche Justizverwaltung ins Feld geführt wurden - Vermeidung von Kompetenzstreitigkeiten, bessere Bezirkseinteilung über die Landesgrenzen hinweg, einheitliches Ausbildungs-, Beurkundungs-, Gebührenwesen usw. -, tat Gürtner als „untergeordnete Fragen“ betreffend und als nicht stichhaltig ab. Im Gegensatz zum Sprecher der Deutschnationalen, dem Landtagsabgeordneten Lent, der bei der Übernahme der Personalverwaltung durch das Reich eine „Politisierung“ der bayerischen Justiz voraussah ${ }^{188}$, meinte Gürtner, daß die Gefahr der Einflußnahme der Parteien auf die Personalpolitik bei einer Reichsjustizverwaltung oder einer Landesjustizverwaltung in gleicher Weise gegeben sei; „die Überlieferung der Justiz an die Parteien“, die „das Ende der Justiz“ bedeute, könne nur verhindert werden, wenn sie ,auch von den Parteien in weiser Selbstbeschränkung und wohlverstandenem Interesse nicht gewünscht und nicht betrieben" werde. Eine wirksamere Garantie als ein solcher Appell an die „Selbstbeschränkung“ der Parteien dürfte nach Gürtners Staatsauffassung die grundsätzliche Ausschaltung ihres Einflusses auf den Staatsapparat, d.h. die Beseitigung der parlamentarischen Regierungsform dargestellt haben; die Gefahr, daß einmal eine monopolisierte Staatspartei einen unsachlichen Einfluß auf die Personalpolitik der Justiz ausüben könnte, war 1929 noch nicht vorauszusehen.

Entscheidend für Gürtners Einstellung zur Übernahme der Justiz durch das Reich aber war, daß sie für ihn „eine rein politische Frage“ darstellte: wer den Einheitsstaat wolle, führte er im Landtag aus, brauche die Forderung nach Verreichlichung der Justiz gar nicht weiter zu begründen, da die Justiz nun einmal ein wesentlicher Bestand-

187 Ebenso hatte schon der Ref. für die Reichsreform in Helds StM des Äußern, MinRat Karl Sommer, in einem Artikel „Verreichlichung der Justiz“ argumentiert, der Anfang September 1928 in der Leipziger Zeitschrift für Deutsches Recht (1928, S.1159ff.) erschien und in dem allen für die Verreichlichung vorgebrachten Gründen im einzelnen widersprochen wurde.

${ }^{188} \mathrm{Zu}$ Lents Ausführungen vgl. Verhandlungen des Bayerischen Landtags 1928/29, 23. Sitzung vom 21.2. 29, Sten. Berichte, Bd. I, S.692. 
teil der Staatsgewalt sei. ${ }^{189}$ Damit machte Gürtner unmißverständlich klar, daß alle auch von ihm vorgebrachten - Gegenargumente sachlicher und wirtschaftlicher Art eine untergeordnete Rolle spielen würden, falls die Umstände einmal eine Entscheidung für die Umgestaltung des Reichs zum Einheitsstaat erfordern würden.

Während Gürtner bei der gegebenen politischen Konstellation im Reich mit den Koalitionspartnern in der Verteidigung des bayerischen Föderalismus gut zusammenarbeitete $^{190}$, kam es in der Frage der Haltung der Regierung gegenüber Hitler und den Nationalsozialisten zu Meinungsverschiedenheiten. Der Grund, weshalb Gürtner im Kabinett verschiedentlich als deren Fürsprecher auftrat, war gewiß nicht eine besondere Sympathie für Hitler ${ }^{191}$, sondern vielmehr die bei den Deutschnationalen vorherrschende Vorstellung, daß allen gegen links wirkenden „wertvollen“ vaterländischen Kräften freie Betätigung gewährt werden müsse. Als im Januar 1925 im Kabinett die teilweise Aufhebung des Ausnahmezustandes zur Sprache kam, befürwortete Gürtner die Wiederzulassung jener verbotenen Organisationen, die das Ziel verfolgten, „den vaterländischen Geist zu wahren und zu fördern“, verlangte aber die Beibehaltung des Verbots für die KPD. Da Held diese einseitige Regelung ablehnte, weil sie geradezu „wie eine besondere Empfehlung“ der NSDAP in der Öffentlichkeit wirken müsse ${ }^{192}$, wurde im Februar das Verbot für beide Parteien, den Bund „Oberland“ u.a. Verbände aufgehoben, aber grundsätzlich für Versammlungen, Umzüge, Flugblätter usw. eine Genehmigungspflicht aufrechterhalten. Bereits nach seiner ersten öffentlichen Rede, die Hitler am 27. Februar 1925 - am Tage nach der Neugründung der NSDAP - im Bürgerbräukeller hielt, verbot die Münchner Polizeidirektion alle fünf seiner für den 10. März geplanten Massenversammlungen, weil nach Ansicht Innenminister Stützels (BVP) Hitlers „ganze Art und seine Grundeinstellung die gleiche geblieben" waren und insbesondere durch die Wirkung seiner Ausführungen auf die $\mathrm{Zu}$ hörer „eine Gefährdung der Staatssicherheit“ gegeben sei. ${ }^{193}$ Darüber hinaus erhielt Hitler auf unbestimmte Zeit ein für ganz Bayern geltendes Redeverbot, das erst im März 1927 wieder aufgehoben werden sollte. Auch diese Maßnahmen stießen bei Gürtner auf kein Verständnis: er hielt es für falsch, Hitler „alle fünf Versammlungen zu verbieten, anstatt ihm wenigstens eine zu erlauben“; denn „den Kommunisten müsse man jetzt doch auch Versammlungen gestatten“.194 Dieselbe Begründung

${ }^{189}$ Vgl. Gürtners Ausführungen in derselben Sitzung, a.a.O., S.681 ff.; zum letzten Satz s. das ausführliche Zitat im Kapitel II.1., S.85.

190 Über Gürtners Mitwirkung an den bayer. Regierungsdenkschriften von 1924 und 1926 zur Erhaltung der Eigenstaatlichkeit der Länder vgl. Reitter, a.a.O., S. $79 \mathrm{ff}$.

191 Vgl. Gürtners Ausführungen gegenüber dem württemb. Gesandten Moser v. Filseck v. 14.3.25: „Wenn man sich frage, ob Hitler irgendeinen Nutzen bringe oder gebracht habe, so müsse man das rundweg in Abrede stellen. Den marxistischen Parteien habe er keinen ernsthaften Abbruch getan, sie dagegen gelehrt, wie man es machen müsse ... Außerdem habe er nicht nur die Entwicklung in Bayern gestört, sondern dasselbe auch dem Ausland gegenüber in Mißkredit gebracht und verdächtig gemacht" (Politik in Bayern 1919-1933 [s. Anm. 36], S. 174); ferner seine Äußerung im Ministerrat am 10.11.23: „ein Mann, der so auftrete wie Hitler [im Bürgerbräukeller am 8.11.23], könne nicht erwarten, daß er wie ein Gentleman behandelt werde“ (Niederschr. der Ministerratssitzung, BayerHStArch., Sign. MA 99518).

192 Vgl. Niederschr. der Ministerratssitzung vom 23.1.25 (a.a.O., Sign. MA 99519).

193 Vgl. die Ausführungen Stützels im bayer. Landtag v. 17.3.25 (Verhandlungen des Bayerischen Landtags 1924/25, Sten. Berichte, Bd. II, S. 557 f., auch abgedruckt in: Ursachen und Folgen. Vom deutschen Zusammenbruch 1918 und 1945 bis zur staatlichen Neuordnung Deutschlands in der Gegenwart, herausg. von $\mathrm{H}$. Michaelis und E. Schraepler unter Mitwirkung von G. Scheel, Berlin o.J., S.464f.).

194 Vgl. Moser v. Filseck, a.a.O. (voranstehende Anm. 191). 
brachte Gürtner vor, als er im April bei der Reichspräsidentenwahl im Kabinett abermals forderte, das Redeverbot gegen Hitler aufzuheben: „Es gefalle ihm politisch nicht, daß Hitler in der Woche vor der Reichspräsidentenwahl, während die Kommunisten die gefährlichsten Redner auftreten lassen könnten, nicht einmal in einer einzigen Versammlung mit allen Kautelen auftreten dürfe." Wiederum konnte sich Gürtner gegen seine Koalitionspartner in der Regierung nicht durchsetzen, die die Aufhebung des Redeverbots als eine rein polizeiliche Angelegenheit ansahen und die Gefahr ihres Mißbrauchs durch Hitler hervorhoben. ${ }^{195}$

Gürtner wegen dieser Aktivitäten, die seinen ,nationalen“ Motiven und dem Auftrag der bayerischen DNVP entsprangen, als „Schutzherrn“ der Hitlerbewegung in Bayern anzusehen und eine Mitschuld an der Aufrichtung der nationalsozialistischen Gewaltherrschaft zu geben, ist historisch nicht haltbar. Diese reichlich überdehnte Kausalkette wird allein schon durch die Tatsache unterbrochen, daß Gürtner mit seinen Forderungen im Kabinett nicht durchdrang und das Interesse an der nationalsozialistischen Bewegung in Bayern durch Hitlers Redeverbot so stark absank, daß sich das Schwergewicht der Aktivität Hitlers und seiner Partei in der Folgezeit in andere Teile des Reichs verlagerte. Aber auch von der Intention her wollte Gürtner 1925 alles andere als ausgerechnet dem Winkelpolitiker Hitler zur Diktatur im Reich zu verhelfen: noch waren die späteren Ereignisse von niemandem vorauszusehen.

Gürtners Stellung im Kabinett blieb auch nach den Landtagswahlen vom Mai 1928 - bei denen die Koalitionsparteien verhältnismäßig gut abschnitten und die Nationalsozialisten erheblich verloren - gesichert, da Held in der BVP die Fortführung seines national-konservativen Kurses durchsetzen konnte. ${ }^{196}$ Jedoch verschlechterte sich Gürtners Position in den folgenden Jahren sichtlich, so daß ihm seine Berufung nach Berlin im Juni 1932 nicht ungelegen gekommen sein dürfte. Einmal ging der Einfluß seiner eigenen Partei in Bayern bis zur Bedeutungslosigkeit verloren, nachdem der Vorsitzende Hilpert in innerparteilichen Kämpfen die Unterstützung der Politik Hugenbergs erreicht hatte, die in der Organisierung einer kompromißlosen „nationalen Opposition" aller vaterländischen Kräfte einschließlich der Nationalsozialisten gegen das "System“ von Weimar bestand und damit die Abspaltung der gemäßigten Gruppen aus der bayerischen DNVP bewirkte: in der Reichstagswahl vom September 1930 verlor die Partei in Bayern drei Viertel ihrer bisherigen Wähler, und in der Landtagswahl vom April 1932 sank die Zahl ihrer Mandate von dreizehn auf ganze drei herab. Auf Gürtners Verbleiben im Kabinett wirkte sich dieser katastrophale Schwund seiner parlamentarischen Basis nur deshalb nicht aus, weil die Regierung Held nach dem Austritt des Bayerischen Bauernbundes aus der Koalition seit 30. August 1930 ohnehin schon zurückgetreten und nur noch geschäftsführend im Amt war. Mit der Durchsetzung der Hugenbergrichtung in der DNVP - die sich im Juli 1929 mit der NSDAP in der „Harzburger Front“ gegen den Young-Plan zusammentat und damit Hitlers Partei beim nationalen Bürgertum generell „bündnisfähig“ machte - verstärkte

195 Vgl. Niederschr. der Ministerratssitzung vom 20.4.25 (BayerHStArch., Sign. MA 99519).

196 Vgl. auch zum folgenden Schwend, a.a.O., S. $373 \mathrm{ff}$.; Reitter, a.a.O., S. $92 \mathrm{ff}$. 
sich zum anderen die schon seit 1924 vorhandene ${ }^{197}$ Opposition innerhalb der BVP gegen Gürtner. Vor den Angriffen von dieser Seite konnte ihn Held, mit dem Gürtner persönlich befreundet war und mit dem er auch zusammen musizierte ${ }^{198}$, nicht mehr bewahren, seitdem 1929 Schäffer den Vorsitz in der Partei übernommen hatte. Während Schäffer im Gegensatz zu Held eine Koalition mit der SPD nicht von vornherein ablehnte, um wieder eine Regierung auf parlamentarischer Grundlage bilden zu können, bedrängte Hilpert den Ministerpräsidenten, die Nationalsozialisten in die Regierung hereinzunehmen und eine Koalition aus BVP, DNVP und NSDAP unter eventueller Beteiligung des Bayerischen Bauernbundes zu bilden. ${ }^{199} \mathrm{Wie}$ Gürtner zwischen den politisch immer weiter auseinanderdriftenden Parteien BVP und DNVP lavieren mußte, zeigen zwei Vorfälle im Sommer und Herbst 1931.

Als das Kabinett am 10. Juli ein bis Ende September befristetes Uniformverbot und gegen die Stimme Gürtners ein ebenso befristetes Aufzugsverbot beschloß, veröffentlichte die Parteiführung der Deutschnationalen drei Tage später in der „MünchenAugsburger Abendzeitung“ die Gegenargumente, die Gürtner im Ministerrat vorgebracht hatte ${ }^{200}$; sie wollte die Partei damit von der Verantwortung für diese Maßnahme vor der Öffentlichkeit entlasten. Das Sprachrohr der BVP, der „Bayerische Kurier“, stellte zu dieser Veröffentlichung fest, es sei zwar „vom Standpunkt der Deutschnationalen aus zu begreifen“, daß Gürtner in der Betätigung der Nationalsozialisten keine Gefahr für die öffentliche Sicherheit sehe - es habe ,ja auch vor dem November 1923 Leute gegeben, die trotz der dauernden Gefährdung der öffentlichen Sicherheit den Dingen ihren Lauf ließen" ${ }^{201}$-, kritisierte aber scharf den Bruch der Vertraulichkeit der Beratungen im Ministerrat durch die Veröffentlichung und sah die Zusammenarbeit im Kabinett dadurch „als endgültig beendet“ an. Dieser Schritt stelle eine „politische Kündigung der bisherigen Koalition“ durch die deutschnationale Parteiführung dar. ${ }^{202}$ Noch weiter ging die sozialdemokratische "Münchener Post“ vom 14. Juli, die durch die Veröffentlichung der Rechtsauffassung des Justizministers, daß die erlassene Anordnung für den Schutz der öffentlichen Sicherheit nicht notwendig sei, verhängnisvolle Rückwirkungen auf ihren Vollzug, auf die Verfolgung von Verstößen durch die Justizorgane, voraussah, die diesen Wink verstehen und „den ,nationalen`Unruhestiftern zu billigen Triumphen“ vor den Gerichten verhelfen würden. ${ }^{203}$

197 Vg. z. B. das Schr. Gürtners an Held v. 28.11.27, in dem er sich über die dauernden Angriffe durch das Organ der BVP, den „Bayerischen Kurier“, beschwerte und um parteioffizielle Gegenäußerung bat (BayerHStArch., Nachlaß Held 375). Neu belebt wurden diese Angriffe im März 1928, als der Untersuchungsausschuß des Landtags seinen Bericht über die Vorgänge vom Mai und November 1923 vorlegte und dabei Gürtners „Verschieben“ des Prozesses gegen Hitler wegen der Vorgänge am 1. Mai 1923 bekannt wurde (vgl. dazu voranstehend S. 30 und Anm.99).

198 Vgl. eidesstattl. Erklärung von Gürtners Schwager Dr. Friedrich Bretzfeld v. 20.5.47 (Spruchkammerakten Gürtner, StArch. München).

199 Vgl. Ber. des württemb. Gesandten Moser v. Filseck v. 9.9 .31 (Politik in Bayern 1919-1933 [s. Anm. 36], S. $247 \mathrm{f}$.).

200 Vgl. München-Augsburger Abendzeitung v. 13.7.31, wörtlich zit. in: Chronik der Bayerischen Justizverwaltung, a.a.O., Eintr. unter dem Datum der Regierungsanordnungen 10.7.31.

201 Vgl. Bayerischer Kurier v. 13.7.31 (wörtlich zit. a.a.O.).

202 Bayerischer Kurier v. 14.7.31 (wörtlich zit. a.a.O.).

${ }^{203}$ Vgl. Münchener Post Nr. 159 v. 14.7.31 (wörtlich zit. a.a.O.): „Die Staatsanwälte und Gerichte werden diesen Wink ihres Chefs mit dem Zaunpfahl deutlich verstehen“, die Verfahren einstellen oder zumindest "den Übeltätern Bewährungsfrist zubilligen“. Das JM als oberste Gnadeninstanz werde „eine besonders milde Praxis handhaben“. 
Sie forderte die BVP auf, Schritte zu unternehmen, um Gürtner aus dem Kabinett zu entfernen. ${ }^{204}$ Von seiner Partei gedrängt, wandte sich Held am 17. Juli mit einem Schreiben an Gürtner, daß „die Ausgabe eines öffentlichen Berichtes über die Vorgänge im Ministerrat ohne Einverständnis des Kollegiums selbst oder doch des Vorsitzenden" ungewöhnlich sei, weil er neben der Vertraulichkeit auch „die Einheit und Geschlossenheit der Staatsregierung nach außen in Frage" stelle. Er nehme deshalb an, daß Gürtner zwar den Parteivorstand der Deutschnationalen von seiner Haltung unterrichtet, mit der Veröffentlichung seiner Erklärung ,aber nichts zu tun“ habe. ${ }^{205} \mathrm{Da}-$ mit schien Gürtner vor die klare Entscheidung gestellt, sich entweder von seiner Partei zu distanzieren und damit für die Zukunft deren Unterstützung zu verlieren, oder aber aus dem Kabinett auszuscheiden, da er dessen Beschlüsse gegenüber seiner Partei nicht mehr verantworten und damit nicht mehr vollziehen konnte. Dennoch erreichte Gürtner einen Ausgleich. In seinem Antwortschreiben an Held führte er aus, daß ein im Kabinett überstimmter Minister entweder den Beschluß vorbehaltlos durchführen oder zurücktreten müsse. Letzteres hätte er im vorliegenden Falle auch getan, wenn es sich bei der gegenwärtigen Regierung noch um eine parlamentarisch verantwortliche Regierung gehandelt hätte. In einer nunmehr geschäftsführenden Regierung, die ihren Rücktritt als Gesamtheit bereits erklärt habe, könne ein einzelner Minister nicht mehr zurücktreten. Die Gründe, die die Parteiführung zu der umstrittenen Veröffentlichung veranlaßt hätten - die aber keinesfalls mit einer Rücksichtnahme auf die NSDAP zusammenhingen -, bat er in einer persönlichen Aussprache darlegen zu dürfen. ${ }^{206} \mathrm{Da}$ beide kein Interesse daran hatten, durch Gürtners Ausscheiden „der Regierung eine weitere Stütze zu entziehen und ihr damit noch weitere Schwierigkeiten zu bereiten"207, fand sich Held offensichtlich mit der unter vier Augen gegebenen Erklärung Gürtners ab: Gürtner blieb und wurde im Kabinett am 26. September bei der Verlängerung der Uniform- und Aufzugsverbote um ein halbes Jahr abermals überstimmt. Während er diesmal seine abweichende Haltung nicht öffentlich zu bekunden brauchte, war er im selben Monat in einer anderen Sache gezwungen, durch eine öffentliche Erklärung seiner Partei gegenüber zu manövrieren. Am 26. August hatte der Ministerrat eine Notverordnung zum Vollzug des Staatshaushalts erlassen, die zur Deckung des Defizits Steuererhöhungen, neue Abgaben und Sparmaßnahmen einführte. Als die deutschnationale Fraktion unter Hilpert beschloß, diesmal nicht nur eine distanzierende Verlautbarung abzugeben, sondern im Landtag einen Antrag auf Aufhebung dieser unpopulären Notverordnung einzubringen, stellte der „Bayerische Kurier" fest, daß die bayerische DNVP damit ihre Stillhaltepolitik gegenüber der geschäftsführenden Regierung aufkündige, in der ihr eigener - von ihr als „parteitreu“ bezeichneter - Minister dem Beschluß offensichtlich zugestimmt habe, da er diesmal keine gegenteilige Erklärung veröffentlicht habe. ${ }^{208}$ Darauf erwiderte die deutschna-

204 So schon in der Nr. 158 v. 13.7.31 (a.a.O.).

205 Vgl. Schr. Helds an Gürtner v. 17.7.31 (BayerHStArch., Sign. MA 102035).

$206 \mathrm{Vgl}$. Antwortschr. Gürtners an Held v. 20.7.31 (a.a.O.).

207 So in er Beurteilung des württembergischen Gesandten Moser v. Filseck, der ergänzend feststellt, er halte Gürtner „für viel zu anständig, um sich seinen Ministerposten nur für sich erhalten zu wollen“ (Politik in Bayern 1919-1933, a.a.O. [s. Anm.36], S.251).

${ }^{208}$ Vgl. Bayerischer Kurier Nr. 259 v. 16.9.31 (Wortlaut in Chronik der Bayerischen Justizverwaltung, a.a.O., Eintr. v. 16.-25.9.31). An der öffentlichen Auseinandersetzung beteiligten sich außer den im folgenden erwähnten Zeitungen die Bayerische Volkspartei-Korrespondenz, die überparteiliche Münchner Zeitung und die sozialdemokratische Münchener Post. 
tionale „München-Augsburger Abendzeitung“ triumphierend, daß Gürtner „an dem Beschluß des Ministerrats vom 26. August überhaupt nicht beteiligt“, sondern durch Staatsrat Schmitt aus dem Justizministerium vertreten gewesen sei. In der Tat weilte Gürtner im Sommerurlaub, wo er gerade an diesem Tage seinen 50. Geburtstag beging. ${ }^{209}$ Weiter meinte das Blatt, es sei im übrigen müßig, über die parlamentarische Verantwortung der einzelnen Ressortminister zu sprechen, da es in Bayern gegenwärtig keine parlamentarische Regierung gebe. ${ }^{210}$ Der „Bayerische Kurier“ entgegnete, wenn Gürtner auch an der formellen Beschlußfassung nicht beteiligt gewesen sei, so beweise das noch nicht, „daß er inhaltlich mit dem - doch naturgemäß reichlich vorbereiteten - Beschluß nicht einverstanden war“. Ferner könne der Landtag die geschäftsführende Regierung zwar nicht durch einen Mißtrauensantrag stürzen, dennoch trage sie dem Parlament gegenüber die politische Verantwortung, da der Landtag sonst unmöglich die Aufhebung von ihr erlassener Notverordnungen verlangen könne. Daraus folgerte der „Kurier“: Entweder sei die fragliche Notverordnung „ohne parlamentarische und politische Verantwortlichkeit erlassen“ - was außer der „München-Augsburger Abendzeitung" niemand annehme -, dann sei der Antrag der deutschnationalen Fraktion auf ihre Aufhebung „rechtlich und politisch unzulässig“. Oder der Antrag sei zulässig, dann beruhe die Notverordnung „auf einer politischen Entscheidung des Kabinetts, für die das Gesamtkabinett und daher auch der Herr Justizminister die volle politische Verantwortlichkeit besitzt“". ${ }^{21}$

Tatsächlich hatte sich in dieser Sache eine Kluft zwischen Gürtner und seiner Partei aufgetan $^{212}$, die aber nach außen hin zu verdecken gesucht wurde. Ihre Ursache wird durch eine Entschließung des Parteivorstandes deutlich, die besagte, daß allein „die Notverordnungspolitik der Regierung Brüning“ am gegenwärtigen „Wirtschafts- und Finanzzusammenbruch" schuld sei, und die den Antrag der Fraktion auf Aufhebung der bayerischen Notverordnung begrüßte, mit der lediglich „die verfehlten Mittel Brüningscher Politik in Bayern wiederholt werden" sollten. ${ }^{213}$ Während also die bayerische DNVP eine „unverantwortliche“ Oppositionspolitik à la Hugenberg betrieb, die eine einigermaßen geordnete Finanzwirtschaft in Bayern sabotierte, bekannte sich Gürtner nach der Rückkehr aus seinem Urlaub in einer Presseerklärung zu einer sachlichen und verantwortlichen bayerischen Staatspolitik. Er lehnte die billige Art und Weise ab, in der ihn das deutschnationale Blatt von seiner Verantwortung durch „Abwesenheit" bei der entscheidenden Kabinettssitzung zu entlasten suchte: „Die geschäftsführende Regierung des Landes hat die Verpflichtung, die ihr niemand abnehmen kann, die laufenden Geschäfte bis zur Bildung einer verfassungsmäßigen Regierung fortzuführen. Dazu gehört, daß der Staat für die Erfüllung seiner täglichen Verpflichtungen ... zahlungsfähig bleibt. Hierfür ist jedes Mitglied einer geschäftsführenden Regierung dem Staate und sich selbst gegenüber persönlich verantwortlich."

209 Gürtner verbrachte seinen Sommerurlaub in Ebersberg (Oberbayern), vgl. „Geburtstagsständchen für Herrn Justizminister Gürtner“, Grafinger Zeitung v. 29.8.31 (Zeitungsausschnitt im Nachlaß Gürtner).

210 Vgl. München-Augsburger Abendzeitung v. 16.9.31 (Wortlaut in der Chronik, a.a.O.).

211 Vgl. Bayerischer Kurier Nr. 260 v. 17.9.31 (Wortlaut a.a.O.).

212 Der Bayerische Kurier Nr.263 v. 20.9.31 lag mit seinem Artikel „Krach in der Bayerischen Deutschnationalen Partei“ (Wortlaut a.a.O.) allerdings insofern falsch, als es der besonnene Gürtner eben nicht zum „Krach" kommen ließ.

213 Wiedergegeben im Bayerischen Kurier Nr.262 v. 19.9.31 (a.a.O.). 
Daß er sich in dieser Frage seiner Partei gegenüber nicht als politisch verantwortlich ansah, drückte Gürtner mit folgenden Worten aus: „Solange Parteien das Recht nicht ausüben, eine verfassungsmäßige Regierung zu bilden, halten sie sich selbst $z$ war von der Verantwortung entlastet, sie begeben sich aber auch des Rechtes, Rechenschaft zu fordern." Dennoch war Gürtner zu besonnen, um es durch eine öffentliche Kritik an dem Schritt seiner Partei mit ihr zum offenen Bruch kommen zu lassen. Dabei ging er mit diplomatischem Geschick vor. Er erwähnte die vergeblichen Bemühungen der bayerischen Regierung, in den vorangegangenen Jahren den Staatshaushalt im Gleichgewicht zu halten, und betonte, „daß die öffentlichen Finanzen durch Erhöhung des Steuerdrucks nicht mehr nachhaltig saniert werden können, wenn nicht die gesamte innere deutsche Finanzpolitik auf neue Grundlagen gestellt", d.h. die Ergebnisse der Erzbergerschen Finanzreform nicht zugunsten einer föderalistischen Lösung geändert würden, wie es die bayerische Regierung seit Jahren gefordert habe. In diesem Punkt, der auch von weiten Kreisen der Wirtschaftsexperten und der Bevölkerung anerkannt werde, bestehe zwischen seiner Partei und ihm "nicht nur keine Meinungsverschiedenheit, sondern die vollste Übereinstimmung“. Aus dieser Überzeugung aber sei der Antrag der deutschnationalen Fraktion hervorgegangen: Er sei „der Ausdruck des Willens zur Abkehr von dem Verusch, ohne grundlegende Änderung des deutschen Finanzwesens den Verfall der öffentlichen Haushalte mit Mitteln aufzuhalten, die immer unzulänglicher und drückender werden. Wollte man den Antrag nur als eine Kritik und Ablehnung der einzelnen Bestimmungen auffassen, so würde man seiner Bedeutung nicht gerecht" ${ }^{214}$ Indem Gürtner den Antrag seiner Partei über die parteipolitische Ebene hinaushob und ihm die Bedeutung einer Direktive für die geforderte Finanzreform gab - ohne allerdings den konkreten, im Grunde destruktiven Schritt ausdrücklich zu billigen -, stellte er äußerlich den Einklang zwischen seiner Partei und den Zielen der bayerischen Regierung her. Was immer sich über die Richtigkeit seiner Darlegungen sagen lassen mochte: er hatte sowohl seine wie die Handlung seiner Partei vor der Öffentlichkeit gerechtfertigt.

Die beiden angeführten Beispiele zeigen, daß der Widerspruch, der sich aus der Oppositionshaltung der bayerischen DNVP und der verantwortlichen Mitwirkung ihres „Exponenten“ in der Regierung ergab, sowohl für die Öffentlichkeit wie für Gürtner trotz seiner diplomatischen Haltung immer unerträglicher wurde. „Gürtner ist in letzter Zeit merkwürdig schweigsam geworden und tritt sehr wenig in Erscheinung, auch ist er auffallend viel in Urlaub abwesend", berichtete der württembergische Gesandte im Herbst 1931 an seinen Staatspräsidenten in Stuttgart. ${ }^{215}$ Es war nicht verwunderlich, daß sich die ständigen Reibereien und die Belastungen, denen sich Gürtner in seinem Amt gegenübersah, auf seine Gesundheit auswirkten: im Frühjahr erkrankte er an einer Nierenentzündung mit Fieber, die einen starken Gewichtsverlust verursachte. Deshalb war Gürtner auch nicht in der Lage, am 12. Mai 1932 an der 350-Jahr-Feier der Würzburger Julius-Maximilian-Universität teilzunehmen, auf der ihm als dem „tapfern Vorkämpfer dereinst für die kriegerische Ehre des Vaterlands, jetzt aber für ungebeugte Gerechtigkeit in demselben“" neben Held und Kultusminister Goldenber-

214 Vgl. Gürtners Presseerklärung v. 23.9.31 (Wortlaut in der Chronik a.a.O.).

215 Vgl. Politik in Bayern 1919-1933 (Anm. 36), S. 251. 
ger die Ehrendoktorwürde der Rechts- und Staatswissenschaftlichen Fakultät verliehen wurde. ${ }^{216}$ In den letzten Maitagen begab sich Gürtner nach Feldafing am Starnberger See mit der Absicht, eine mehrwöchige Diät- und Erholungskur durchzuführen. In dem Schreiben vom 25. Mai, in dem er Held seinen Aufenthaltsort mitteilte, äußerte er seine Besorgnis darüber, ob die bisherige Finanzpolitik der Steuererhöhung und Ausgabenkürzung auf die Dauer fortgeführt werden könne und die für Juni vorgesehene Konferenz in Lausanne für das Reparationsproblem eine Lösung finden werde $^{217}$ : er ahnte nicht, daß er zum Zeitpunkt dieser Konferenz schon als Minister in der Reichsregierung sitzen werde. "Wie ein Blitz aus heiterem Himmel“ traf ihn am Abend des 1. Juni ein Ferngespräch des neuen Reichskanzlers von Papen, der ihm das Reichsjustizministerium anbot und sehr erstaunt war, daß Gürtner „nicht gleich am Apparat Ja und Amen“ sagte. ${ }^{218}$ Gürtner beriet sich telefonisch mit Held, der ihm jedoch keinen konkreten Rat geben und ihm nur versprechen konnte, daß ihm der Rücktritt in den bayerischen Staatsdienst offengehalten werde ${ }^{219}$; ob er allerdings wieder bayerischer Justizminister werden könne, sei insofern ungewiß, als er (Held) unter den gegebenen Umständen selbst nicht wisse, wie lang er noch Ministerpräsident bleiben werde. Gürtner brach seine Kur ab,-traf nach nächtlicher Bahnfahrt am nächsten Morgen in Berlin ein und sprach zunächst mit dem demissionierten Reichsjustizminister Joël, der ihm mitteilte, daß er das Angebot, im Amt zu bleiben, abgelehnt habe, "weil er nicht gut den Abbau von Notverordnungen zeichnen könne, die er selbst mitgemacht habe“. Nach einer längeren Unterredung mit v. Papen, den er vom Palästinafeldzug her kannte, und Reichspräsident v. Hindenburg entschloß sich Gürtner, das Amt zu übernehmen: damit hatte Gürtner im 51. Lebensjahr die oberste Sprosse seiner Berufslaufbahn erklommen.

\section{Reichsjustizminister in den Kabinetten v. Papen und v. Schleicher bis Januar 1933}

Das aus national-konservativen Männern und parteilosen Fachleuten zusammengesetzte „Kabinett der nationalen Konzentration “220 unter Reichskanzler v. Papen kam den politischen Idealvorstellungen Gürtners sehr nahe. Als Präsidialkabinett mit dem Notverordnungsrecht des Reichspräsidenten nach Artikel 48 der Reichsverfassung und mit der Zusage der Reichstagsauflösung ausgestattet, war es vom Opportunismus und dem „Kuhhandel“ der von ihm abgelehnten Parteienherrschaft zumindest für

216 Vierter Ehrendoktor beider Rechte wurde der RegPräs. von Unterfranken Günder, vgl. Münchner Neueste Nachrichten Nr. 129 v. 13.5.32, S.5, und Promotionsurkunde Gürtners (Nachlaß Gürtner).

217 Vgl. Schr. Gürtners an Held aus Feldafing v. 25.5.32 (BayerHStArch., Sign. Nachlaß Held 357).

218 Vgl. auch zum folgenden Gürtners Schr. aus Berlin v. 2.6.32 an Staatsrat Spangenberger (Nachlaß Gürtner), der mit der Leitung des bayer. JM betraut wurde und diese Funktion bis zur Ernennung Franks zum bayer. JM im März 1933 behielt.

219 Zum Gespräch mit Held vgl. Moser v. Filseck (Politik in Bayern 1919-1933 [s. Anm. 36], S. 259). Der bayer. Ministerrat billigte Gürtner im Beschl. v. 6.6.32 im Falle seines Ausscheidens aus dem Reichs- bzw. Staatsdienst das Ruhegehalt eines Staatsrats zu. Schr. des bayer. StM der Finanzen an das RJM v. 23.6.32 (Personalakten Gürtner, BA).

220 Zur Regierung v. Papen vgl. vor allem K. D. Bracher, Die Auflösung der Weimarer Republik. Eine Studie zum Problem des Machtverfalls in der Demokratie, 3.Aufl., Villingen 1960, S. $529 \mathrm{ff}$.; und E. R. Huber, a.a.O., Bd. VII, S. $977 \mathrm{ff}$. 
eine gewisse Zeit unabhängig und konnte „überparteilich“-autoritär regieren. In einem späteren, von ihm durchgesehenen und genehmigten Lebenslauf Gürtners heißt es daher folgerichtig: „Dr. Gürtner kennt ... die Schäden des vorangegangenen Systems so gut wie wenige. Der Übergang zu neuen Regierungsformen, den die Berufung von Papens zum Reichskanzler einleitete, entsprach seiner politischen Grundanschauung. “221 Aber immer noch existierten die politischen Parteien; falls ihre verfassungsmäßigen Mitwirkungsrechte an der Regierung nicht durch einen Staatsstreich von oben abgeschafft wurden, mußte die Regierung folglich auf die Dauer eine Tolerierung wenigstens durch die Rechtsparteien zu erreichen suchen, vor allem aber durch die nationalsozialistische Massenbewegung, die in den Septemberwahlen von 1930 mit 107 Mandaten zur zweitstärksten Fraktion des Reichstages aufgestiegen war. Wenn eine „Zähmung“ der Nationalsozialisten auf die eine oder andere Weise nicht gelang, mußte auch die Regierung des „Neuen Staates“ lediglich ein Übergangskabinett darstellen.

Die Berufung ins Papen-Kabinett verdankte Gürtner zweifellos seiner fachlichen Qualifikation und seiner in der bayerischen Ministerzeit offenbarten politischen Gesinnung, aber auch seiner parteipolitischen „Ungebundenheit“. Sein Name als möglicher Reichsjustizminister war dem Kreis um Hindenburg bereits bei der Umbildung der Brüning-Regierung zum Präsidialkabinett Anfang Oktober 1931 von Exkanzler Cuno „als Vertreter einer Gruppe von Industrie und Banken“ "genannt worden. ${ }^{222} \mathrm{Kei}$ nesfalls verdankte er die Ernennung seiner Partei ${ }^{223}$ : im Gegenteil verlor er mit seiner Berufung nach Berlin in ihr seinen einzigen politischen Rückhalt. Auch die BVP beeilte sich zu erklären, daß sie Gürtner nicht als den Vertrauensmann Bayerns im Reichskabinett ansehe. ${ }^{224}$ Das Fehlen jeglicher parteipolitischer Stütze schwächte aber Gürtners Stellung im Kabinett bis zur politischen Einflußlosigkeit. So konnte er z.B. als „unabhängiger“ Fachminister seine Ablehnung illegaler Staatsstreichpläne nur vorsichtig vortragen, solange die beiden wichtigsten Vertrauensmänner des Reichspräsidenten - der Reichskanzler und der Reichswehrminister v. Schleicher - in dieser Hinsicht einig schienen. Das zeigte sich in der Sitzung vom 10. August, als v. Papen und Reichsinnenminister v. Gayl ihre - mit Hilfe des Artikels $\mathbf{4 8}$ der Reichsverfassung zu verwirklichenden - Pläne einer langfristigen Ausschaltung des Parlaments, seiner künftigen Ausbalancierung durch eine Art Oberhaus und eines geänderten Wahlrechts darlegten. Gürtner beschränkte sich hierzu auf die Äußerung, wenn dieser Weg beschritten werde, werde er als Justizminister „dem Herrn Reichspräsidenten, auf die zweifellos von diesem zu erwartende Frage nach den verfassungsrechtlichen Möglichkeiten dieses Weges, pflichtgemäß antworten müssen, daß der Weg ohne Bruch der Verfassung nicht gegangen werden könne. Die Entscheidung werde daher letzten Endes bei dem Herrn Reichspräsidenten liegen“. Es kennzeichnet Gürtners realistisches Urteilsvermögen, daß er die im Kabinett als Alternative erörterte Beteiligung der $\mathrm{Na}$ -

221 Vgl. Lebenslauf Gürtners und Verm. seines persönl. Ref. Kaulbach v. 15.3.34 (Personalakten Gürtner, BA).

222 Vgl. Reitter, a.a.O., S. 111 f., der sich auf die Untersuchung von F. Klein, Zur Vorbereitung der faschistischen Diktatur durch die deutsche Großbourgeoisie 1929-1932 (Zeitschrift für Geschichtswissenschaft [Berlin-Ost] 1953, S.872 ff.) stützt.

223 Vgl. Bracher, a.a.O., S. 535.

224 Vgl. die Rede Schäffers über den „neuen Kurs“ im Reich v. 8.6.32 (Schulthess' Europäischer Geschichtskalender 1932, S. $101 \mathrm{f}$.$) .$ 
tionalsozialisten - die in den Wahlen vom 31. Juli 37\% der Wählerstimmen und 230 Reichstagsmandate errungen hatten - an der Papenregierung als illusorisch ansah: er sei „davon überzeugt, daß die Einbeziehung der Nationalsozialisten, ohne Übertragung der Führung an sie, ein Wunschbild bleibe“. ${ }^{225}$ Als diese Alternative an der Forderung Hitlers auf den Kanzlerposten und am Widerstand Hindenburgs tatsächlich gescheitert war, die Reichstagswahlen vom 6 . November zwar einen Rückgang der nationalsozialistischen Mandate auf 196, aber wiederum keinerlei Koalitionsmöglichkeit ergeben hatten und daher die Staatsstreichpläne am 9. November im Kabinett abermals erörtert wurden, riet Gürtner gemeinsam mit Reichsfinanzminister Schwerin v. Krosigk und Außenminister v. Neurath diesmal entschieden ab. Er warnte vor den Schwierigkeiten, die entstehen würden, „wenn die Regierung nach abermaliger Auflösung des Reichstags nicht wieder wählen lasse“ und "gezwungen sein sollte, ohne jede politische Untermauerung zu arbeiten". 226

Dagegen stand Gürtner dem Vorgehen v. Papens gegen Preußen durch eine Reichsexekution nach Artikel 48 der Weimarer Verfassung - dem „Preußenschlag“ vom 20. Juli 1932 - positiv gegenüber, wenngleich er auch hier nicht als aktiv Handelnder hervortrat. Der Plan, Reichskanzler v. Papen aufgrund einer auf diesen Artikel gestützten Verordnung des Reichspräsidenten „zur Wiederherstellung der öffentlichen Sicherheit und Ordnung" zum Reichskommissar für Preußen zu bestellen und die aus Vertretern der SPD und des Zentrums bestehende, seit Mai nur noch geschäftsführende preußische Regierung Braun ihres Amtes zu entheben, paßte in Gürtners politische Vorstellungen: wurden doch dadurch der politische Dualismus Reich-Preußen und der sozialdemokratische Einfluß in der preußischen Verwaltung beseitigt, die bislang von Innenminister Severing (SPD) geleitete preußische Polizei der Befehlsgewalt der Reichsregierung unterstellt, damit die unmittelbare Einflußnahme der autoritären Präsidialregierung auf zwei Drittel des Reichsgebiets gewährleistet und die Machtmittel des Reichs und Preußens in einer Hand konzentriert. Als Reichsinnenminister v. Gayl am 11. Juli im Kabinett ausführte, daß nunmehr „der psychologische Moment zum Eingreifen gekommen sei“ - am Vortage hatte es zwischen Nationalsozialisten und Reichsbanner in Ohlau blutige Zusammenstöße mit zahlreichen Toten und Verletzten gegeben -, waren sich alle Kabinettsmitglieder über eine baldige Verwirklichung dieser Absicht einig. Gürtner forderte jedoch eine Begründung, die vor den Augen der Öffentlichkeit bestehen konnte und geeignet war, die geplanten Maßnahmen als verfassungsmäßig zu rechtfertigen. Er schlug daher vor, als zusätzlichen Grund anzuführen, „daß der Etat in Preußen nicht in Ordnung gebracht werde“. ${ }^{227} \mathrm{Da}$ so weitreichende Maßnahmen wie die Absetzung der preußischen Regierung nicht allein mit der Notwendigkeit einer Wiederherstellung der öffentlichen Sicherheit und Ordnung (Diktaturgewalt des Reichspräsidenten nach Artikel 48 Abs. 2) begründet werden konnten, sondern dafür der preußischen Landesregierung eine Pflichtverletzung bei der Erfüllung der Reichsverfassung oder der Reichsgesetze nachgewiesen werden

225 Vgl. Niederschrift über die Ministerbesprechung v. 10.8. 32 (Akten der RK. Weimarer Republik, Das Kabinett von Papen, Bd. 1, Dok. Nr. 99, S. 385).

226 Vgl. Niederschrift über die Ministerbesprechung v. 9.11 .32 (a.a.O., Bd. 2, Dok. Nr. 200, S. 901 ff.).

227 Vgl. Niederschrift über die Ministerbesprechung v. 11.7.32 (a.a.O., Bd. 1, Dok. Nr. 57, S. 204 ff.), dazu: Th. Trumpp, Franz von Papen, der Preußisch-Deutsche Dualismus und die NSDAP in Preußen. Ein Beitrag zur Vorgeschichte des 20. Juli 1932, Phil. Diss. Tübingen 1963. 
mußte (Reichsexekution nach Artikel 48 Abs. 1), genügte Gürtner das Argument, daß die preußische Regierung die Abwehr kommunistischer Ausschreitungen und hochverräterischer Unternehmungen vernachlässige, als Begründung für den geplanten Schritt nicht. Am 13. Juli wies Gürtner im Kabinett auf den am Vortag ergangenen Erlaß Severings an die preußischen Regierungspräsidenten hin, der diesen Vorwurf gegen die preußische Regierung weitgehend entkräftete: in dem Erlaß hatte Severing angeordnet, daß die Polizeibehörden Versammlungen unter freiem Himmel verbieten sollten, wenn ihnen keine ausreichenden Polizeikräfte zum Schutz der Teilnehmer zur Verfügung stünden. Von Gayl mußte zugeben, daß Severing dadurch „der Reichsregierung den Boden für die geplante Aktion in Preußen im Moment entzogen habe“. Das Kabinett beschloß daraufhin, zunächst abzuwarten, wie sich der Erlaß auswirken werde. ${ }^{228}$ Am nächsten Tag wurde auch das von Gürtner vorgeschlagene Argument der Rechtfertigung einer Reichsexekution hinfällig, da die preußische Regierung den Etat für das Rechnungsjahr 1932 ohne den zu konstruktiven Beschlüssen unfähigen Landtag durch eine gesetzesvertretende Verordnung verabschiedete. ${ }^{229}$ Dennoch lieBen v. Papen und v. Gayl am 14. Juli die im Reichsinnenministerium ausgearbeitete $^{230}$, zunächst undatiert bleibende „Verordnung des Reichspräsidenten betreffend die Wiederherstellung der öffentlichen Sicherheit und Ordnung im Gebiet des Landes Preußen" durch v. Hindenburg in Neudeck (Ostpreußen) blanko unterzeichnen. ${ }^{231} \mathrm{Als}$ v. Papen den „Blutsonntag von Altona“ vom 17. Juli - an dem bei bürgerkriegsähnlichen Straßenkämpfen zwischen Nationalsozialisten und Kommunisten 18 Menschen getötet und 61 verletzt wurden - zum Anlaß nahm, die Inkraftsetzung der Verordnung und ihre Durchführung auf den 20. Juli festzusetzen, erneuerte Gürtner seine Bedenken hinsichtlich einer ausreichenden verfassungsrechtlichen Begründung, stellte sie aber zurück, als er auf die entschlossene Front von Reichskanzler und Reichswehrminister stieß. ${ }^{232}$ Das Urteil des Staatsgerichtshofs für das Deutsche Reich vom 25.

228 Vgl. Niederschrift über die Ministerbesprechung v. 13.7 .32 (a.a.O., Bd. 1, Dok. Nr. 60, S. 217).

$229 \mathrm{Vgl}$. VO über die Feststellung des Haushaltsplans für das Rechnungsjahr 1932 vom 14.7.32 (Preuß. GS 1932, S. 237). Die preuß. Regierung war dazu aufgrund der VO des Reichspräsidenten zur Sicherung der Haushalte von Ländern und Gemeinden („Dietramszeller Verordnung“) v. 24.8.1931 (RGBl. I, S. 453) ermächtigt.

230 Obwohl es das Kabinett in seiner Sitzung v. 11.7.32 (a.a.O.) v. Gayl auf seinen Wunsch hin überlassen hatte, den RJM bei der Ausarbeitung der VO heranzuziehen, wurde die bereits am nächsten Tag dem Kabinett unterbreitete VO im RMdI von v. Gayl selbst und vom Leiter der politischen Abteilung, MinDir. Gottheiner, formuliert. Vgl. J. Bay, Der Preußenkonflikt 1932/33. Ein Kapitel aus der Verfassungsgeschichte der Weimarer Republik, Jur. Diss. Erlangen-Nürnberg 1965, S.109, Anm.576; dazu auch Trumpp, a.a.O., S.140; Aussage MinDir. Brecht vor dem Staatsgerichtshof (in: Preußen contra Reich vor dem Staatsgerichtshof. Stenogrammbericht der Verhandlungen vor dem Staatsgerichtshof in Leipzig vom 10. bis 14. und vom 17. Oktober 1932, Berlin 1933, S.18), der eine Beteiligung des RJM gleichfalls verneint.

231 Vgl. den Ber. v. Gayls, Niederschrift über die Ministerbesprechung vom 16.7.32 (Akten der RK, a.a.O. Bd. 1, Dok. Nr. 63, S. 240). Hindenburg unterzeichnete in Neudeck eine zweite Blankoverordnung über die Verhängung des militärischen Ausnahmezustandes in Berlin und in der Provinz Brandenburg, mit der eventueller Widerstand nach Generalstreik o.ä. gebrochen werden konnte. Text der beiden VOen des Reichspräsidenten v. 20.7.32 s. RGBl. I, S.377.

232 Auch v. Gayl als zuständiger „Verfassungsminister“ äußerte aus denselben Gründen „im letzten Augenblick“ Bedenken. So nach dem Ber. v. Schleichers an Sts. Pünder, vgl. H. Pünder, Politik in der Reichskanzlei. Aufzeichnungen aus den Jahren 1929-1932, herausg. von Th. Vogelsang, Stuttgart 1961, S.149 (Aufz. v. 8. 10.32): „Papen, der in solchen Situationen immer erfreulich deutlich sei, habe den beiden Herren einfach erklärt, dann müsse es eben ohne sie beide gehen! Darauf hätten Gayl und Gürtner aber eingeschwenkt und gesagt, wenn der Reichskanzler und der Reichswehrminister mitmachten, seien sie schließlich auch bereit.“ 
Oktober 1932, vor dem nicht der Reichsjustizminister, sondern das Reichsinnenministerium das Reich zu vertreten hatte ${ }^{233}$, sollte seine Bedenken bestätigen. ${ }^{234}$

In die Zeit der Papen-Regierung fiel eine aufsehenerregende Strafsache, die die Handhabung des Rechts durch Gürtner in heiklen politischen Situationen abermals verdeutlicht. Am 22. August waren fünf SA-Männer vom Sondergericht in Beuthen aufgrund der Verordnung des Reichspräsidenten gegen politischen Terror vom 9. August 1932 zum Tode verurteilt worden, weil sie in dem oberschlesischen Ort Potempa einen kommunistischen Bergmann in seiner Wohnung viehisch $\mathrm{zu}$ Tode getrampelt hatten. ${ }^{235}$ Hitler hatte den Verurteilten ein Solidaritätstelegramm geschickt, in dem er ihre Freiheit als „eine Frage unserer Ehre“ bezeichnete, und im „Völkischen Beobachter" seine Anhänger zum Kampf gegen die Papenregierung und deren „blutige Objektivität“ aufgerufen, die zwischen nationalen Freiheitskämpfern und „marxistischen Zerstörern und Verderbern" keinen Unterschied mache. Er kündigte an, er werde dereinst „den Begriff National befreien von dieser Umklammerung durch eine ,Objektivität “ “. ${ }^{236}$ Damit rührte Hitler an Gürtners Auffassung, daß bei politischen Straftaten das „nationale“ Motiv berücksichtigt werden müsse. ${ }^{237}$ Obwohl es in einer amtlichen Verlautbarung hieß, die Regierung werde sich keinesfalls „durch politischen Druck in der pflichtmäßigen Prüfung“ der Ausübung des Begnadigungsrechts beeinflussen lassen $^{238}$, und auch v. Papen auf einer Kundgebung in Münster Hitler das Recht absprach, seine Anhänger „allein als deutsche Nation anzusehen und alle übrigen Volksgenossen als Freiwild zu behandeln“239, folgte er Gürtners Vorschlag, die Todesstrafen in lebenslängliche Zuchthausstrafen umzuwandeln. Maßgebend dafür war in diesem konkreten Fall allerdings nicht die Überzeugung, daß es bei diesem brutalen Verbrechen überwiegend nationale Motive anzuerkennen gegeben hätte, sondern vielmehr die Überlegung, den Nationalsozialisten keine Märtyrer zu schaffen und ihnen für die Wahl vom 6. November dadurch kein „besonderes Propagandamittel“ zu liefern. ${ }^{240}$ Bei v. Papen und bei Gürtner stand vermutlich auch die Absicht dahinter, „nicht alle Brücken nach rechts“ abzubrechen. ${ }^{241}$ Wieder einmal fand Gürtner einen Weg, politische Erwägungen rechtlich zu untermauern. Die von ihm vorgebrachte juristische Begründung lautete: da die Tat nur eineinhalb Stunden nach (!) Inkrafttreten der Terrorverordnung verübt worden war, hätten die Täter zur Tatzeit noch keine Kenntnis von der Verordnung haben können, die die Todesstrafe für solche Delikte einführte. ${ }^{242}$

${ }^{233}$ Als Vertreter des Reichs traten auf: MinDir. Gottheiner und Hoche vom RMdI sowie die Professoren Carl Schmitt, Jacobi und Bilfinger, vgl. Preußen contra Reich, S.3.

${ }^{234}$ Der Staatsgerichtshof entschied, daß das Einschreiten des Reichs zwar nach Art. 48 Abs. 2, nicht dagegen nach Art. 48 Abs. 1 gerechtfertigt sei, und erklärte daher nur einen Teil der getroffenen Maßnahmen für zulässig (a.a.O., S. 492, $511 \mathrm{ff}$ ): die preußische Staatsgewalt wurde zwischen der wieder eingesetzten „Hoheitsregierung“ und der die tatsächliche Macht ausübenden „Kommissariatsregierung“ geteilt.

${ }^{235}$ Vgl. dazu die Dokumentation von P. Kluke, Der Fall Potempa, VfZ 1947, S. $279 \mathrm{ff}$.

${ }^{236}$ Telegramm und Aufruf vgl. VB, Bayernausgabe, v. 24.8.32, S.1.

${ }^{237}$ Vgl. dazu insbesondere voranstehend $\mathrm{S} .19 \mathrm{f}$.

238 Vgl. Schulthess' Europäischer Geschichtskalender 1932, S. 142. Zuständig für die Begnadigung war v. Papen in seiner Eigenschaft als kommissarischer preuß. Ministerpräsident.

239 Auf der Kundgebung des Westfälischen Bauernvereins v. 28.8.32, vgl. F. von Papen, Der Wahrheit eine Gasse, München 1952, S. 226.

240 Vgl. a.a.O., S. 227.

241 So Bracher, a.a.O., S.620, hinsichtlich v. Papens.

242 Laut Meldung v. 2.9.32, Schulthess, a.a.O., S. 152, dazu v. Papen, a.a.O. Vgl. demgegenüber die unbedenkliche Einführung rückwirkender Strafbestimmungen unter dem NS-Regime (Kapitel VII.3., S. 829 f., 894 ff., 897 ff.). 
Da die Regierung v. Papen am 17. November zurücktrat, um Hindenburg Verhandlungen mit allen Parteien rechts von der SPD zu erleichtern, die eine breitere Unterstützung - eine „nationale Konzentration“ - für eine neue Präsidialregierung erreichen sollten, wurde Gürtner wieder einmal nur geschäftsführender Justizminister. Bei seiner erneuten Betrauung mit der Kabinettsbildung durch v. Hindenburg am 1. Dezember, die der ergebnislos gebliebenen Sondierung bei den Parteien folgte, versicherte sich v. Papen nunmehr der vollen Unterstützung des Reichspräsidenten, um unter Ausrufung des „Staatsnotstandes“ und Bruch der Weimarer Verfassung die „Ausschaltung des widerstrebenden Reichstags, Unterdrückung aller Parteien und halbpolitischen Organisationen durch die Reichswehr und die Polizei und Verfassungsreform mit Billigung durch eine Volksabstimmung oder eine, neuzuberufende Nationalversammlung “ durchzusetzen. ${ }^{243}$ In einer anschließenden Unterredung mit Gürtner stimmte ihm der „scharfsinnige Jurist“ zwar zu, daß aufgrund der Lage und Hitlers unnachgiebiger Haltung vom Vorliegen des Staatsnotstandes gesprochen werden könne, berichtete aber, v. Schleicher habe ihm gegenüber geäußert, daß v. Papens Absicht zu einem Bürgerkrieg führen werde, dem die Reichswehr nicht gewachsen sei. ${ }^{244}$ Tatsächlich lehnte v. Schleicher den Einsatz der als „unpolitisches“ Instrument geschaffenen und zum Teil mit den Nationalsozialisten sympathisierenden Reichswehr für diesen innenpolitischen Zweck ab. Als es in der Sitzung des Kabinetts - dessen Zusammensetzung v. Papen nicht zu verändern wünschte - am 2. Dezember über die Pläne einer Verfassungsänderung mit Hilfe des militärischen Ausnahmezustandes zwischen v. Papen und v. Schleicher zum Bruch kam, gewann Gürtner seine ansonsten in diesem Kabinett „zementierte“ politische Entscheidungsfreiheit als Minister zurück: Nachdem v. Schleicher dargelegt hatte, daß die Kräfte der Reichswehr nicht ausreichten, um gegen Unruhen der Nationalsozialisten und Kommunisten, gegen den Generalstreik der Gewerkschaften und den wiederauflebenden Separatismus vorgehen und gleichzeitig die ostpreußischen Grenzen gegen polnische Insurgenten schützen zu können, schlug sich Gürtner trotz der „Autorisierung“ der Papenschen Pläne durch den Reichspräsidenten auf die Seite der Minister, die sich offen gegen den „Staatsstreich“ aussprachen. Es zeigte sich, daß Gürtner wie 1923 so auch 1932 nicht gewillt war, das an sich von ihm unterstützte Ziel eines autoritären Staates für den Preis eines Bürgerkrieges zu erreichen. Mit seiner Entscheidung trug Gürtner zum Sturz v. Papens bei: da v. Hindenburg eine Ablösung des Reichswehrministers ablehnte, gab v. Papen seinen Auftrag zur Regierungsbildung zurück und schlug die Ernennung v. Schleichers zum Reichskanzler vor. ${ }^{25}$

Die Konzeption des neuen Kanzlers ${ }^{246}$, einen Flügel der NSDAP unter Gregor

${ }^{243}$ Vgl. Bracher, a.a.O., S.672; Aktennotiz des Sts. Meißner v. 2.12.32 über die Besprechung (Dokumentation von Th. Vogelsang, a.a.O., S. 105 f.); Papen, a.a.O., S. $243 \mathrm{ff}$.

${ }^{244}$ Vgl. v. Papen, a.a.O., S. 246. An dieser Unterredung v. 1.12.32 nahm auch Verkehrsminister Eltz v. Rübenach teil.

${ }^{245} \mathrm{Zu}$ den Besprechungen v. 2.12 .32 vgl. Bracher, a.a.O., S.674 ff.; Papen, a.a.O., S. 247 ff.; Aktennotiz Meißners v. 2.12.32, a.a.O.; und Th. Vogelsang, Reichswehr, Staat und NSDAP. Beiträge zur deutschen Geschichte 1930-1932, Stuttgart 1962, S. 333 f., der sich u. a. auf den Tagebucheintrag v. Krosigks v. 4.12.32 stützt.

246 Zur Regierung Schleicher vgl. Bracher, a.a.O., S. 677; E. R. Huber, a.a.O., Bd. VII, S. 1162 ff.; A. Golecki, Das Kabinett v. Schleicher und das Ende der Weimarer Republik, Einleitung zu: Akten der Reichskanzlei, Weimarer Republik, herausg. für die Historische Kommission bei der Bayerischen Akademie der Wissenschaften von K. D. Erdmann, für das Bundesarchiv von H. Booms, Das Kabinett von Schleicher, 3. Dezember 1932 bis 30.Januar 1933, bearbeitet von A. Golecki, Boppard a. Rhein 1986, S. XIX ff. 
Strasser - mit dem er seit Ende November erfolgversprechende Gespräche geführt hatte - an der Regierung zu beteiligen und durch geplante Maßnahmen auf dem Gebiet der Sozialpolitik und der Arbeitsbeschaffung die Unterstützung der Christlichen und Freien Gewerkschaften zu gewinnen, traf bei Gürtner auf Sympathie: sollte sie doch der neuen Präsidialregierung jene politische Basis geben, die der Papen-Regierung gefehlt hatte. Denn auch in Gürtners politischen Vorstellungen sollte die „autoritäre Regierung“ eine Basis im Volk besitzen; sie war keineswegs als eine bloße Diktatur gedacht, die er wegen ihrer „Erziehung zum mangelnden Verantwortungsbewußtsein" ablehnte. Eine solche nichtparlamentarische Regierung sollte möglichst auf dem Konsens einer „nationalen Idee“ beruhen, die „durch Angleichung und Ausgleichung der verschiedenen Weltanschauungen in den verwandten Fragen ... zur Idee und Verwirklichung der Volksgemeinschaft“ (!) führen sollte. ${ }^{247}$ Doch v. Schleichers Pläne scheiterten, da sich Strasser gegen Hitler nicht durchsetzen konnte und daraufhin seine Parteiämter niederlegte und sich auch die Freien Gewerkschaften unter dem Einfluß der SPD dem „reaktionären General“ versagten. Als ihm v. Hindenburg die Auflösung des Reichstags unter Hinweis auf „andere Möglichkeiten“ verweigerte ${ }^{248}$, trat v. Schleicher am 28. Januar 1933 zurück, um seinem Sturz durch das Parlament zuvorzukommen. Gürtner war erneut geschäftsführender Justizminister. ${ }^{249}$

\section{6. Übernahme ins Kabinett Hitler und die Folgen der Gleichschaltung 1933}

Bei der von Hindenburg angedeuteten Alternative handelte es sich um den Plan, an dessen Verwirklichung der durch seinen Sturz gekränkte und gegenüber v. Schleicher auf Rache sinnende v. Papen hinter dem Rücken des Reichskanzlers und anfänglich auch ohne Wissen v. Hindenburgs in wochenlangen Verhandlungen gearbeitet hatte, um die Nationalsozialisten aus der Opposition in die Mitverantwortung zu bringen: Hitler sollte in einer neuen Präsidialregierung die Kanzlerschaft und seinen Gefolgsleuten einige Ministerposten anvertraut werden; er sollte aber durch v. Papen als Vizekanzler, durch eine Koalition mit der DNVP und ein Übergewicht von zuverlässigen national-konservativen Ministern im Kabinett „eingerahmt“ und daran gehindert werden, eine einseitige Parteidiktatur aufzurichten. Nachdem der Widerstand Hindenburgs, der wieder v. Papen als Reichskanzler vorgezogen hätte, schließlich überwun-

247 Vgl. Gürtners Vortrag „Macht und Recht“, wiedergegeben in der Coburger Zeitung Nr. 111 v. 14.5.29. Er fuhr fort: „Dieser Weg ist für die Veranlagung des Deutschen wohl der schwerste, aber derjenige, der den stärksten Erfolg verspricht.“

248 Vgl. Niederschrift über den Empfang v. Schleichers durch den Reichspräsidenten v. 28.1.33 (Akten der Reichskanzlei, a.a.O. [Anm. 246], Dok. Nr.72).

249 Die Tãtigkeit Gürtners im Kabinett v. Schleicher bestand im wesentlichen in seiner Mitwirkung an der VO des Reichspräsidenten zur Erhaltung des inneren Friedens v. 19.12.32 (RGBl. I, S. 548), die die NotVOen der Papenregierung gegen politische Ausschreitungen aufhob und durch mildere Bestimmungen ersetzte, an der VO der Reichsregierung über die Aufhebung der Sondergerichte v. 19.12.32 (RGBI. I, S.550), die gleichfalls unter v. Papen eingerichtet worden waren, und am G. über Straffreiheit v. 20.12.32 (RGBI.I, S. 559), das vom Reichstag ausging und politische Straftaten amnestierte (s. Kapitel IV.1.b., S. 325 und dortige Anm. 21); bei diesem G. gelang es Gürtner, durch Einwirkung auf die im Rechtsausschuß des Reichstags vertretenen Fraktionen bestimmte Straftaten von der Amnestie auszuschließen. Vgl. W. Hoegner, Der schwierige Außenseiter, München 1959, S.72 f. Nach dem Resümee von Golecki, a.a.O., S.XXXII, fand sich Gürtner auch in dieser Regierung bereit, „,im Interesse eines vermeintlich übergeordneten Staatsinteresses“ politisch motivierte Maßnahmen im Bereich der Justiz zu sanktionieren. 
den war, konnten am 29. Januar die letzten Verhandlungen über die Kabinettsliste abgeschlossen werden, die auch eine Einigung über die Beibehaltung Gürtners als Reichsjustizminister erbrachten. ${ }^{250}$

Über seinen Entschluß, Gürtner als Justizminister zu übernehmen, berichtete Hitler später, „als er die Hirse der für diesen Posten vorhandenen Männer von der Spreu habe aussortieren müssen, habe er keinen Besseren gefunden". ${ }^{251}$ Sein Entschluß dürfte nicht nur auf Gürtners erprobter nationaler Gesinnung bei gleichzeitiger Qualifikation als Jurist und Fachminister beruht haben, sondern vor allem auf der in zehnjähriger Ministerzeit vielfach bewiesenen Fähigkeit und auch dem Willen, Forderungen der Politik und Staatsräson entweder innerhalb der bestehenden Rechtsordnung zu berücksichtigen oder das positive Recht entsprechend zu ändern. Hinzu kam, daß Gürtner bei der Beamtenschaft der Justiz als Fachmann hohes Ansehen und als Person großes Vertrauen genoß - ein Potential, das Hitler bei der Verfolgung seines Zieles, schrittweise die Diktatur zu errichten, ausnutzen konnte. Mit der Ernennung eines Nationalsozialisten wie etwa Hans Franks hätte er - abgesehen davon, daß er sie im Januar 1933 bei seinen Koalitionspartnern wahrscheinlich gar nicht hätte durchsetzen können - die Justizverwaltung unnötigerweise mißtrauisch gemacht, und bei dem Gehabe, das Frank bald als „Reichsrechtsführer“ an den Tag legen sollte, sogar regelrecht vor den Kopf gestoßen. Auch der mittlere Justizbeamte und spätere preußische Justizminister Hanns Kerrl, der damals Präsident des Preußischen Landtages war, und Rechtsanwalt Roland Freisler, der als Abgeordneter in diesem Parlament saß, hätten 1933 in der Reichsjustizverwaltung niemals die Autorität eines Gürtner besessen. Außerdem mochte Hitler Freisler - der während seiner fünfjährigen Kriegsgefangenschaft in der Sowjetunion eine Zeitlang Kommissar und nach seiner Rückkehr 1920 zunächst Kommunist gewesen war ${ }^{252}$, ehe er über den völkisch-sozialen Block 1925 in die NSDAP eintrat - persönlich nicht: „Freisler sei ja in seiner ganzen Art ein Bolschewik“. ${ }^{253}$ Die Beibehaltung Gürtners als Reichsjustizminister, die auch Hindenburg und der deutschnationale Koalitionspartner wünschten, schien Hitler daher die beste Lösung zu sein.

Aus Gürtners Sicht wiederum mußte das „Kabinett Hitler“ im Vergleich zu den vorangegangenen beiden Präsidialregierungen seinen politischen Vorstellungen insofern am nächsten kommen, als zu allen Vorzügen, mit denen die Kabinette v. Papen und v. Schleicher ausgestattet gewesen waren, ein wesentlicher hinzutrat: daß die Regierung durch die „Nationale Front“ von NSDAP, DNVP und Stahlhelm eine breitere Basis im Volk besaß.

Zwar hatte sie im Reichstag nach den Novemberwahlen von 1932 mit $40,2 \%$ der Stimmen und 248 von 584 Mandaten keine Mehrheit; immerhin bestand aber die Aussicht, daß sie sie bei den Neuwahlen vom 5. März 1933 erhalten würde, die bereits

250 Úber die Verzögerung der Bestätigung Gürtners im Amt aus taktischen Gründen vgl. voranstehend S.9f.

251 Vgl. H. Picker, Hitlers Tischgespräche im Führerhauptquartier 1941-42, Bonn 1951, S.212, am 29.3.42 abends.

252 Vgl. den Bericht über die Rede Freislers in den Berliner Pharussälen am 9.6.32 im VB, Bayernausg. v. 16.6.32, S. 3: „War Pg. Freisler doch selbst einmal Kommunist. Darum konnte er um so schärfere Abrechnung mit dieser Partei des Arbeiterverrats halten. Er ist selbst in Sowjetrußland Lebensmittelkommissar gewesen und hat so die rote Sowjetbonzokratie zur Genüge kennengelernt.“

${ }^{253}$ Vgl. H. Picker, Tischgespräche, a.a.O. Hitler machte Freisler auch nach Gürtners Tod nicht zum RJM, hielt ihn aber 1942 als Präsidenten des VGH für geeignet. Zu Freisler vgl. Personalakten des RJM, BA; Personalunterlagen im DC Berlin; Das Deutsche Führerlexikon 1934/35, S. 130 f.; ferner G. Buchheit, Richter in Roter Robe, München 1968, L. Gruchmann, Freisler, Biograph. Lexikon (1998), S. 130 f. 
am Tage der endgültigen Bestätigung Gürtners als Minister von der neuen Regierung ausgeschrieben worden waren. War somit die Hoffnung ganz unbegründet, daß die anderen bürgerlichen Parteien die nationale Regierung schließlich wenigstens tolerieren oder sie sogar einmal aktiv unterstützen würden, wenn sie mit Leistungen hervorgetreten sein würde? Öffnete sich hier nicht vielleicht ein Weg zu jener „Volksgemeinschaft", die Gürtner durch den Abbau der ideologischen Gegensätze zugunsten einer „nationalen Idee“ als erstrebenswert ansah? ${ }^{254}$ Aber ganz unabhängig davon schien ein autoritäres und stabiles Regiment auf jeden Fall gesichert, solange die Regierung Hitler an der Macht blieb: hatte doch Hitler im Kabinett unmißverständlich erklärt, daß - unabhängig vom Wahlausgang - die Zusammensetzung der gegenwärtigen Regierung nicht geändert und keinesfalls zur parlamentarischen Regierungsweise zurückgekehrt werde. ${ }^{255}$ Die zu erwartende Kontinuität eröffnete Gürtner die Aussicht, in absehbarer Zukunft jene längst fälligen Reformen auf dem Justizgebiet durchzuführen, die der dauernde Wechsel der verantwortlichen Minister, der Mehrheitsverhältnisse und damit auch der jeweils maßgeblichen Grundanschauungen über die beabsichtigten Gesetzgebungswerke im parlamentarischen „System“ bislang vereitelt hatte. Diese erwartete und später auch erwiesene Effektivität war für Gürtner und für viele Angehörige der „unpolitischen“ Ministerialbürokratie das Bestechende am neuen Regime, für das seine zweifellos erkennbaren negativen Erscheinungen in Kauf genommen wurden. Denn daß die nationalsozialistische Bewegung, auf die sich die neue Regierung hauptsächlich stützte, negative Seiten aufwies, daß insbesondere ihre Kampftruppe, die SA, bei ihrer Auseinandersetzung mit politischen Gegnern - vor allem den Kommunisten, die ihnen darin in nichts nachstanden - kriminelle Ausschreitungen beging, die wie der Potempa-Mord von ihrer Führung als Mittel der Politik gerechtfertigt wurden, war dem Justizminister schließlich nichts Neues. Es war auch zu erwarten, daß sie mit dem Machtwechsel vom 30. Januar 1933 nicht sofort aufhören würden. Aber Gürtner war der Ansicht, daß es sich hier um eine vorübergehende politische „Ausnahmesituation“ handelte, wie er sie 1919 und 1923 in Bayern erlebt hatte und wie sie bei jeder politischen Umwälzung zwangsläufig auftrat. Solange jedoch der Staats- und Justizapparat intakt war, sah er alle Voraussetzungen für gegeben, die destruktiven Gruppen innerhalb der nationalsozialistischen Bewegung in Schach zu halten, während ihre positiven nationalen Kräfte dem Staat durch Mitarbeit dienstbar gemacht werden konnten. Schließlich mußte auch Hitler - der persönlich integer schien und bis zu seiner Emennung zum Kanzler zwar 1923 als Anführer eines hochverräterischen Unternehmens für die nationale Sache, aber bis dato nie als Organisator „krimineller" Taten in Erscheinung getreten war - in seinem neuen Amt selbst ein Interesse daran haben, die Staatsautorität zu wahren: die Hoffnung auf eine evolutionäre Entwicklung der nationalsozialistischen Bewegung sollte Gürtner noch lange hegen. Aber davon abgesehen, bestanden als Sicherungen immer noch der Reichspräsident mit dem Oberbefehl über die Reichswehr und die Mehrheit der nichtnationalsozialistischen Minister im Kabinett, die dem Terror und der Errichtung einer totalitären Diktatur würden entgegentreten können. Wie die meisten Konservativen - aber kei-

254 Vgl. Gürtners Vortrag v. Mai 1929 (s. voranstehende Anm. 247).

255 Vgl. Ministerbesprechung v. 30. Januar 1933, 17 Uhr (künftige Zusammensetzung des Kabinetts) und Ministerbesprechung vom 31.Januar 1933, $16 \mathrm{Uhr}$ (keine Rückkehr zum parlamentarischen System), Akten der Reichskanzlei, Die Regierung Hitler, Teil I: 1933/34, Band 1 [s. Anm. 3], Dok. Nr.1, S.3, und Dok. Nr.2, S.6. 
neswegs nur sie - verkannte Gürtner Ende Januar 1933 den revolutionären Charakter der nationalsozialistischen Bewegung und ihre Dynamik gründlich. Die Ernennung Hitlers und des Kabinetts, dem Gürtner angehörte, durch den Reichspräsidenten war zwar nach dem Buchstaben der Verfassung der Weimarer Republik legal erfolgt; aber da der Staatsapparat ihrem entschiedensten Feind anvertraut wurde, sollten die alten Institutionen und Gesetze binnen kurzem in einem völlig neuen Geist angewendet werden, der entschlossen auf die Errichtung der totalitären Diktatur abzielte.

Mit den Zielen, die Hitler in seinem „Aufruf an das Deutsche Volk“ vom 1. Februar zu verfolgen vorgab, konnte sich Gürtner voll identifizieren: Dieses Grundsatzprogramm der "nationalen Regierung“, das am Abend jenes Tages vom Kabinett beschlossen wurde und auch Gürtners Unterschrift trägt ${ }^{256}$, entsprach völlig der Vorstellungswelt des konservativ-bürgerlichen Nationalisten. In ihm wurden die Novemberrevolution als Ursache des ,inneren Verfalls“, die Anerkennung jeglicher deutscher Kriegsschuld und das Versailler Diktat der Sieger verurteilt, das „das Vertrauen von Nation zu Nation und damit auch die Wirtschaft der Welt" zerstöre; ferner wurde gegen Marxismus, Klassenkampf, liberalen Individualismus, den Pluralismus „politischegoistischer Meinungen, wirtschaftlicher Interessen und weltanschaulicher Gegensätze“ und die parlamentarische Demokratie zu Felde gezogen. Dem wurden als Ideale die Einheit der Nation, Unterordnung, Disziplin, Ehre und Treue, die „Liebe zu unserem Heere als Träger unserer Waffen und Symbol unserer großen Vergangenheit“, aber auch das "Christentum als Basis unserer gesamten Moral" gegenübergestellt, vor allem aber die Wiederherstellung der „geistigen und willensmäßigen Einheit" des Volkes gefordert. Als innenpolitische Ziele für die nächsten vier Jahre wurden die Beseitigung der Arbeitslosigkeit und die Gesundung des Bauerntums genannt. Mit einem wirtschaftlich stabilen, einigen und starken Vaterland sollte dann auch außenpolitisch die „Freiheit unseres Volkes“ und die Gleichberechtigung Deutschlands im Kreise der übrigen Nationen wiederhergestellt, d.h. Versailles revidiert werden. Von Hitlers kontinentalen Zukunftsplänen einer „Eroberung neuen Lebensraums im Osten“, die er nur zwei Tage später vor den Befehlshabern von Heer und Marine geheim andeutete $^{257}$, aber im Kabinett nie zur Sprache brachte, war in dem „Aufruf“" mit keinem Wort die Rede, ebensowenig von antijüdischen Maßnahmen.

Wer wie Gürtner diese proklamierten Ziele wollte, der mußte auch die dazu notwendigen Mittel wollen: Was aber lag näher, als zur Erreichung der „geistigen und willensmäßigen Einheit“ des Volkes, d.h. zur Schaffung der „Volksgemeinschaft“, vorübergehend die Freiheitsrechte einzuschränken, wie es auch in früheren Fällen von Verhängung des Ausnahmezustandes geschehen war und mit der Reichstagsbrandverordnung vom 28. Februar 1933 abermals geschah. Wenn es die politische Führung für unvermeidlich hielt, sollte auch ermöglicht werden, daß politische Gegner, die diesen Prozeß aktiv störten, ohne direkt gegen Strafgesetze zu verstoßen - das waren anfänglich ohnehin meist Gürtners Gesinnungsgegner, die Kommunisten und Sozialisten -,

256 Vgl. Ministerbesprechung v. 1. Februar 1933, 19 Uhr, a.a.O., Dok. Nr.5, S.15. Text des Aufrufs, in dem es hieß: „Nun, deutsches Volk, gib uns die Zeit von vier Jahren und dann urteile und richte uns!" s. Schulthess' Europäischer Geschichtskalender 1933, S. 34 ff.

$257 \mathrm{Vgl}$. Aufz. Gen.Lt. Liebmanns über die Ausführungen Hitlers vor den Befehishabern des Heeres und der Marine am 3.2.33 (Dokumentation von Th. Vogelsang, Neue Dokumente zur Geschichte der Reichswehr, VfZ 1953, S. 397 ff., 434 f.). 
für einige Zeit in polizeiliche "Schutzhaft" genommen werden konnten. Nur sollten nach Gürtners Vorstellungen die Modalitäten der Verhaftung geordnet, ihre Ausführung verantwortlich kontrolliert und persönliche Motive sowie Willkürakte untergeordneter Stellen dabei ausgeschlossen werden. Auch sollten die Schutzhäftlinge während ihrer Verwahrung - ähnlich den Untersuchungs- und Strafhäftlingen bei der Justiz - unter dem Schutz der Gesetze stehen und nicht gefoltert, verletzt oder getötet werden. Überdies hielt Gürtner die Polizeihaft aus rein politischen Gründen für eine nur vorübergehend notwendige Einrichtung. ${ }^{258}$

Schon nach kurzer Zeit sollte sich jedoch herausstellen - und gerade den Justizminister erreichten entsprechende Beschwerden ${ }^{259}$-, daß die Festnahme und Verwahrung der politischen Gegner nicht der staatlichen Polizei, sondern den als „Hilfspolizei“ eingesetzten oder eigenmächtig handelnden Formationen der SA und SS überlassen wurde, die auch gelegentlich deutschnationale „Reaktionäre“ verhafteten und mit ihren Gefangenen in brutaler und verbrecherischer Weise umgingen und persönlich „abrechneten“. Es trat zutage, daß diese Verbrechen nicht nur von der Parteiführung, sondern auch von den staatlichen Behörden der inneren und Polizei-Verwaltung gedeckt wurden, deren Schlüsselpositionen und Instanzen sukzessive mit Partei-, SAund SS-Führern besetzt wurden. Gürtner mußte mit der Zeit erkennen, daß Rechtlosigkeit und Gewalt nicht vorübergehende Erscheinungen der "nationalen Erhebung“, sondern inhärente Mittel der nationalsozialistischen Herrschaft waren, die auch beibehalten wurden, als die Bekämpfung der politischen Gegner aus den Händen der SA und regionaler Organe bei der SS- und Polizeiführung zentralisiert wurde, die ihren Apparat gegenüber dem nationalsozialistischen Reichsinnenminister Frick verselbständigte und ihre Tätigkeit von den Schranken der Gesetze befreite. ${ }^{260}$ Die dadurch erzeugte Rechtsunsicherheit sollte der Sicherung der Herrschaft dienen.

Auf diese Entwicklung, die sich außerhalb seines Ressorts als Justizminister vollzog, hatte Gürtner auch als Mitglied der Reichsregierung keinen Einfluß mehr, da sich im Kabinett das Führerprinzip durchsetzte und dem Gesamtkabinett die Zuständigkeiten für wesentliche Bereiche entzogen wurden, die Hitler mit dem zuständigen Ressortchef unmittelbar regelte. Das Ermächtigungsgesetz vom 23. März 1933, für dessen Annahme die bürgerlichen Parteien der Mitte der „nationalen Regierung“ zur verfassungsmäßig notwendigen Zweidrittelmehrheit verholfen hatten, brachte Hitler auf diesem Wege einen wesentlichen Schritt voran. Es machte ihn vom Notverordnungsverfahren durch den Reichspräsidenten unabhängig und schwächte damit die Stellung der konservativen Minister, die bislang gelegentlich bei Hindenburg Rückendeckung

${ }^{258}$ Zur Auseinandersetzung der Justiz mit der SS- und Polizeiführung wegen der Schutzhaft und ihrer Regelung vgl. Kapitel VI.2.a. Die Erwartung der „restlosen Wiederherstellung des Rechtsstaates“ wurde nach Hitlers Erklärung über die Beendigung der Revolution im Juli 1933 (s. dazu Kapitel IV.1.c., Anm. 40) auch in der Presse ausgesprochen: sie sei schon aus außenpolitischen Gründen notwendig, da das ,weitgehende Mißtrauen anderer Nationen gegen die Rechtssicherheit in Deutschland“ ein Hindernis im Kampf um die deutsche Gleichberechtigung darstelle; seine Beseitigung gebe diesem Kampf erst „eine der wichtigsten moralischen Grundlagen“. So z. B. die Bayerische Staatszeitung v. 28.10.33 in dem Artikel „Neues Recht“ nach einer Pressekonferenz Gürtners in Berlin.

$259 \mathrm{Vgl}$. dazu im folgenden S. $74 \mathrm{ff}$.

260 Zur Verfolgung der Ausschreitungen von SA- und SS-Bewachern in den Konzentrationslagern s. Kapitel IV, zur Entwicklung des Himmlerschen Polizeiapparats und der Auseinandersetzung mit der Justiz wegen der Zustände in den Konzentrationslagern s. Kapitel VI. 
gefunden hatten. ${ }^{261}$ Gürtner hatte daher zu erreichen versucht, daß auch die auf Grund des Ermächtigungsgesetzes erlassenen Gesetze der Zustimmung Hindenburgs bedürfen, d.h. vom Reichspräsidenten unterzeichnet und veröffentlicht werden sollten. Der Versuch scheiterte an der Laschheit Hugenbergs, dem mangelnden Willen Papens und dem Desinteresse Hindenburgs, der nach der Zeit der Präsidialverordnungen der Mitverantwortung an der Legislative überdrüssig war. ${ }^{261 a} \mathrm{Da}$ die nunmehr von der Regierung beschlossenen Gesetze nur noch "vom Reichskanzler ausgefertigt und im Reichsgesetzblatt verkündet" wurden, war neben dem Reichstag auch der Reichspräsident von der Legislative ausgeschlossen worden. Die Gesetze „der Reichsregierung" galten aber dann als beschlossen, wenn sich Hitler ungeachtet der Bedenken einzelner Minister für ihre Annahme entschied. ${ }^{262}$ Gürtner und die anderen nichtnationalsozialistischen Reichsminister hätten somit - selbst wenn sie es gewollt hätten - keine Möglichkeit mehr gehabt, sich kraft ibres Amtes der Entwicklung entgegenzustemmen. Abgesehen davon hatten sich die realen Machtverhältnisse bis Sommer 1933 durch die Auflösung aller anderen politischen Parteien und der Gewerkschaften, durch die Gleichschaltung der Länder - als letzte Landesregierung war Mitte März in Bayern die Regierung Held abgesetzt und zunächst „kommissarisch" durch eine nationalsozialistische ersetzt worden - und der beruflichen und wirtschaftlichen Verbände, durch die Anbahnung der Zusammenarbeit der Wehrmacht unter Reichswehrminister v. Blomberg mit Hitler und andere Maßnahmen völlig verändert. Gürtner war zum Opfer seines eigenen Ideals vom autoritären Staat geworden, in dem es keine wirksame Kontrolle der Regierung durch politische Gegengewichte wie Oppositionsparteien, ein oppositionelles Parlament oder andere Verfassungsinstitutionen mehr gab. Sein Verfassungsideal beruhte auf der grundanständigen, aber irrigen Auffassung von Gürtners Charakter wird noch zu sprechen sein -, daß eine „nationale“ autoritäre Regierung nie Verbrechen anordnen und organisieren werde: ihre Tätigkeit sollte selbstverständlich an Recht und Gesetz gebunden sein. So hielt er den Hans Frank zugesprochenen Grundsatz „Recht ist, was dem deutschen Volke nützt“ für eine „schwere Verirrung“.263

261 Das zeigte sich z.B. Anfang März 1933, als Hitler die lex van der Lubbe mit rückwirkenden Strafbestimmungen forderte, Hindenburg aber eine entsprechende Präsidialverordnung verweigerte, da das RJM Bedenken äußerte. Das Gesetz konnte erst am Monatsende aufgrund des Ermächtigungsgesetzes erlassen werden (vgl. dazu Kapitel VII 3a, S. 826f., 829).

26la Vgl. Schreiben Schlegelbergers an Papen vom 16.3.1933: Der (wegen Erkrankung an den Kabinettsberatungen verhinderte) Reichsjustizminister sei der „Auffassung, daß die Einschaltung der Autorität des Herrn Reichspräsidenten in das Ermächtigungsgesetz unentbehrlich ist“. Gürtner sei „sehr betroffen, daß die Ablehnung des Antrags Hugenberg in Erwägung gezogen worden“ sei und begrüße es „sehr lebhaft“, daß Papen "sich entschlossen habe(n), in dieser Richtung tätig zu werden" (Akten der RK, BA, Sign. R 53/77, Bl. 83, veröffentlicht in: Morsey, Ermächtigungsgesetz, 1992, S. 33f.). Zur Behandlung von Hugenbergs Vorschlag in der Kabinettssitzung am Vortag s. Niederschrift über die Ministerbesprechung am 15. März 1933, Akten der RK. Die Regierung Hitlers (s. Anm.3), Dok. Nr. 60, S. 212 ff. Der „entschlossene" Papen kam jedoch bei der abschließenden Beratung des Ermächtigungsgesetzes in der folgenden Kabinettssitzung am 20. März 1933 auf diesen Vorschlag nicht mehr zurück; entsprechende Bemühungen Papens sind auch sonst nirgends nachweisbar (a.a.O., S. 216, Anm. 14).

262 Vgl. dazu Kapitel VII.1. Zur inneren Entwicklung des NS-Staates 1933/34 s. K. D. Bracher, W. Sauer, G. Schulz, die nationalsozialistische Machtergreifung. Studien zur Errichtung des totalitären Herrschaftssystems in Deutschland 1933/34. 2. Aufl., Köln u. Opladen 1962: K. D. Bracher, Die deutsche Diktatur. Entstehung, Struktur, Folgen des Nationalsozialismus, 6. Aufl., Köln 1980; M. Broszat, Der Staat Hitlers. Grundlegung und Entwicklung seiner inneren Verfassung, München 1975; K.-H. Minuth, Einleitung zu: Akten der Reichskanzlei. Regierung Hitler, Teil 1: 1933/34, Band 1 (s. Anm. 3); insbesondere zur Auflösung der Parteien: E. Matthias u. R. Morsey (Herausg.), Das Ende der Parteien 1933, Düsseldorf 1960.

263 So Prof. Emil Niethammer, der von 1935-1938 Mitglied der amtl. Kommissionen für die Erneuerung des Strafrechts und des Strafverfahrensrechts war, in seiner eidesstattl. Erkl. v. 22.11.48 (Spruchkammerakten Gürtner, StArch. München). H. Frank, Im Angesicht des Galgens, S. 170, behauptete, das von ihm 1929 in 
$\mathrm{Daß}$ er daraus kein Hehl machte, geht aus einem im Januar 1941 für ihn veröffentlichten Nachruf hervor, in dem es mit erstaunlicher Offenheit hieß:

„Er war ein scharfer Gegner der utilitaristischen Auffassung, daß Recht sei, was dem Volke nütze. Denn, so meinte er, dann müsse man zuerst den Nutzen untersuchen, und für diesen eine Norm zu finden, sei unmöglich. Der Nutzen bleibe immer eine Frage der Auslegung. Er formulierte einfacher: Das Recht nutzt dem Volke! Darum müsse das Recht gesucht werden! Der Nutzen stelle sich dann von selber ein in der Bejahung, die der gerechte Staat im Volke finde.“264

Als rechtlich denkender Mann vertrat Gürtner den Gedanken des „Rechtsstaates“ im Sinne des gesetzmäßigen Handelns der Staatsorgane wie des einzelnen und der Unabhängigkeit der Gerichte ${ }^{265}$; aber diese „Rechtsstaatlichkeit“ war bei ihm nicht absolut: Gesetzesbindung und Unabhängigkeit durften nie so weit gehen, daß ihre Ergebnisse die vitalen „nationalen“ Interessen gefährdeten. Von rechtsstaatlichen Prinzipien durfte in Situationen abgewichen werden, bei denen es die „Staatsräson“ erforderte, deren konkreten Inhalt aber jeweils der autoritäre Inhaber der souveränen Staatsgewalt bestimmte. Wie seine verfassungspolitischen, so machten Gürtner daher auch seine rechtspolitischen Vorstellungen gegenüber dem nationalsozialistischen $\mathrm{Re}-$ gime ohnmächtig: an zahlreichen Beispielen ist nachweisbar, daß Gürtner in dem Moment seinen Widerspruch gegen illegale Maßnahmen von Staats- oder Parteiorganen aufgab, in denen Hitler als Träger der obersten Staatsgewalt ihre Durchführung entschied. ${ }^{266}$ Nur solange ihm Hitlers Entscheidung nicht eindeutig oder durch den jeweiligen Übermittler „verfärbt“ schien, suchte er für das Recht zu retten, was zu retten war. ${ }^{267}$ Aber mit der grundsätzlich von ihm anerkannten Unterordnung des Rechtsstaates unter die Staatsräson öffnete Gürtner der politischen Führung eine Tür, in konkreten Fällen die Rechtsordnung zu suspendieren. Als Gürtner erkannte, zu welchen Zwecken der Vorrang der „nationalen Interessen“ vor dem Recht ausgenutzt wurde, war er längst in eine Lage geraten, aus der ihn nur noch ein Rücktritt von seinem Amt hätte befreien können.

München gesprochene Wort sei „völlig falsch wiedergegeben“ worden; er widersprach jedoch nie, wenn öffentlich behauptet wurde, er habe diesen rechtspolitischen Grundsatz geprägt, so z. B. durch den Leiter des Amtes für Rechtspolitik im Reichsrechtsamt der NSDAP H. Barth auf dem Juristentag 1936 (Rechtssicherheit und Gerechtigkeit, Deutscher Juristentag 1936, herausg. vom NSRB, Berlin o.J., S. 140).

${ }^{264}$ Vgl. den Nachruf im Fränkischen Kurier v. 30.1.41, S.3, für den Hauptschriftleiter Dr. R. Kötter, Nürnberg, zeichnete, der zu Gürtners Bekanntenkreis gehörte. In seinem Ber. an das RJM v. 3.3.41 bezeichnete der OLGPräs. Nürnberg diesen Nachruf als ein „lebensnahes Bild des Heimgegangenen“ (Akten des RJM, BA, Sign. R 22/3381). Dazu auch die Erkl. des evang.-luth. Landesbischofs Meiser v. 23.5.47: „Bekannt ist sein Ausspruch: ,Nicht recht ist, was dem Volke nützt, sondern was recht ist, nützt dem Volk'“ (Spruchkammerakten, a.a.O.).

265 In seiner Rede „Richter und Rechtsanwalt im neuen Staat“, die er am 17. März 1934 auf einer Arbeitstagung der AkDR hielt (DJ 1934, S. 369 ff.), führte Gürtner dazu aus, „der einfachste deutsche Mann würde den Richter, der auf Befehl des politischen Machthabers einen Vollstreckungstitel gäbe oder ein Todesurteil unterzeichnete, wohl als Büttel und Henker, aber nicht als Richter gelten lassen. Die richterliche Unabhängigkeit ist für uns Deutsche so untrennbar mit der Vorstellung des Rechtsstaates verbunden, daß über ihre Fortgeltung jegliche Erörterung sich erübrigt."

${ }^{266}$ Dazu wird auf die Darstellung in diesem Buch verwiesen. Als Beispiele seien an dieser Stelle nur Gürtners Haltung zur Euthanasie (Kapitel V.3.c.) und zur Exekution von Straftätern durch die Polizei (Kapitel VI.6.a.) genannt, ferner seine Reaktion auf Hitlers Weisung vom Juni 1935, alle anberaumten Verhandlungstermine in Devisenprozessen gegen katholische Ordensangehörige aus politischen Gründen auf unbestimmte Zeit zu verschieben: Gürtner warnte zwar, daß das „Rechtsgefühl des Volkes und sein Vertrauen in die Rechtspflege" dadurch „aufs schwerste erschüttert" werde, meldete aber gleichzeitig den Vollzug (vgl. Schr. Gürtners an Hitler v. 26.6.35, Akten der RK, BA, Sign. R 43 II/175).

267 Vgl. z. B. Gürtners Haltung in der Frage der Zulassung von Rechtsanwälten in Schutzhaftsachen (S. 570 f.) und der Überstellung der Sicherungsverwahrten ins KZ (S. 652). 


\section{Reichsjustizminister unter Hitler bis zum Tod im Januar 1941}

Zum besseren Verständnis von Gürtners Verhalten und seiner in den folgenden Kapiteln geschilderten Tätigkeit als Justizminister unter Hitler sei - über das bereits Angedeutete hinaus - einiges über sein Wesen, seinen Charakter und Lebensstil ausgeführt und seine persönliche Entwicklung bis zu seinem Tode im Januar 1941 dargestellt. Der Mann mit dem „gescheiten, rotgesunden, frischen Gesicht und den hellen blitzenden Augen mit dem präzisen Zwicker", wie ihn Hans Frank treffend beschreibt ${ }^{268}$ und er in zahlreichen Abbildungen überliefert ist, war trotz seines vielleicht eher robust erscheinenden Äußeren ein ausgesprochen feinsinniger, musischer und außerdem vielseitig gebildeter Mensch. Bildung, so äußerte er einmal, sei „nicht der Erwerb von Wissen“, sondern „die Sehnsucht nach Erkenntnis“. ${ }^{269} \mathrm{Er}$ verfügte auch außerhalb seines Fachgebiets über reichhaltiges Wissen auf den Gebieten der Kunst und deutschen Literatur, sprach Italienisch - die Mittel für den Unterricht hatte er sich als Oberprimaner durch Privatstunden verdient ${ }^{270}$-, Englisch und Französisch. Seine musikalische Begabung verlieh ihm eine „leidenschaftliche Liebe zur Musik, zum eigenen Cellospiel in einer schönen Kammermusik“"271 und machte ihn zu einem „Orgelspieler von Rang, für den Hausmusik mehr als Erholung bedeutete“272; nach dem Modell in einer alten hessischen Dorfkirche hatte er sich dafür eine eigene kleine Orgel anfertigen lassen. ${ }^{273}$

Menschen, die ihn näher kannten, hoben seine "unerschütterliche, fast phlegmatische sichere Ruhe“ und „schwerdurchdringliche altbayerische Beharrlichkeit“ her$\operatorname{vor}^{274}$, ferner seine „nüchterne Beurteilung, das bedachtsame Abwägen, eine Zuverlässigkeit, die jede Phrase haßte“. ${ }^{275}$ Selbst ausgeglichenen Gemütes, „allem Übermaß und Extremen abhold, suchte er seiner gütigen Natur entsprechend überall ausgleichend zu wirken “ ${ }^{276}$ Der jüdische Anwalt Fliess, der dem Ausschuß von Vertrauensmännern der jüdischen Rechtsanwälte Deutschlands angehörte und im Frühjahr 1933 mit Gürtner Härtefälle bei der Durchführung des Rechtsanwaltsgesetzes vom 7. April 1933 erörterte, charakterisierte Gürtner nach dem Kriege als einen Mann von ,innerer

268 H. Frank, Im Angesicht des Galgens, S. 132.

269 So Gürtner in einer Festrede, die er 1925 in seiner Heimatstadt Regensburg hielt (Zeitungsausschnitt o.D., Nachlaß Gürtner).

270 Vgl. Lutz Graf Schwerin von Krosigk, Es geschah in Deutschland. Menschenbilder unseres Jahrhunderts, Tübingen u. Stuttgart 1951, S.318. Gürtner hielt z.B. am 30. Mai 1939 in Rom seinen Vortrag über die Grundlagen des neuen deutschen Strafvollzugsrechts ,in vollendetem Italienisch“ (vgl. Nachruf des Generaldirektors der italienischen Strafvollzugsanstalten Giovanni Novelli, deutsche Úbersetzung aus der ital. Zeitschr. für Strafvollzugsrecht 1941, S.159, im Nachlaß Gürtner).

271 K. A. von Müller, Im Wandel einer Welt. Erinnerungen, Bd.3, 1919-1932, München 1966, S. 315.

272 Vgl. v. Krosigk, a.a.O.

273 Vgl. R. Kötter, Nachruf, a.a.O. (voranstehende Anm. 264).

274 K. A. von Müller, Aus Gärten der Vergangenheit. Erinnerungen 1882-1914, Stuttgart 1954, S. 262.

275 Vgl. v. Krosigk, a.a.O.

276 Vgl. eidesstattl. Erklärung von Dr. Sigmund Nörr v. 28.11.48 (Spruchkammerakten Gürtner, StArch. München), der seit 1928 im bayer. JM, später als MinRat im RJM tätig war. Für den Bereich der Gefolgschaft des Ministeriums vgl. dazu Schlegelberger (Nachruf beim Staatsakt v. 1.2.41, DJ 1941, S. 181): „Mit unermüdlicher Geduld und feinstem Einfühlungsvermögen suchte er stets jenen Zustand herzustellen, den er als Freund der Musik so innig erstrebte, Harmonie. " Das ausgleichende Wesen Gürtners wurde dem Verf. mündlich von den Söhnen Fritz und Franz Gürtner auch für den familiären Bereich bestätigt. 
Vornehmheit und menschlicher Güte“, von „tiefer Gerechtigkeitsliebe und warmherziger Menschlichkeit". ${ }^{277}$

Gürtner war in der Tat kein Antisemit und Rassenfanatiker ${ }^{278}$ : wie die Rassenfrage in seiner Personalpolitik als bayerischer Minister nie eine Rolle spielte und er nach 1933 seine „nichtarischen“ Mitarbeiter im Reichsjustizministerium so lange wie möglich behielt ${ }^{279}$, brach er auch private Kontakte zu jüdischen Bekannten nicht ab. Er ließ seine Kinder von dem jüdischen Arzt Dr. Reinach behandeln und verhalf dessen Sohn - einem Rechtsanwalt - zur Auswanderung. ${ }^{280}$ Der Hamburger Oberlandesgerichtspräsident und spätere Staatssekretär im Reichsjustizministerium unter Thierack, Curt Rothenberger, bestätigte Gürtner gleichfalls einen „unbestechlichen Gerechtigkeitssinn, aber leider ohne Kampfgeist“. ${ }^{281}$ In der Tat war Gürtner „keine kämpferische Natur“ ${ }^{\text {“282 }}$, die Auseinandersetzungen vom Zaun brach und den eigenen Willen aggressiv durchzusetzen suchte. „Für die Verwirklichung einer Erkenntnis im eigentlichen Sinne des Wortes zu kämpfen lag ihm nicht. Er erwartete alles von der menschlichen Einsicht, die zu erwecken er sämtliche Argumente, die es gab, ganz schlicht und ganz klar vor aller Augen legen konnte." ${ }^{283}$ Diese Beurteilung bestätigt sich z. B. bei der Lektüre der bayerischen Landtagsdebatten aus den Jahren 1922 bis 1932, in denen Gürtner auch heftigen Angriffen seiner Opponenten stets mit ruhiger Sachlichkeit begegnete, ohne selbst verletzend und ausfallend zu werden. ${ }^{284}$ Gürtner glaubte an die Überzeugungskraft des gesunden Menschenverstandes, von dem er selbst ein gerüttelt Maß besaß ${ }^{285}$, und des fundierten, fachlichen Urteils: „Alle Labyrinthe des formalen Rechtes schienen sich vor seinen Augen in übersichtliche Ordnungen aufzulösen, und

277 Vgl. eidesstattl. Versicherung des RAs Dr. Fliess v. 5.11.47 (a.a.O.). Den ausgeprägten Gerechtigkeitssinn Gürtners heben gleichfalls hervor: v. Krosigk, a.a.O.; v. Müller, Im Wandel einer Weit, S.315; eidesstattl. Versicherungen von: Prof. Emil Niethammer (s. voranstehende Anm. 263) v. 22.11.48, Dr. Werner Grussendorf (MinRat im RJM, später RGRat) v. 19.4.49, RA Dr. Rüdiger Graf von der Goltz v. 10.11.48, Dr. Sigmund Nörr (s. voranstehende Anm.) und Dr. Erich Volkmar (MinDir. im RJM) v. 6.3 .49 (sämtlich Spruchkammerakten Gürtner, a.a.O.).

${ }^{278}$ Vgl. z.B. seine Weigerung in der Strafrechtskommission 1934, die von Freisler geforderten Bestimmungen zum „Rasseschutz" in den Entwurf eines neuen StGB aufzunehmen, und seine dortigen despektierlichen Äußerungen über die „nordische Rasse“ (s. Kapitel VII.3.c., S. 868); ferner die von ihm gegen den Widerstand der nationalsozialistischen Landesjustizminister erreichte Durchsetzung von Ausnahmen bei der gesetzlichen Regelung des Berufsverbots für jüdische Rechtsanwälte im April 1933 (s. Kapitel IIl.1.a., S. $136 \mathrm{ff}$., $139 \mathrm{ff}$.); s. auch die Hilfe, die er und sein Ministerium dem früheren RJM und „Volljuden“ Curt Joël angedeihen ließen (K.-D. Godau-Schüttke, Rechtsverwalter des Reiches. Staatssekretär Dr. Curt Joël, Frankfurt a. M. 1981, S. $221 \mathrm{ff}$.).

279 Vgl. Näheres im Kapitel III.3.a., S. 242 f., 248 f., 251 ff.

280 Vgl. die eidesstattl. Erklärungen von Frau Oberin Irma Lümkemann (zur Person s. Anm. 302) v. 27.5.47 und von Dr. Sigmund Nörr v. 24.5. 47 (Spruchkammerakten Gürtner, a.a.O.).

281 So Rothenberger in den nach seiner Entlassung als Sts. geschriebenen Aufzeichnungen: Im Kampf ums Recht (1944), Abschnitt B, S. 5 (BA, Personalakten des RJM Curt Rothenberger).

282 Vgl. Erklärung von Dr. Walter Kriege (MinRat im RJM, nach Gürtners Tod MinDirig.) v. 28. 5. 49 (Spruchkammerakten Gürtner a.a.O.).

283 Vgl. R. Kötter, Nachruf, a.a.O. (Hervorheb. im Original).

284 Vgl. die Protokolle in den entsprechenden Bänden der „Verhandlungen des Bayerischen Landtags. Stenographische Berichte“. Als weiteres Beispiel der gelassenen Reaktion Gürtners s. die Konferenz der Landesjustizminister in Stuttgart v. 6.5.33 (Kapitel III.1.a., S. $148 \mathrm{ff}$.).

28s Der langjährige persönl. Ref. Gürtners Hans v. Dohnanyi (Näheres über ihn s. Kapitel III.3.a., S. 253 ff.) beschrieb Gürtner 1943 als einen „Mann von der umfassenden Erfahrung und dem tiefen Wissen um den Menschen ..., der bei aller Güte, die sein Wesen bestimmte, ein so großer Skeptiker war“. Vgl. Eingabe an Oberreichskriegsanwalt Kraell v. 29.8.43, Nachlaß Dohnanyi (obige Anm. 39). 
innerhalb ihrer Welt gab es gegen seine Entscheidungen kaum einen Einwand.“286 Sein Kollege in den beiden Reichskabinetten vor Hitler, Reichswirtschaftsminister Freiherr von Braun, sah in Gürtner „ein wandelndes Beispiel für das hohe Maß an Klarheit und Folgerichtigkeit des Denkens" und berichtete, er habe in Kabinettssitzungen mehrfach erlebt, „daß nach wogendem Hin und Her der Ansichten Gürtner eine zusammenfassende Darstellung gab, die meist schon die klare Entscheidung enthielt““287 Wer die Protokolle der unter Gürtners Vorsitz tagenden amtlichen Strafrechts- und Strafprozeßkommissionen studiert, kann der Beobachtung von Brauns nur beipflichten: Gürtner bewies auch hier ein erstaunliches Talent, die zerfahrene Diskussion immer wieder zusammenzuführen, komplizierte Fragen auf einen einfachen Nenner zu bringen und den jeweils entscheidenden Punkt mit seinen praktischen Auswirkungen herauszustellen. ${ }^{288}$ Dazu besaß er einen überlegenen Humor, der auch ernste Angelegenheiten farbig und anschaulich machte. ${ }^{289}$ Die Kunst der Verhandlungsführung, die durch den „Klang der ruhigen Stimme, die gepflegte Sprache, die dabei nie die bayerische Färbung verlor ${ }^{\text {“290 }}$, unterstützt wurde, verfehlte manchmal sogar Hitler gegenüber ihre Wirkung nicht: laut Hitlers Adjutanten Wiedemann hatte Gürtner „eine besonders geschickte Art, Hitler auch Entscheidungen abzuringen, die gegen seine ursprüngliche Absicht gingen".291 Wo immer er auftrat, übte er eine „selbstverständliche Autorität“ aus, „obwohl er sie nicht hervorkehrte“. ${ }^{292}$ Ein Beispiel dafür bietet jene Sitzung unter Schlegelbergers Vorsitz im Reichsjustizministerium am Vormittag des 7. April 1933, auf der die nationalsozialistischen Landesjustizminister in ziemlich aggressiver Form die ausnahmslose Entfernung aller Juden aus der Rechtsanwaltschaft forderten: da Schlegelberger mit ihnen „nicht fertig“ wurde, mußte gegen Mittag der an Mittelohrentzündung erkrankte Gürtner in die Sitzung geholt werden, dem es gelang, „die Verhandlungen zunächst in etwas ruhigere Bahnen zu lenken“ und schließlich am Nachmittag bei Hitler die Wiederzulassung der von den Landesjustizministern bereits ausgebooteten jüdischen Frontkämpfer und Alt-Anwälte zu erreichen. ${ }^{293}$ Dabei blieb Gürtner stets „anspruchslos und war bescheiden bis zur Selbstverleugnung“. ${ }^{294}$ Schlegelberger hob die Bescheidenheit Gürtners in einem Nachruf

286 Vgl. v. Müller, Aus Gärten der Vergangenheit, S. 262.

287 Magnus Frhr. von Braun, Von Ostpreußen bis Texas. Erlebnisse und zeitgeschichtliche Betrachtungen eines Ostdeutschen, Stollhamm 1955, S. 239.

288 Vgl. die Protokolle der amtlichen Strafrechtskommission 1933-1936 (Schubert, Quellen II, Bd.2. Teile 1-4) und der Großen Strafprozeßkommission 1936-1938 (a.a.O. III, Bd.2. Teile 1-3). Dazu Kommissionsmitglied Niethammer (a.a.O., obige Anm. 263): „Er verstand es, jeden Vorschlag, der das Recht gefährden konnte, in seiner Wirkung aufzuklären und damit abzuwenden.“

289 Nach Krosigk (a.a.O., S.319) bedurfte Gürtner in den späteren Jahren allerdings „der Philosophie, um nicht das Lachen zu verlieren“.

290 R. Kötter, Nachruf, a.a.O.

291 Wiedemann fährt fort, Gürtner habe „auf diese Weise eine Reihe von Fällen zurechtgebogen, die ohne sein Dazwischentreten ungünstig für den Betroffenen ausgegangen wären" (eidesstattl. Erklärung v. 4.12.48, Spruchkammerakten Gürtner, a.a.O.), und nennt den Fall des Rennfahrers Manfred v. Brauchitsch (vgl. dazu Diensttageb. des RJM, Bd.8, Eintr. v. 28.4.36; Bd.10, Eintr. v. 11.1.37, Arch. des IfZ, Sign. F 90) und den Fall Rasmussen (vgl. dazu zahlreiche Eintr. in Gürtners erhalten gebliebenen beiden Notizkalendern aus den Jahren 1937 und 1938, Nachlaß Gürtner).

292 Vgl. v. Müller, Im Wandel einer Welt, S.315.

293 Die Vorgänge an jenem "Schwarzen Freitag“ schildert anschaulich Prof. R. Pohle, der als LGRat bzw. LGDir. bis Kriegsausbruch im RJM tätig war (eidesstattl. Versicherung v. 1.12.48, Spruchkammerakten, a.a.O.). Vgl. dazu Kapitel III.1.a., S. 136 f.

294 Vgl. v. Krosigk, a.a.O., S. 318. 
vom August 1941 als einen „Grundzug seines Wesens“ hervor: er sei ein Mann gewesen, „der nichts für sich, aber ... stets am meisten von sich selbst verlangte, und sein Glück darin fand, anderen mit Rat und Tat zur Seite zu stehen“; das Gebot „Mehr sein als scheinen" habe er wie kein anderer beherzigt. ${ }^{295}$

Diese Anspruchslosigkeit bewies Gürtner auch im privaten Bereich. Im Gegensatz zu vielen NS-Größen, die im Dritten Reich zu Amt und Würden kamen, erwarb Gürtner keinen Grundbesitz, baute keine Villa, sondern lebte mit seiner Familie in einer Dienstwohnung im Gebäude des Ministeriums in der Voßstr. 5, ab Dezember 1936 - als das Gebäude für die Erweiterung von Hitlers Reichskanzlei abgerissen wurde in einem gleichfalls der Justizverwaltung gehörenden Haus mit Garten in Berlin-Dahlem, Cecilienallee 27. Sofort nach Kriegsbeginn verzichtete er für die Fahrt zwischen Wohnung und Ministerium auf einen Dienstwagen und legte den Weg mit der UBahn zurück, obwohl er dabei abends durch verdunkelte Straßen laufen mußte. ${ }^{296}$ Der einzige größere Luxus, den sich Gürtner in den letzten Friedensjahren leistete, war ein Motor-Kajütboot, mit dem die Familie auch mehrtägige Fahrten auf den Seen, Flüssen und Kanälen rings um Berlin bis zur Mecklenburgischen Seenplatte unternahm. ${ }^{297}$ Denn in der Natur, im Kreise der Familie - das Familienleben war sehr harmonisch - und bei häuslicher Musik verbrachte Gürtner seine freien Stunden und fand er seine Entspannung. ${ }^{298}$ Wie in der Münchener Zeit wurde der Haushalt auch in Berlin in einfacher bürgerlicher Weise geführt. Bei privaten und repräsentativen Gesellschaften erfüllte Gürtner seine Gastgeberpflichten durch „gute ernste Musik und einfache Bewirtung ${ }^{\text {(299 }}$; Prunk und Protzerei lagen ihm fern. Die einfache Lebensart kam nicht nur vom volksverbundenen süddeutschen Milieu her, dem Gürtner entstammte, sondern war auch im Charakter seiner Lebensgefährtin begründet, die „weder Ehrgeiz noch Geltungsdrang besaß ${ }^{\text {“300 }}$, gesellschaftlich nie die Rolle der „großen Dame“ spielen wollte, sondern als Hausfrau ganz in der Sorge um die Familie aufging. ${ }^{301}$ Politisch nicht engagiert - sie hatte die Aufforderung, auch nur der NSFrauenschaft beizutreten, mehrmals abgelehnt ${ }^{302}$-, war sie um so stärker in der evan-

295 In einem Artikel zum Gedächtnis von Gürtners 60. Geburtstag am 26. August 1941 (DJ 1941, S. 849).

296 Vgl. die Aussage seiner Ehefrau Luise Gürtner im Prot. der öffentlichen Spruchkammersitzung in Bad Tölz am 14.7.47 (Spruchkammerakten Gürtner, StArch. München). Die Tatsache wird bestätigt durch Gürtners Begründung zum Antrag auf einen Waffenschein v. 19.9.39 (Personalakten Gürtner, BA).

297 Vgl. Eintr. in Gürtners Notizkalender von 1937 u. 1938 (Nachlaß Gürtner).

298 Vgl. eidesstattl. Erklärung o.D. von Frau Christine v. Dohnanyi, Ehefrau Hans v. Dohnanyis, die zu Gürtners engeren Bekanntenkreis gehörten. Bei den Eintr. in Gürtners Notizkalender von 1937/1938 (a.a.O.) heißt es auffallend häufig: „Abends zu Hause“, „Abends Hausmusik“ usw.

299 Vgl. die eidesstattl. Erklärungen von: Christine v. Dohnanyi (s. voranstehende Anm.) o.D., Dr. Sigmund Nörr (s. Anm. 276) v. 24.5.47, Dr. Cécil von Renthe-Fink (ab 1936 deutscher Gesandter in Dänemark) v. 19.1.50 und Dr. Kurt Schmitt (Reichswirtschaftsminister Juli 1933-August 1934) v. 12.1.49 (sämtlich Spruchkammerakten Gürtner, a.a.O.).

300 Eidesstattl. Erklärung Christine v. Dohnanyi, a.a.O.

301 Eidesstattl. Erklärungen von: Prof. Eduard Kohlrausch (Mitgl. der amtlichen Strafrechtskommission, mit der Familie Gürtner befreundet) v. 5.9.47, MinDirig. im RMdI a.D. Max Schattenfroh (Maximilianeer seit 1909) v. 20.6.47 und Dr. Friedrich Bretzfeld (seit 1905 im bayer. Justizdienst, zuletzt SenPräs. am OLG München, Schwager Gürtners) v. 20.5.47 (Spruchkammerakten, a.a.O.). Als Beispiel dafür, daß Frau Gürtner stets nur unter ihrem einfachen Namen ohne Titel auftrat, führt Bretzfeld an, daß sie sich auch beim Besuch ihres verwundeten Sohnes 1944 in Linz nicht zu erkennen gab und daraufhin ebenso wie jeder andere nur für drei Tage Aufenthaltserlaubnis bekam; vgl. Prot. der Spruchkammersitzung Bad Tölz v. 14.7.47 (a.a.O.).

302 Vgl. Entsch. der Spruchkammer Bad Tölz v. 15.7.47 (a.a.O.); eidesstattl. Erklärung der Oberin Irma Lümkemann (Leiterin des Prinzessin Arnulf Krankenhauses in München, mit Frau Gürtner seit deren Eintritt als Schwesternschülerin 1915 bekannt) v. 27.5.47 (a.a.O.). 
gelischen Kirche gebunden und sorgte für eine streng christliche Erziehung ihrer drei Söhne: der Dahlemer bekennenden Gemeinde des vom Regime angefeindeten Pastor Niemöller zugehörig, waren die Jungen mit den Söhnen des in derselben Straße wohnenden Niemöller eng befreundet. ${ }^{303}$ Erhalten gebliebene Briefe von Luise Gürtner an ihren Mann vom September 1932 - als der neu ernannte Reichsjustizminister zum ersten Mal längere Zeit von seiner Familie getrennt lebte - zeugen von harmonischen Beziehungen zwischen den Eheleuten und von einer selbstverständlichen und natürlichen Religiosität. So schrieb sie z. B., sie habe keinen Zweifel, daß er den Anforderungen seiner neuen Aufgabe gewachsen sein werde: „... denn mit Dir ist immer Gott. Er wird Dich sicher auch in diesem schweren Amt beschützen und stärken“. ${ }^{304}$ Auch Gürtner war - ohne praktizierendes Mitglied der katholischen Kirche zu sein „ein gläubiger Christ" ${ }^{405}$ mit hohen sittlichen und moralischen Maßstäben, der auch in der Öffentlichkeit aus seinem Glauben an den überirdischen Ursprung des Rechtes kein Hehl machte. Auf einer Arbeitstagung der Akademie für Deutsches Recht im März 1934 führte er aus, der Fortschritt in den Naturwissenschaften habe die Menschen ,in die Versuchung geführt zu glauben, daß alles, was nicht materiell, d.h. was nicht wägbar, meßbar und zählbar ist, nicht wirklich vorhanden sei oder jedenfalls im Leben eines Menschen ... keine besondere Bedeutung habe“. Aber „der Urquell des Rechtes läßt sich so wenig mit dem Verstande begreifen, wie etwa der Urquell der Kunst oder der Religion“. ${ }^{306}$ In juristischen Erörterungen Gürtners wird seine Religiosität immer wieder spürbar. ${ }^{307} \mathrm{Zu}$ dem ihm seit 1923 bekannten Orgelbauer Steinmeyer äußerte er: „Etwas können sie [die Nationalsozialisten] uns doch nicht nehmen: das Wissen, das Können und die Religion."308

Bei Gürtners anständigem Charakter und seiner menschlichen Gesinnung war es nicht verwunderlich, daß sich von den Maßnahmen des Regimes Betroffene oder deren Angehörige um Hilfe an ihn wandten und dabei vertrauensvoll ihr Herz ausschütteten, ohne Unannehmlichkeiten befürchten zu müssen. ${ }^{309}$ Daß Gürtner in dieser

${ }^{303}$ Vgl. D. Martin Niemöller, Bescheinigung v. 21.5.47 u. eidesstattl. Erklärung v. 24.1.50 (a.a.O.) und eidesstattl. Erklärung Irma Lümkemann (s. voranstehende Anm.). Im November 1940 trat der jüngste Sohn Heinz zusammen mit den beiden Dohnanyi-Söhnen in das Klostergymnasium Ettal (Obb.) ein, obwohl der bayer. Innen- und Unterrichtsminister, Gauleiter Wagner, den Klosterschulen schon 1938 jegliche Neuaufnahmen verboten hatte; vgl. Bestätigung des Abts Dr. Angelus Kupfer v. 22.5.47 (a.a.O.).

$304 \mathrm{Vgl}$. Brief v. 10.6.32 (Nachlaß Gürtner).

305 Vgl. die Memoiren von Wolfgang Heintzeler, Der rote Faden, Stuttgart 1983, S.40, der als württemb. Assessor von 1934 bis 1936 persönl. Ref. von Sts. Schlegelberger im RJM war; ferner die eidesstattl. Erklärungen von Nörr v. 24.5.47, von Domkapellmeister Prof. Schrems v. 6.8.49 und von Niethammer v. 22. 11.48, der schreibt, Grundzug von Gürtners Wesen sei „eine tiefe Frömmigkeit“ gewesen (Spruchkammerakten Gürtner, a.a.O.).

306 Vgl. Richter und Rechtsanwalt im neuen Staat (DJ 1934, S.370). Ähnlich sein Kieler Vortrag v. Oktober 1934, Einheitliche Justiz im einheitlichen Reich (a.a.O., S. 1332).

307 So, wenn er z.B. über den Richter ausführt: „Das Wort vom Paulus, das ja in weiterem Sinn für alles Menschenwerk gilt, gilt nach meinem Empfinden in ganz besonderem Maße für das Amt des Richters: Wenn ich mit Menschen- und Engelszungen redete und hätte der Liebe nicht, so wäre ich ein tönend Erz und eine klingende Schelle“ (a.a.O., S.371), oder wenn er über das große Maß der Verantwortung bei der Entscheidung über die Sicherungsverwahrung eines Verbrechers spricht und dabei mahnt: „Kein Mensch weiß mit Sicherheit, wie ein anderer sich in Zukunft verhalten werde; das weiß nur Gott“ (Grundgedanken des kommenden deutschen Strafrechts und Strafvollzugs, DJ 1939, S.979).

308 Vgl. Erklärung Hans Steinmeyers v. 12.2.48 und sein Schr. an Franz Gürtner jr. v. 29.11.66 (Privatkorrespondenz der Familie Gürtner).

309 Vgl. zahllose Vorgänge in der Korrespondenz von Gürtners Ministerbüro (Akten des RJM, BA, Sign. R. 22/ 4091-4155); z. B. auch I. Litten, Eine Mutter kämpft gegen Hitler, 2. Aufl. Rudolstadt 1985, S. 58 ff., betr. RA Hans Litten, der als Verteidiger kommunistischer Angeklagter verfolgt wurde. 
Hinsicht als absolut vertrauenswürdig galt, geht daraus hervor, daß diese Beschwerden in der ersten Zeit häufig mit Warnungen vor den Absichten der Nationalsozialisten und Befürchtungen über die weitere Entwicklung verbunden waren; dafür spricht auch, daß der bayerische Gesandte Sperr noch Ende Februar mit ihm ganz offen Fragen wie den eventuellen Einsatz der Reichswehr gegen die Nationalsozialisten durch Hindenburg nach der Märzwahl oder Absichten zur Wiederherstellung der Monarchie erörtern konnte. ${ }^{310}$ Aus der erhalten gebliebenen Korrespondenz seines Ministerbüros geht hervor, daß sich Gürtner um die Eingaben tatsächlich kümmerte, bei offensichtlichen Ungerechtigkeiten im eigenen Zuständigkeitsbereich half, soweit es sich mit den Vorschriften nur irgendwie vereinbaren ließ, oder sich an seine nichtnationalsozialistischen Ressortkollegen wandte: z. B. aus politischen Gründen Entlassene mit Empfehlungen an Reichswehrminister v. Blomberg zur Unterbringung in der Wehrmacht vermittelte ${ }^{311}$ oder wegen der Unterstützung entlassener jüdischer Beamter an den preuBischen Finanzminister Popitz schrieb. ${ }^{312}$ Selbst in Schutzhaftsachen bat er den Innenminister, wenigstens die Notwendigkeit einer weiteren Inhaftierung beschleunigt zu prüfen. Es waren nicht nur deutschnationale Parteigänger, ehemalige Kriegskameraden oder Zöglinge des Maximilianeums, die Gürtner um Hilfe angingen, sondern auch seine ehemaligen politischen Opponenten, die Sozialdemokraten. So nutzte z.B. Hoegner im Mai 1933 seine landsmannschaftlichen Beziehungen zu Gürtner, um ihn zu bitten, sich für die Freilassung des sozialdemokratischen Abgeordneten Erhard Auer einzusetzen, der im bayerischen Kabinett Eisner Innenminister gewesen war. Gürtner, der beim Empfang des Bittbriefes „zunächst ratlos“ war, kam eine Kurzmeldung in der Londoner „Times“ zu Hilfe, daß „der im Jahre 1919 von den Kommunisten schwer verwundete" Auer nunmehr von den Nationalsozialisten verhaftet worden sei: es gelang Gürtner, „wegen des Aufsehens im Ausland“ von den damals noch zuständigen bayerischen Instanzen die Freilassung Auers zu erreichen. ${ }^{313}$ Er versicherte auch Hoegner selbst - der aufgrund des Berufsbeamtengesetzes vom April 1933 aus dem bayerischen Justizdienst entlassen worden war und Gürtner im Frühsommer 1933 mehrmals in Berlin aufsuchte, um Beschwerden vorzubringen -, daß er sich „zu jeder Tages- und Nachtzeit telefonisch an ihn wenden“ könne, falls er seines Schutzes bedürfe. ${ }^{314}$ Der Präsident des Deutschen Anwaltvereins, der im Mai 1933 sein Amt niederlegte, nahm in der Folgezeit häufig Gürtners Hilfe bei der anwaltschaftlichen Vertretung politisch Verfolgter in Anspruch und berichtete, Gürtner habe „immer ein offenes Ohr und Hilfsbereitschaft" gezeigt; obwohl der Einfluß des Justizministers begrenzt gewesen sei, habe Dix „niemals den Eindruck gehabt, daß er weniger tat und

${ }^{310}$ Vgl. dazu Schwend, a.a.O., S. 524 .

311 So z. B. im Falle des früheren Hauptschriftleiters der Münchner Neuesten Nachrichten, Fritz Büchner, der 1933 auch vorübergehend verhaftet war. Vgl. Gürtners Schr. v. 26.7.36 an das Wehrbezirkskommando Darmstadt: es handle sich bei Büchner um einen „einwandfreien Charakter und fähigen Kopf, der für eine Führerstellung in Frage kommen dürfte“ (Korrespondenz Ministerbüro, a.a.O., Sign. R 22/4095).

312 Im Falle des mit gekürztem Gehalt entlassenen nichtarischen Landrats Heinrich Cossmann - Frau Cossmann hatte sich in einem Bittbrief an Frau Gürtner gewendet - schrieb Gürtner am 16.3.37 an Popitz, "nach dem Buchstaben des Gesetzes" sei die Sache zwar in Ordnung. „Ich glaube aber nicht, daß diese Regelung der Billigkeit und Gerechtigkeit entspricht. Was könnte man in der Sache tun?"“ Popitz teilte ihm wenige Tage später mit, die Sache sei „aussichtslos“ (a.a.O., Sign. 4098).

${ }^{313}$ Vgl. Schr. Hoegners an Gürtner v. 26.5.33 (a.a.O., Sign. 4091), ferner W. Hoegner, Der schwierige Außenseiter. Erinnerungen eines Abgeordneten, Emigranten und Ministerpräsidenten, München 1959, S.112 f.

314 Vgl. Hoegner, a.a.O., S. 106, 115 f. 
weniger erreichte, als ihm zu erreichen möglich war". 315 Seine Verzweiflung darüber, daß er in dieser Beziehung wenig genug tun konnte, drückte Gürtner im Mai 1935 „sehr erregt" dem Berliner Oberbürgermeister Sahm gegenüber aus, nachdem sich ein amerikanischer Journalist bei ihm nach dem Schicksal eines Verhafteten erkundigt hatte:

„Er möchte schon gar nicht mehr in eine Gesellschaft gehen, wo er Ausländer antreffen könnte. Denn regelmäßig würden ihm ähnliche Fragen wie heute vorgelegt, immer mit leichtem Hinweis auf den Begriff des Rechtsstaates. Es sei zum Verzweifeln. In den letzten Wochen seien wieder sechs Morde in den Konzentrationslagern vorgekommen. Wenn man Himmler das erzähle, dann bekomme man die Antwort, er müsse die kommunistische Gefahr bekämpfen.“

Auf Sahms Frage, ob denn hier der zuständige Reichsinnenminister Frick nicht Abhilfe schaffen könne, antwortete Gürtner: „Göring und Heydrich wiegen mehr als 100 Frick. “316

Das Verhalten Gürtners innerhalb seines eigenen Ressorts geht aus der vorliegenden Arbeit hinreichend hervor. Ergänzend dazu seien drei Komplexe erwähnt, die Gürtners Bemühungen um die Aufrechterhaltung des Rechts zeigen: der Fritsch-Prozeß, die Sittlichkeitsprozesse gegen katholische Geistliche und Ordensangehörige sowie die Prozesse gegen die Repräsentanten der lutherischen Bekennenden Kirche Dibelius und Niemöller. Da diese Ereignisse in der Literatur ausführlich dargestellt worden sind ${ }^{317}$, sei für die Beurteilung Gürtners nur folgendes hervorgehoben. In der Fritsch-Affäre von 1938 erreichte Gürtner durch sein von Hitler angefordertes Gutachten, an dessen Ausarbeitung auch v. Dohnanyi beteiligt war ${ }^{318}$, daß die von der Gestapo gegen den Generalobersten aus politischen Gründen aufgestellte Beschuldigung homosexueller Verfehlungen durch eine ordnungsgemäße Voruntersuchung und ein mündliches kriegsgerichtliches Verfahren entkräftet und Fritsch freigesprochen wurde. ${ }^{319}$ Wie Gürtner gegenüber dem Verteidiger Fritschs, Graf von der Goltz, bemerkte, wollte er dadurch „über den vorliegenden Fall hinaus allen maßgeblichen Persönlichkeiten ein für allemal klarmachen“, wie verhängnisvoll die Methoden der Ge-

315 Vgl. eidesstattl. Versicherung Dr. Rudolf Dix v. 24.10.47 (Spruchkammerakten Gürtner, StArch. München). Auch Carl Goerdeler „hat viele schwierige Fälle mit ihm besprochen und hat stets volles Verständnis und Beistand gefunden“, vgl. Erklärung von Anneliese Goerdeler v. 8.7.49 (a.a.O.).

316 Vgl. Tagebuchnotizen des Berliner Oberbürgermeisters Dr. Sahm, Eintr. 14.5.35, zit. bei H. Krausnick, Vorgeschichte und Beginn des militärischen Widerstandes gegen Hitler, in: Vollmacht des Gewissens, herausg. von der Europäischen Publikation e.V., Frankfurt a. M.-Berlin 1960, S. 271.

317 Vgl. Graf Kielmansegg, Der Fritschprozeß 1938. Ablauf und Hintergründe, Hamburg 1949; U. Stock, Der Fritsch-Prozeß 1938. Seine rechtliche Beurteilung und seine Lehren, in: Festschrift für Heinrich Lehmann zum 80. Geburtstag, Das deutsche Privatrecht in der Mitte des 20. Jahrhunderts, Berlin-Tübingen-Frankfurt a. M. 1956, S.625 ff.; H. G. Hockerts, Die Sittlichkeitsprozesse gegen katholische Ordensangehörige und Priester 1936/37. Eine Studie zur nationalsozialistischen Herrschaftstechnik und zum Kirchenkampf, Mainz 1971; F. Gollert, Dibelius vor Gericht, München 1959; W. Niemöller, Macht geht vor Recht. Der Prozeß Martin Niemöller, München 1952; J. Schmidt, Martin Niemöller im Kirchenkampf, Hamburg 1971.

318 Vgl. dazu den Bericht Christine v. Dohnanyis (Aufzeichnungen o.D., Arch. des IfZ, Sign. ZS 603): „Tatsächlich hatte Hitler bei der Übergabe der Akten zu Gürtner gesagt: ,Sie werden von selbst wissen, an welchem Tauende Sie zu ziehen haben.' Ich entsinne mich dieser Äußerung deshalb sehr gut, weil mein Mann mir erzählte, Gürtner habe ihm die Akten mit einem ,Augurenlächeln“ übergeben und dabei gesagt, er wiederhole nur die Worte, die der Führer zu ihm gesprochen hätte, das genüge wohl zwischen ihnen beiden. Er meinte nicht das Tauende Hitlers."

319 Kielmansegg, a.a.O., S.48; Stock, a.a.O., S.931. Am 17.3.38 notierte Gürtner in seinen Notizkalender: „Ab $10 \mathrm{~h}$ Fortsetz[ung] der Verh[andlung] i.S. F[ritsch]. Veritas vicit“ (Nachlaß Gürtner). 
stapo und die Verurteilung aufgrund von Polizeiakten ohne Einschaltung der Justiz seien. ${ }^{320}$ Bei den erwähnten Sittlichkeitsprozessen gegen katholische Welt- und Ordensgeistliche 1936/37 sorgte Gürtner dafür, daß durch die Einrichtung einer "Sonderstaatsanwaltschaft Koblenz", die unmittelbar dem Justizministerium unterstellt wurde, den Übergriffen der Gestapo bei den Ermittlungen Einhalt geboten und ein geordneter Rechtsweg gesichert werden konnte. ${ }^{321}$ Nicht verhindern konnte er dabei allerdings, daß diese sachlich durchgeführten Prozesse zu Propagandaaktionen für den nationalsozialistischen Kirchenkampf umgemünzt wurden: obwohl er Hitler gegenüber geschickt argumentierte, daß durch Propaganda „der wuchtige Eindruck der Prozesse nicht gestärkt, sondern geschwächt“ werde ${ }^{322}$, mußte er zu Propagandazwecken das Prozeßmaterial den Parteistellen und dem Reichspropagandaministerium zur Verfügung stellen und auf ausdrückliche Weisung Hitlers sogar die Prozesse auf bestimmte Zeiten legen. ${ }^{323}$ Daß Gürtners Sympathie aber auf seiten der bedrängten Kirchen lag, wird durch seine Bereitwilligkeit bezeugt, die Nöte und Beschwerden der Vertreter der Bekennenden Kirche anzuhören und ihnen nach Möglichkeit zu helfen. ${ }^{324}$ In den Prozessen, die den damaligen Superintendenten Dibelius betrafen - es handelte sich um einen durch zwei Instanzen gehenden Privatklageprozeß in den Jahren 1935/36, in dem Dibelius von dem Vorwurf des Hoch- und Landesverrats entlastet wurde, und um ein Heimtückeverfahren im Jahre 1937, in dem der Kirchenführer freigesprochen wurde ${ }^{325}$, und im Sondergerichtsprozeß gegen Pfarrer Niemöller von $1938^{326}$ wehrte Gürtner Versuche der Partei ab, durch massive Einschüchterung und andere Eingriffe auf die Prozesse einzuwirken, und sicherte damit unabhängige und einwandfreie Gerichtsverfahren. ${ }^{327}$ Gürtner, der Niemöller in den vorangegangenen Jahren „von Zeit zu Zeit durch Vertrauensmänner“ über die Absichten der Machthaber im Kirchenkampf hatte informieren und ihn wenige Tage vor seiner Verhaftung

$320 \mathrm{Vgl}$. Kielmansegg, a.a.O., S. $48 \mathrm{f}$.

321 Vgl. Hockerts, a.a.O., S. 10 f., 21 ff., $26 \mathrm{ff}$., 217.

322 Vgl. das zum Vortrag bei Hitler bestimmte Schr. Gürtners an den Chef der RK Lammers v. 22.6.37, zit. a.a.O., S.61.

323 A.a.O., S.65f., 73 ff. Über die Methode für die Ausführung dieser Weisung vgl. Kapitel VIII.3., S. 1106, Anm. 59 a.

324 Vgl. dazu den Bericht von Bischof Dibelius v. 24. 11.48; ferner die eidesstattl. Erklärungen von Kirchenpräsident Niemöller v. 24.1.50; vom Präsidenten des Centralausschusses für die Innere Mission der Deutschen Evangelischen Kirche D. Paul Braune v. 22.4.49; von Oberkirchenrat D. Thomas Breit v. 9.1.50 („Herr Dr. Gürtner machte keinen Hehl daraus, daß nach seiner Überzeugung das Recht auf Seiten der Bekennenden Kirche stand."); von Landesbischof D. Meiser v. 23.5.47 (sämtlich Spruchkammerakten Gürtner, StArch. München); ferner den Ber. von Pfarrer Karl-Otto Stoffer v. 31.1.86 über den Empfang einer Bittdelegation aus dem Ruhrgebiet nach Niemöllers Verhaftung, bei dem Gürtner das Gespräch mit der Bemerkung einleitete, „daß sie ganz offen mit ihm sprechen könnten. Sie hätten von seiner Seite nichts zu befürchten“ (Privatkorrespondenz der Familie Gürtner).

325 Vgl. Urt. des AG Neuruppin v. 18.4.35 und Urt. des SG I beim LG Berlin v. 6. 8. 37, H. Schorn, Der Richter im Dritten Reich. Geschichte und Dokumente, Frankfurt a.M. 1959, S. 560 ff., 565 ff. Das zweitinstanzliche Urt. des LG Neuruppin von 1936 fehlt a.a.O.

326 Vgl. Urt. des SG II beim LG Berlin v. 3.3.38. Hinsichtlich des Vorwurfs der Heimtücke wurde N. für nicht schuldig befunden, aber wegen Kanzelmißbrauchs, Zuwiderhandlungen und Aufforderung zum Ungehorsam gegen ministerielle Anordnungen zu 7 Monaten Festungshaft und 2000 RM Geldstrafe verurteilt. Die Freiheitsstrafe und 500 RM Geldstrafe wurden durch die Untersuchungshaft als verbüßt angesehen (Schorn, a.a.O., S. 589 ff., W. Niemöller, a.a.O., S.83ff.). Auf Festungshaft statt auf Gefängnis durfte „nur dann erkannt werden, wenn die Tat sich nicht gegen das Wohl des Volkes gerichtet und der Täter ausschließlich aus ehrenhaften Beweggründen gehandelt hat" ( $\$ 20 \mathrm{StGB})$.

327 Vgl. F. Gollert (Anwalt von Dibelius), a.a.O., zu Gürtner insbes. S. $131 \mathrm{ff} ., 138 \mathrm{ff}$. M. Niemöller, eidesstattl. Erklärung v. 24.1.50 (Spruchkammerakten Gürtner, AG München, Registratur S), W. Niemöller, a.a.O., S.83f. 
hatte warnen lassen ${ }^{328}$, konnte nicht verhindern, daß die Gestapo Niemöller nach der Urteilsverkündung im Gefängnistrakt des Moabiter Gerichtsgebäudes verhaftete, obwohl die verhängte Freiheitsstrafe durch die erlittene Untersuchungshaft als verbüßt angesehen und der richterliche Haftbefehl aufgehoben worden war. Auch seine Bemühungen, Niemöllers Freilassung in einer persönlichen Unterredung mit Hitler in Linz am 8. April 1938 und später wenigstens seine Verlegung aus dem Konzentrationslager - möglicherweise durch die Einleitung eines neuen Strafverfahrens gegen ihn - zu erreichen, schlugen fehl. ${ }^{329}$

$\mathrm{Zu}$ Gürtners humanitären Beweggründen, Unrecht dort, wo er es nicht verhindern konnte, zu mildern, abzuschwächen, manchmal auch nur aufzuschieben, um Zeit zu gewinnen, und in seinem Ressort wenigstens in bescheidenen Grenzen im Sinne der Erhaltung des Rechtsstaatsgedankens zu wirken, dürfte später der Wunsch hinzugetreten sein, seinen Irrtum bezüglich des Wesens und der wahren Ziele Hitlers und des Nationalsozialismus wieder gutzumachen. Jedenfalls darf man unterstellen, daß sein Handeln nicht nur vom Ressortegoismus und der Verteidigung von Zuständigkeiten der Justiz diktiert, sondern auch ethisch motiviert war. ${ }^{330}$ Bei seinen Bemühungen, in der Gesetzgebung das überkommene Recht mit den nationalsozialistischen Forderungen und Vorstellungen in Einklang zu bringen und dabei eine rechtlich vertretbare Synthese zu finden - wobei es ohne Gebrauch der NS-Phraseologie nicht abging -, ferner eine unabhängige Rechtsprechung aufrechtzuerhalten und die Übernahme von Justizaufgaben durch Himmlers Polizei wenigstens abzubremsen, mußte Gürtner $\mathrm{Zu}$ geständnisse machen und wurde damit in die Unrechtsmaßnahmen des Regimes verstrickt. Wie Hitler später rückblickend feststellte, sei es Gürtner „sehr schwer gefallen, vom Juristischen abzukommen“: er habe „durch Drohungen [auf] der einen Seite und durch Verächtlichmachung auf der anderen Seite zu Entscheidungen gezwungen“ werden müssen, die den nationalsozialistischen Bedürfnissen entsprachen. ${ }^{331}$ Gürtner litt unter diesen Mißerfolgen, die er bei der Verteidigung der Grundpositionen des Rechts erlebte, die aber in diesem ungleichen Kampf unausbleiblich waren; und er litt darunter, „daß sein guter Juristenname als Deckschild für Handlungen benutzt" wurde, „die seinem Rechtsgefühl zuwiderliefen“. ${ }^{332}$ Gegenüber v. Dohnanyi drückte er diesen inneren Konflikt mit den Worten aus: „Man muß für sein Vaterland vieles opfern, ich opfere sogar meinen guten Namen, und das ist vielleicht das Schwerste.“"333

${ }^{328}$ M. Niemöller, a.a.O., W. Niemöller, a.a.O., S. 28.

329 Vgl. Eintr. Gürtners in seinen Notizkalender v. 8.4.38 über seine Bespr. mit Hitler in Linz: „Vorm. beim Führer. Alles nach Antrag [bezieht sich auf die Verabschiedung des neuen StGB-Entw., s. dazu Kapitel VII.2.d., S.805]. Niemöller abgelehnt"; ferner Schr. von Frau Else Niemöller an Gürtner v. 19. und 27.10.38, mit denen sie angeforderte Unterlagen übersandte. Aus handschriftl. Vermerken Gürtners auf der Rückseite einer Abschrift des Schr. Lammers' an Frau Niemöller v. 25.4.39, durch das Hitler ihr Freilassungsgesuch v. 18.4.39 ablehnte, geht hervor, daß sich Gürtner daraufhin wenigstens um eine Veriegung Niemöllers aus dem KZ, Sprecherlaubnis für Frau und Kinder sowie offensichtlich um ein „Neues Verfahren gegen N.“ bemühte (Nachlaß Gürtner). Dazu auch die Zeugenaussagen Frau Niemöllers in der Sitzung der Berufungskammer München v. 26.1.50 (Protokoll in den Spruchkammerakten, a.a.O.).

330 Anders Th. Rasehorn, Hitlers Justizminister (Besprechung der Gürtner-Biographie von Reitter in der JZ 1977, S. 167), der meint, wenn sich Gürtner einmal engagiert habe, sei es „nicht um eine Sache, sondern um seine Position“ gegangen. Er beurteilt Gürtner als „Ehrgeizling“ und spricht ihm einen „selbstsüchtigen schrankenlosen Opportunismus“ zu.

331 H. Picker, Hitlers Tischgespräche im Führerhauptquartier 1941-42, Bonn 1951, S.211f., 29.3.42 abends.

332 v. Krosigk, a.a.O., S. 320.

333 Vgl. eidesstaatl. Erklärung Christine v. Dohnanyi o.D. (Spruchkammerakten Gürtner, StArch. München). 
Die Frage, warum Gürtner diese Opfer auf sich nahm und nicht zurücktrat, wird von allen, die ihn näher kannten, dahingehend beantwortet, daß Gürtner im Amt geblieben ist, um nach Möglichkeit ein weiteres Abgleiten in den Unrechtsstaat zu verhindern. Denn es war vorauszusehen, daß Hitler einen ausgesprochenen Nationalsozialisten zu seinem Nachfolger ernennen würde, von dem in dieser Hinsicht keine Gegenwehr mehr ausging. Gerade aus diesem Grunde wurde Gürtner von gleichgesinnten, engeren Mitarbeitern in Augenblicken des Zweifelns darin bestärkt, zu bleiben. ${ }^{34}$ In der Tat konnte kein anderer nichtnationalsozialistischer Angehöriger des Ministeriums gegenüber den Parteimännern - auch in den eigenen Reihen, wie etwa gegenüber Freisler - mit der Autorität auftreten wie Gürtner; so gesehen mußte Gürtner Außenstehenden tatsächlich wie „ein Fels in der Brandung“ anmuten. ${ }^{335}$ Deshalb sah Gürtner das Verbleiben in seinem Amt, dessen Ausübung ihn seelisch zunehmend belastete, als Pflicht an, um „Schlimmeres zu verhüten“, und die Entwicklung zum Schlimmeren nach seinem Tode gab ihm bis zu einem gewissen Grade recht, wenngleich bei der folgenden Radikalisierung des Regimes die verschärfte Kriegslage berücksichtigt werden muß. Als v. Dohnanyi 1936 die Absicht andeutete, aus dem Justizdienst auszuscheiden, entgegnete ihm Gürtner, das sei in seinen Augen „Fahnenflucht vor dem Feinde“. ${ }^{336}$ Auch Rücktrittsgedanken des Reichsgerichtspräsidenten Bumke trat er mit den Worten entgegen: „Herr Präsident, Sie wissen doch, was nach Ihnen käme, Sie dürfen nicht gehen. Was noch zu retten ist, müssen wir retten.“"337

Bei Gürtner darf jedoch auch das nationale Motiv, das in seinem Ausspruch gegenüber v. Dohnanyi vom „Opfer fürs Vaterland“ anklingt, nicht völlig außer acht gelassen werden, das ihn auch stets von einer aktiven Opposition gegen das nationalsozialistische Regime abgehalten haben dürfte. Denn schließlich erlebte das Deutsche Reich vom Gesichtspunkt des Nationalismus aus, der Konservative und Nationalsozialisten verband, durch die militärische Wiedererstarkung und die staatliche Einigung aller Deutschen einen einmaligen äußeren Aufstieg und wies beim Tode Gürtners im Januar 1941 nach den Siegen in Polen, Norwegen und Frankreich eine bis dahin einzigartige hegemoniale Großmachtstellung auf. Um sich in dieser Zeit des Aufschwungs von Deutschland und seiner „rechtmäßigen“ Regierung loszusagen und die Hemmschwelle des nationalen Denkens für einen Rücktritt zu überwinden, bedurfte es einer absoluten „Gegenideologie“ zum Nationalsozialismus, wie sie außer den Marxisten z. B. die Anhänger der Bekennenden Kirche oder die überzeugten Katholiken aufwie-

${ }^{334}$ Vgl. eidesstattl. Erklärung des früheren MinRat im RJM Dr. Werner Grußendorf v. 19.4. 49 (a.a.O.). Auch die Berufungskammer München kommt in ihrem Spruch gegen den Verstorbenen vom 26.1.50 zu dem Ergebnis, daß Gürtner durch sein Verbleiben im Amt die Fundamente der Justiz „als Grundlage des Staates und des Wiederaufbaus" in Deutschland gerettet habe (a.a.O.).

335 So laut OReiA Ernst Lautz in seiner Erklärung v. 10.3.49 (a.a.O.). Als Zeuge der Anklage im Nürnberger Juristenprozeß sagte der Amberger katholische Strafanstaltspfarrer Benedikt Wein aus: „Unter dem Herrn Dr. Gürtner, da war es noch menschlich, der war eine Fackel am Himmel“ (Militärgerichtshof III, Sitzung v. 28.4.47, Prot. (d), S. 2667, Arch. des IfZ).

336 Vgl. eidesstattl. Erklärung Christine v. Dohnanyis o.D. (Spruchkammerakten, a.a.O.). Dort ferner: „Als ich ihn einmal gelegentlich eines persönlichen Zusammenseins, bei dem er wieder verzweifelte Äußerungen über sein Amt getan hatte, fragte, warum er es nicht aufgäbe, antwortete er ziemlich wörtlich folgendes: ,der Nationalsozialismus ist eine Fieberkrankheit des deutschen Volkes und solange das Fieber dauert, verläßt ein Arzt das Krankenbett nicht, selbst wenn er glaubt nicht mehr viel helfen zu können““.

337 Oswald Bumke (Bruder des RGPräs. Erwin Bumke), Erinnerungen und Betrachtungen. Der Weg eines deutschen Psychiaters, München 1952, S. 49. 
sen, zu denen Gürtners Kollege, der Reichspost- und -verkehrsminister Freiherr Eltz v. Rübenach gehörte, der am 30. Januar 1937 wegen der christentumfeindlichen Haltung der Partei zurücktrat, als ihm Hitler das Goldene Parteiabzeichen und die Mitgliedschaft in der NSDAP verleihen wollte. ${ }^{338}$ Die „Gegenideologie“ eines vorbehaltlosen Rechtsgehorsams aber, die den Grundsatz „Fiat justitia, et pereat mundus“ vertrat, hatte Gürtner nicht aufzuweisen, da er das Recht unter die Staatsräson stellte. Neben der Vorstellung einer „Fahnenflucht von der Justiz“ spielte für den eingefleischten Weltkriegsoffizier daher auch die Vorstellung der „Fahnenflucht vom Vaterland“ als Hindernis für einen Rücktritt eine Rolle. Es war das tragische Dilemma des Deutschnationalen, der durch seinen Einsatz für das Vaterland ungewollt zugleich dem Regime diente. ${ }^{339}$ Niemand weiß, wie sich Gürtner - wenn er am Leben geblieben wäre - in den folgenden Jahren verhalten hätte, ob ihm nicht wie den Offizieren des 20. Juli die ansteigende Flut nationalsozialistischer Verbrechen, die den deutschen $\mathrm{Na}$ men entehrten und damit eine endgültige Unterscheidung zwischen „Deutschland“ und der nationalsozialistischen Regierung herausforderten, den Absprung hätte finden lassen; denn die größten Zumutungen standen der Justiz nach seinem Tode noch bevor.

Auf jeden Fall wird der Beurteilung Niemöllers beizupflichten sein, daß Gürtner bei seinem Verbleiben im Amt nicht „aus irgendwelchen unlauteren Motiven gehandelt hat, weder aus Habsucht, noch aus Ehrgeiz ${ }^{\text {"340 }}$, noch - darf getrost hinzugefügt werden - aus Bedürfnis nach persönlicher Geltung, Sozialprestige oder aus Machtbesessenheit. Obgleich Gürtner in seiner beruflichen Laufbahn starken Ehrgeiz entwickelte, wurde dieser Wesenszug durch seinen anständigen Charakter und seine moralische Integrität mehr als genügend aufgewogen, als daß er allein zur Befriedigung dieses Ehrgeizes auf seinem Posten geblieben und weiter „mitgemacht“ hätte. Gewiß kann man keinem Menschen in die Seele schauen, aber daß die geschilderten positiven Charaktereigenschaften, die Gürtner seiner unmittelbaren Umwelt gegenüber an den Tag legte, lediglich eine unaufrichtige und biedere Kulisse abgegeben haben sollen, hinter der sich ein berechnendes, „über Leichen gehendes“ Streben nach Anerkennung und Macht verbarg, ist höchst unwahrscheinlich.

Seine Ablehnung eines Rücktritts hatte u. a. auch zur Folge, daß Gürtner im Gegensatz zu Eltz v. Rübenach am 30. Januar 1937 zusammen mit den anderen nichtnationalsozialistischen Kabinettsmitgliedern die Aufnahme in die NSDAP und die Verleihung des Goldenen Parteiabzeichens über sich ergehen lassen mußte. Er quittierte dieses Ereignis v. Dohnanyi gegenüber überspitzt, aber treffend mit der Bemerkung, das habe „wenigstens das eine Gute, daß nun nicht jeder Kanzleibeamte, der PG ist, sich erlauben kann, mir Vorschläge für meine Amtsführung zu machen “ ${ }^{341}$ In Parteikreisen wurde er deswegen nicht beliebter, und auch Gürtners schwieriges Verhältnis zur Partei änderte sich deshalb nicht. Vor allem waren ihm deren Veranstaltungen

\footnotetext{
338 Vgl. J. Huck, Reichsminister Paul Frhr. v. Eltz-Rübenach. Sein Leben und Wirken 1875-1943, in: Unser Porz. Beiträge zur Geschichte von Amt und Stadt Porz, herausg. vom Heimatverein Porz e. V. in Verbindung mit dem Stadtarchiv Porz, Porz a. Rhein 1961, S. $30 \mathrm{ff} .$, S. $57 \mathrm{ff}$.

339 „Seine Tragödic war die Tragödie des Bürgers, aber nicht die der Verbrecherclique um Hitler“, so Martin Niemöller in seiner eidesstattl. Erklärung v. 24.1.50 (Spruchkammerakten Gürtner, StArch. München).

340 A.a.O. (Hervorhebung vom Verf.).

341 Vgl. eidesstattl. Erklärung von Christine v. Dohnanyi o.D. (Spruchkammerakten, a.a.O.).
} 
nach wie vor zuwider: bei den alljährlich stattfindenden Nürnberger Parteitagen, an denen er schon in seiner Eigenschaft als Reichsminister hatte teilnehmen müssen - „Gürtner litt sichtbar in dieser Umgebung“ -, suchte er sich viele Jahre lang ein privates Quartier bei Bekannten, um dem Parteibetrieb wenigstens in den freien Stunden zu entgehen. ${ }^{342}$

Nach mehreren vorliegenden Berichten empfand Gürtner sein Amt in den letzten Monaten vor seinem Tode zunehmend als eine Bürde, die er auf sich nehmen zu müssen glaubte, um den befürchteten Ministerwechsel bei der Justiz zu vermeiden. Am 24. Juni 1940 - Frankreich hatte zwei Tage vorher kapituliert und Deutschland stand auf dem bisherigen Höhepunkt seiner Erfolge - äußerte Gürtner „offenbar tief unglücklich ..., er wäre lieber der letzte Amtsrichter in Bayern als auf seinem Posten " ${ }^{343}$ Angesichts der Ohnmacht gegenüber den ohne sein Wissen eingeleiteten Unrechtsmaßnahmen wie der beginnenden Deportation der Juden, mit der er im Frühahr dieses Jahres durch die Verschleppung jüdischer „Rechtskonsulenten“ konfrontiert wurde, und der Euthanasieaktion, von der er im Juli erfuhr ${ }^{344}$, wurde sein Amt „zu einem immer hoffnungsloseren Leidensweg “. ${ }^{345}$ Daß ihn der vergebliche Kampf seelisch und physisch aufrieb, kann nach den vorliegenden Zeugnissen als sicher angenommen werden. ${ }^{346}$

Am 29. Januar 1941 meldete die Presse, daß Gürtner in der vergangenen Nacht „nach kurzer Krankheit infolge eines Herzschlages verstorben“ sei. ${ }^{347}$ Diese Meldung war zumindest irreführend. Mitte Dezember hatte Gürtner eine mehrtägige Dienstreise ins Generalgouvernement gemacht, dort deutsche Gerichte und Dienststellen besucht und mit Hans Frank - der im Herbst 1939 von Hitler zum Generalgouverneur ernannt worden war - in Krakau ausführliche Gespräche u.a. über die „Entwicklung des Polizeigewaltregimes“ geführt. ${ }^{348}$ Frank, der sich mit der SS- und Polizeifüh-

342 Vgl. W. Heintzeler, Der rote Faden, S.40. Der ehemalige persönl. Referent Sts. Schlegelbergers H. mußte während des Parteitages 1935 vertretungsweise Gürtner zur Verfügung stehen. Zur jährlichen Quartierbeschaffung vgl. auch die Korrespondenz Ministerbüro Gürtner (Akten des RJM, BA).

343 Vgl. eidesstattl. Erklärung von Max Schattenfroh v. 20.6.47 (Spruchkammerakten, a.a.O.), mit dem Gürtner seit 1909 freundschaftlich verbunden war. Ähnlich die eidesstattl. Erklärungen von Karl Hoeller v. 27.9.49 (a.a.O.), der seit Dezember 1939 als GAss. bzw. LGRat im RJM tätig war, und von Rudolf Harmening v. 15.12. 49 (a.a.O.), der bis 1933 im RJM, ab 1934 Vizepräs. des Reichserbhofgerichts war. Dazu auch die durch v. Krosigk (a.a.O., S.324f.) überlieferten Worte Gürtners zu einem Bekannten, den er vor dem Ministerium traf: „Was glauben Sie, lieber Kollege, wie glücklich, wie unendlich glücklich ich wäre, wenn ich nicht in dieses Haus hineinzugehen brauchte. Aber ich muß, ich muß. Sehen Sie, da stehen schon drei [Nationalsozialisten], die hineinwollen ...“

344 Vgl. dazu Kapitel III.1.b., S. 184 (Verschleppung der Rechtskonsulenten), und Kapitel V.3.c., S. 505 ff. (Euthanasieaktion).

345 K. A. von Müller, Im Wandel einer Welt, S.317. Von „einem Leidensweg, den er gehen zu müssen glaubte, um den Einzug eines Parteimannes in sein Amt zu verhindern“, spricht auch Heintzeler, Der rote Faden, S. 40 .

346 Vgl. v. Braun, a.a.O., S. 241; ebenso Rüdiger Graf v. d. Goltz, eidesstattl. Erklärung v. 10.11.48; Anneliese Goerdeler, Erkl. v. 8.7.49, die eine Bemerkung Carl Goerdelers wiedergibt; Dr. Kurt Schmitt, eidesstattl. Erkl. v. 12.1.49; v. Renthe-Fink, eidesstattl. Erkl. v. 19.1.50; und Sigmund Nörr, eidesstattl. Erkl. v. 28.11.48 (Spruchkammerakten, a.a.O.). Schlegelberger konnte diese Tatsache in seinem Nachruf (DJ 1941, S. 849) nur verschlüsselt ausdrücken: Gürtner habe sich seiner Aufgabe „bis zur Grenze der Selbstvernichtung“ hingegeben und sich „bis zum letzten Atemzuge in soldatischer Treue für das Recht und seine Pflege eingesetzt".

347 Vgl. die vom RJM am 29.1.41 herausgegebene Pressenotiz (Personalakten Gürtner des RJM, BA).

$348 \mathrm{Vgl}$. H. Frank, Im Angesicht des Galgens, S.132. Er bezeichnete dieses kritische Gespräch als ein plötzliches „Verstehen über Generationen hinweg“ (a.a.O.). 
rung wegen ihres eigenmächtigen Vorgehens vor allem bei Massenexekutionen innerhalb seines Herrschaftsbereichs auseinanderzusetzen hatte ${ }^{349}$, dürfte bei der Schilderung seines Konflikts mit Himmler - der von Hitler in dieser Frage unterstützt wurde - scharfe Kritik an der inneren Entwicklung des Regimes geäußert und dem Justizminister dabei über das Ausmaß der verübten Verbrechen letzte Klarheit verschafft haben. Laut Frank reagierte Gürtner darauf mit den Worten:

„Hitler liebt Grausamkeit. Er freut sich, glaube ich, ja weiß ich, wenn er andere quälen kann. Er hat einen teuflischen Sadismus. Sonst könnte er Himmler und Heydrich einfach nicht ertragen. Wie soll der uns Juristen anerkennen! Aber bleiben wir auf dem Schiff! Wenn wir doch nicht alles verhindern können - manchem können wir doch helfen, der sonst, wenn wir gar nicht dabei wären, überhaupt verloren wäre." 350

Auf dieser Reise dürfte Gürtner auch von anderer Seite Berichte über die Behandlung von Polen und Juden empfangen und eigene Beobachtungen darüber gemacht haben. Er kam krank nach Berlin zurück und wurde ins Westsanatorium gebracht. Er litt an einer offensichtlich nicht exakt definierbaren Erkrankung des Stoffwechselsystems, die eine Zersetzung des Blutes verursachte; seine Angehörigen konnten jedenfalls „nie erfahren, was er eigentlich hatte“. ${ }^{351}$ Sie hegten daher den - allerdings nicht beweisbaren - Verdacht, daß Gürtner in Polen von der SS vergiftet oder infiziert worden sei. ${ }^{352}$ Vom Ministerium wurde die Erkrankung nach außen hin offenbar verharmlost: In der Absage vom 23. Januar an den Oberlandesgerichtspräsidenten in Leitmeritz auf die Einladung zur Eröffnung des dortigen Erbhofgerichts hieß es, der Minister leide „an einer Grippe, die sich nach einer vorübergehenden Besserung wieder verschlechtert" habe; zwar sei die Wiederaufnahme der Dienstgeschäfte zeitlich noch nicht abzusehen, es bestehe „aber glücklicherweise ein Anlaß zu besonderen Besorgnissen nicht“. ${ }^{353}$ Sechs Tage später war Gürtner tot. Es kann keineswegs ausgeschlossen werden, daß der geringe Widerstand, den Gürtner seiner Krankheit entgegenzusetzen vermochte, auf das Versagen seiner seelischen Kräfte zurückzuführen ist $^{354}$, zu dem der neuerliche Beweis der Aussichtslosigkeit seines Bemühens um die

349 Vgl. dazu: Das Diensttagebuch des deutschen Generalgouverneurs in Polen 1939-1945, herausg. von W. Präg und W. Jacobmeyer, Stuttgart 1975, S.26ff.; M. Broszat, Nationalsozialistische Polenpolitik 1935-1945, Stuttgart 1961, S.80ff.

350 Frank, a.a.O.

351 Zeugenaussage Fritz Gürtners vor der Spruchkammer Bad Tölz am 14.7.47 (Spruchkammerakten Gürtner, AG München, Registratur S). Die mit Unterstützung der Angehörigen unternommenen Versuche des Verf., die Krankengeschichte Gürtners ausfindig zu machen, schlugen fehl.

352 Vgl. Aussage Fritz Gürtner, a.a.O., und Frau Luise Gürtner (Schilderung des Lebenslaufs ihres Mannes) v. 31.10.48; eidesstattl. Erklärung von Gürtners Schwager Dr. Friedrich Bretzfeld v. 20. 5.47; Erwähnung im Spruch der Berufungskammer München v. 26.1.50 (Spruchkammerakten Gürtner, StArch. München). Der Verdacht wurde dadurch genährt, daß auch der Gürtner auf dieser Reise begleitende persönliche Referent, MinRat Martin Sommer, nach der Rückkehr kränkelte und ab Dezember 1941 mit 41 Jahren dienstunfähig wurde (vgl. Verm. im Geschäftsverteilungsplan des RJM vom September 1942, BA, Sign. R 22/58). Er brachte bis zu seinem Tode 1953 elf Jahre in stationärer Behandlung im Berliner Franziskus-Krankenhaus zu und litt an einer langwierigen Zersetzung der inneren Organe. Vgl. die Schr. seiner Schwester Therese Sommer an Dr. Fritz Gürtner v. 27.1. und 6.4.64 (Privatkorrespondenz der Familie Gürtner).

353 Vgl. Schr. des persönl. Ref. MinRat Sommer an den OLGPräs. von Leitmeritz v. 23.1.41 (Akten des RJM, Korrespondenz Ministerbüro, BA, Sign. R 22/4100).

354 Nach dem Ber. des damaligen MinDirig. im RMdI Schattenfroh besuchte Carl Goerdeler Gürtner noch in der Klinik. Von Schattenfroh auf den raschen Tod Gürtners angesprochen, antwortete Goerdeler ,nach einigem Nachdenken: ,Wenn ihm sonst nichts passiert ist, dann hat es ihm das Herz abgedrückt über dem, was er sehen mußte “" vgl. eidesstattl. Erklärung Max Schattenfrohs v. 20.6.47, dazu die bestätigende Erklärung von Frau Anneliese Goerdeler v. 9.7.49 (Spruchkammerakten, a.a.O.). 
Aufrechterhaltung der Kulturinstitution des Rechts im nationalsozialistischen Staat nicht unerheblich beigetragen haben dürfte.

Hitler ordnete für den 1. Februar 1941 einen Staatsakt im Mosaiksaal der Neuen Reichskanzlei an, an dem neben ihm die führenden Männer von Staat, Partei und Wehrmacht fast vollständig teilnahmen und Reichsinnenminister Frick sowie Staatssekretär Schlegelberger Traueransprachen hielten. Himmler und Heydrich waren nicht anwesend und ließen sich auch nicht offiziell vertreten. ${ }^{355}$ Zwei Tage später wurde Gürtner seinem Wunsche entsprechend in seiner bayerischen Heimat mit einer stillen Trauerfeier auf dem Münchner Waldfriedhof beigesetzt.

35s Göring ließ sich durch Generaloberst Weiß, Frank durch seinen Sts. Bühler vertreten. Vgl. die Ber. im VB, Berliner Ausg. v. 2.2.41, S. 1 u. 2, im Fränkischen Kurier v. 2.2.41, S. 3 und in der DJ 1941, S. 177 ff., dort auch Text der Ansprachen. Zur Beisetzung in München vgl. Fränkischer Kurier v. 4.2.41, S.3; Text der dort gehaltenen Grabrede des evangelisch-lutherischen Landesbischofs D. Meiser im Nachlaß Gürtner. 